\title{
PRINCIPLES OF SUSTAINABLE DEVELOPMENT: APPLICATIONS IN THE PLANNING AND DESIGN OF RESIDENTIAL COMMUNITIES
}

\author{
by \\ G.R. LAROCQUE, B.L.A.
}

A thesis submitted to the Faculty of Graduate Studies and Research in partial fulfillment of the requirements for the degree of MASTER OF ARTS

Department of Geography and Environmental Studies

Carleton University

Ottawa, Ontario

APRIL, 2000

(c) GERALD ROBERT LAROCQUE 
Acquisitions and Bibliographic Services

395 Wellington Street Ottawa ON K1A ON4 Canada
Acquisitions et services bibliographiques

395 , rue Wellington

Ottawa ON K1A ON4

Canada
The author has granted a nonexclusive licence allowing the National Library of Canada to reproduce, loan, distribute or sell copies of this thesis in microform, paper or electronic formats.
L'auteur a accordé une licence non exclusive permettant à la Bibliothèque nationale du Canada de reproduire, prêter, distribuer ou vendre des copies de cette thèse sous la forme de microfiche/film, de reproduction sur papier ou sur format électronique.

L'auteur conserve la propriété du droit d'auteur qui protège cette thèse. $\mathrm{Ni}$ la thèse ni des extraits substantiels de celle-ci ne doivent être imprimés ou autrement reproduits sans son autorisation. 


\begin{abstract}
As the global sustainable development paradigm evolves, it can be expected to affect human life in many ways, such as the form of future residential communities. As background, the evolution of the sustainable development concept is reviewed and applications at the local level discussed. A case study team developed sustainability strategies designed to be practical, and implementable. These initiatives were incorporated into the concept plan for a new 12-hectare (30 acre) neighbourhood in Nepean, Ontario. Critical review comments were evaluated, and cost estimates prepared showing the financial impact of sustainability measures. Variable rates of contribution to neighbourhood sustainability for the strategies proposed were demonstrated.

Many initiatives can be readily implemented but barriers do exist to the advancement of local sustainable development: recommendations are made to overcome them. Limitations of the case study were summarized and future sustainable development research and work opportunities at the local level identified.
\end{abstract}




\section{ACKNOWLEDGEMENTS}

Without the insight and inspiration provided by the late Professor Duncan Anderson (Department chair in 1975), this academic quest would never have begun. Over the ensuing years, and more recently as my thesis advisor, the friendship and diligence of Professor Mike Fox and Adjunct Professor Tom Wilkinson has been invaluable. Hazel Anderson, Graduate Secretary, kept me on course throughout.

Mr. Jack Stirling, Deputy City Manager and Mr. Dennis Jacobs, Director of Policy (City of Nepean) are to be recognized for their role in making this case study possible, and for providing the professional advisory team and other civic resources.

Ms. Susan Fisher and Mr. David D'Amour, Canada Mortgage and Housing Corporation, Research Division, lent a national perspective to the study and the current status of sustainable community development.

Mr. Barry Hobin (B.J. Hobin and Associates, Architects) and Mr. Robert Wingate (Cumming Cockburn Associates, Engineers) should be sincerely thanked for their valuable participation as key members of the study team.

Thanks also to my business partner, Rudy Levstek, who agreed to allow me time to undertake the completion of this thesis. Mary Leat ably and cheerfully endured its preparation. Finally to my life partner and best friend Kerry, my sincere thanks for your moral support and understanding during this substantial "part-time" undertaking. This work is dedicated to our children, Alyson Michelle and Kyle Bradley, and the world which we will pass on to them. 


\section{TABLE OF CONTENTS}

Page No.

Acceptance Form

Abstract

Acknowledgements

Table Of Contents

List Of Tables

List Of Figures

CHAPTER 1 INTRODUCTION

- Problem Statement

- Objectives

- Thesis Organization

CHAPTER 2 SUSTAINABLE DEVELOPMENT: A Background Review

- Evolution of World Views

- Development of Concepts of Sustainability

- Sustainability: The Debate About Meaning

- Sustainability: Is it Practicable Politics? 23

- Sustainability: Government Activity

CHAPTER 3 SUSTAINABLE DEVELOPMENT: Local and Urban Sustainable Development

- Evolution of the Concepts 29

- Vision of a Sustainable Community 37

- Sustainable Development at the Local Level 42

- Applications in Local Community Planning 51 
- History and Political Framework

- Site Identification

- Objectives and Tasks

- Site Inventory and Analysis

CHAPTER 5 DEVELOPMENT OF THE CONCEPT PLAN

- Working Sessions

- Concept Plan and Sustainable Development Initiatives

- Cost Estimates: Concept Plan vs. Conventional Neighbourhood

- Cost Comparisons

- Professional, Public and Development Industry Review Comments

- Summary of the Barriers to Local Sustainable Development and Recommendations for Advancement

- Concept Plan Sustainability Performance

- Summary and Limitations of the Case Study

- Linkages to the Global Vision for Sustainable Development

- Potential Future Work in Local Sustainable Development 


\section{LIST OF TABLES}

Page No.

Table 2.1 Priority Requirements of the World Conservation Strategy

Table 3.1 Characteristics in Planning and Designing for a Sustainable Community

Table 3.2 Partial List of Rudimentary Indicators

Table 3.3 Aspects of Healthy Sustainable Communities

Table 6.1 Capital Cost Estimate of Sustainable Development Initiatives

Table 6.2 Summary of Life Cycle Costs - Case Study Concept Plan

Table 6.3 Summary of Life Cycle Costs - Conventional Subdivision Layout

Table 6.4 Concept Plan Sustainability Performance Matrix 


\section{LIST OF FIGURES}

Figure 3.1 Sustainable Development Framework

Figure 3.2 Sustainable Development Strategy

Figure 4.1 Case Study Location Plan

Figure 5.1 Framework for Presentation of Sustainable Community 72 Development Practices

Figure 5.2 Concept Plan Incorporating Strategies for a more Sustainable Neighbourhood

Figure 5.3-5.11 Urban Design / Architectural Strategies

Figure 5.12 Linear Greenway / Bioswale / Stormwater Storage

Figure 5.13 Exfiltration Trench

Figure 5.14 Reduced Slope Grading / Infiltration

Figure 5.15 Alternate Standard Road Rights-of -Way

Figure 5.16 Passive Solar Layout and Design

Figure 5.17 Windbreaks

Figure 5.18 Shade for Cooling

Figure 5.19 Right to Light Considerations

Figure 5.20 Residential Stormwater Storage and Use

Figure 5.21 Conventional Neighbourhood Layout Plan 


\section{CHAPTER 1}

\section{INTRODUCTION}

Sustainable development is a concept which relates the development of human life and activity to the natural systems that sustain life. Originated as a response to a composite of global environmental, social and economic concerns, the concept holds at its core an approach to development which incorporates not only the scientific goals of ecosystem integrity and resource efficiency, but also the political goals of social equity and economic vitality. Sustainable development also claims an ethical foundation, encompassing a much more holistic, unified world view than the physical and resource-based planning and management practices of the last three decades. The notion of linking long term, equitable economic progress with a balanced relationship with the physical environment is one of sustainable development's most distinctive yet ambiguous concepts, because it attempts to link quality of life to quality of environment which, up until now, have been seen as unlinked if not mutually exclusive goals!

First brought to wide spread public attention in 1987 by the World Commission on Environment and Development, sustainable development was defined as "development that meets the needs of the present without compromising the ability of the future generations to meet their own needs" (WCED, 1987:43).

Since then, significant research and debate has occurred with respect to sustainable development at local, national and international levels; yet sustainable development remains, as we enter the new millenium, more an ideal 
or goal than a set of tried and proven practices, just as Van Vliet (1994:1-4) claimed.

Acknowledging that global problems are often the cumulative result of many individual, day-to-day decisions and actions, the key problem to be addressed by this thesis is the development of practical applications and approaches to sustainable development at the local level, using the precepts of the global paradigm as proclaimed by the WCED definition. There is a need to define just what "sustainable" means, conceptually and practically, at the local, municipal level. It is much more than an updated, "respectable environmentalism" to be practised by urban planners, or a new aesthetic to be demonstrated to the marketplace. A response to these questions is approached through a case study of sustainable development principles applied to the planning of a new residential neighbourhood in the City of Nepean, Ontario.

An outline of the principal objectives of this case study (described in detail in Chapter 4) are summarized as follows:

1. To develop a neighbourhood concept plan demonstrating realistic (implementable) strategies for sustainability;

2. Assess the construction and life cycle cost implications of sustainability initiatives;

3. Test professional, public and development industry reactions to the concept plan, so as to identify barriers to local sustainable development; 
4. Consider requirements to achieve more "mainstream" acceptance of sustainable community form; and

5. To reinvest study results back into the sustainable development learning cycle.

The methodology to achieve these objectives required contractual and financial arrangements with the City of Nepean's Planning and Development Department, for the undertaking of an actual case study within an actively developing community in the City.

A study team was assembled, and an approximately 12 month schedule prepared which entailed a multi-disciplinary working process with City Departments (Planning and Development, Public Works, Engineering, Parks and Recreation). From this process, a neighbourhood concept plan was developed which incorporated strategies for improved sustainability.

The following chapter format describes sequentially the work and progress of the case study from background to conclusions.

Chapter 2 reviews the background and history of sustainable development so as to understand the strengths and weaknesses of its roots as a current environmental paradigm.

Chapter 3 reviews the relationship between global, local and urban sustainable development, leading into a vision of a community meeting sustainability definitions and measures. An examination of the appropriate scale and level of delivery of sustainable development initiatives is carried out. 
In Chapter 4, the history and political framework for this case study are reviewed, together with objectives and tasks. The study site is identified and its characteristics described.

Chapter 5 describes the methodology and working sessions through which the concept plan evolved and cost estimates were prepared.

The concept plan is evaluated in Chapter 6: costs are compared, professional, public and development industry reactions described, barriers to sustainable development identified and the sustainability performance of the concept plan evaluated.

Chapter 7 draws conclusions, reveals limitations, links back to the precepts of the global paradigm and looks ahead to the further advancement of sustainable development through opportunities created from the work done for this thesis.

This case study, in which principles of sustainable development are applied to the planning of a new residential neighbourhood, has been undertaken as a geography thesis because of two key factors:

1. There is a wealth of geographic literature which explores in depth the sustainable development paradigm from its global origins to the grass roots level. The author has found this literature complements writings available in the related disciplines of planning, architecture and landscape architecture, where awareness is only now emerging (Taylor and Smith, 200: 28-33). 
2. The trans-discipline academic and professional history of the author, in which the knowledge gained during the MA Geography program has played a central role in the building of a 30 year professional practice in environmental, land planning and development consulting and landscape architecture. This thesis is a natural extension of that career history. 


\section{CHAPTER 2}

\section{SUSTAINABLE DEVELOPMENT:}

\section{A BACKGROUND REVIEW}

Concerns about humanity's effects on the environment have arisen periodically throughout human history, and for much of the past century there has been a growing recognition that we are probably stretching the carrying capacity of the earth to, and beyond its limits. As Mannion states, "the state of the earth is somewhat precarious" (1991:309).

There have been numerous warnings that human population growth and the consequences of economic development are jeopardizing our future, and that we need to rethink the ways in which we live with each other and on the earth.

The problems that are said to be leading to global deterioration and, according to some, catastrophe, include over population, land degradation, desertification, deforestation, global warming, ozone depletion, rising sea levels, fresh water scarcity, air pollution, marine pollution, rural and urban poverty, toxin proliferation and species extinction (Kaplan, 1994: 44-46).

The idea that the quantity and quality of the earth's resources are scarce relative to demand is, of course, not new, nor is the notion that people ought to be involved in the solutions for the planning and management of their own environments (Ehrlich, 1968). Many societies have long practised principles of stewardship in their management of farmlands, forests and fisheries; they have been aware that sustainable yields are only achievable when an understanding is developed of what sustaining productivity entails. Of course, major events such as war or natural disasters can have significant impact, and at corporate and 
personal extremes, greed can overpower sustainability's goals. Sustainable development is a much broader concept of resource management that looks to manage scientifically the whole system for a socially just and environmentally sustainable outcome. For many, however, sustainable development is an oxymoron in that it juxtaposes two mutually exclusive concepts, indeed, two opposing political views - the communal (left) advocating sustainability or balance over time, and the market (right) assuming development expansion to meet society's demands for goods and services, with all of the individual liberties and freedoms implied by the free market system.

\section{Evolution of World Views}

It can be said that we must evolve our dominant attitude, rooted in a mechanistic world view, to one which is more socially just, and more economically and environmentally sustainable. Our world view started evolving a mechanistic paradigm at least 300 years ago. It is claimed (by some who might be described as extremists) that this mechanistic paradigm is the root of our current world view imbalance, resulting in what some argue are lopsided ideologies, technologies, institutions and lifestyles. For instance,

"The values and attendant assumptions of the mechanistic world view on which we still base our decisions are irrelevant to both the present and the future. Yet our continued acceptance of this world view as the absolute truth and the only valid way to knowledge has led to our current global crisis and is propelling us ever closer to social oblivion through environmental destruction"

(Caprac, 1988:464)

If this is an accurate statement, then today's problems are perhaps not solvable with such a worldview paradigm, which was largely fashioned by 
rationalist thinkers such as Francis Bacon (1561-1626), Rene Descartes (15961650) and Adam Smith (1723-1790). They and others legitimised and institutionalised the pursuit of material wealth. Implicit in their assumptions is the attitude that natural systems are just aggregates of interchangeable parts, functioning in a linear fashion.

If in theory, everyone is a free, self-sufficient individual, how then will society survive, and what rules will it follow? This question, when put to Descartes in 1645 , was responded to as follows:

"Although everyone of us is a person separate from the others... one must always reflect that one could not survive alone, and that one is in effect one of the parts of the universe, and more particularly still one of the parts of this earth... this State, this Society, this family to which one is linked by residence, by oath and by birth. One must always serve the interests of the whole of which one is a part, in preference to those of one's own person in particular" (Braudel, 1994: 326).

Looking as far back as Renaissance environmentalism (i.e., pre 1500s) geographers wrote about the environment and recognized that the whole being of humans is integrally linked to the vital being of an enveloping nature (Cosgrove, 1990: 344-358). Science of Enlightenment, Cosgrove claims, separated humans from nature. This sixteenth century view of environmentalism changed drastically with the Industrial Revolution, which began to emerge in the eighteenth century.

Goudie (1994) looked at the 1800's, describing the ways in which humans have changed the earth from its original, hypothetically healthy pristine condition. By the late nineteenth century, modern environmentalism began to emerge as 
early geographers and others began to note that the alteration of the natural world is caused largely by human activity. French rural economist Boussingault wrote about changing terrain in 1845 (Goudie, 1994). Lyell, in Principles of Geology (1872), explored human impact on habitat. Mary Summerville (1858) discussed unexpected results as human beings "assumed" the power to subdue nature. Man and Nature (1861) by G.D. Marsh may have been the earliest definitive study of the role of humans in environmental change to forests, mountain slopes, and soils.

During the 1920s and 30s, the French geographer Jean Brunhes in Human Geography noted inter-relationships between catastrophes brought on by environmental change and human activity. In this same period, Carl Sauer campaigned against destructive exploitation, recognized the ecological virtues of "primitive" peoples, and dealt with themes of domestication and human impacts on changing the landscape (Goudie, 1994). A.G. Tansley introduced the term "ecosystem" in 1935 (referred to in Johnston, 1991:155), and shortly thereafter Leopold (1941:3) was among the first to identify "ecosystem dysfunction" which included erosion, loss of fertility and local species extinction.

Johnston (1991) has provided the following overview of the more recent environmental movement from the 1950 s to the 1980 s.

In 1956, a symposium on Man's Role in Changing the Face of the Earth anticipated the environmental movement of the 1960s. In the 1980s, "deep ecology" spun from the expanding environmental and peace movements, espousing life in harmony with the biotic community. Deep ecology borrowed 
from Buddhist, Native American and other world religions to establish an alternative to materialistic, consumer-driven lifestyles.

In 1972, the United Nation's Conference on the Human Environment was held in Stockholm, where delegates passed the "Declaration on the Human Environment" -109 resolutions for action. These resolutions led to the emergence and growth of such organizations as the United Nations Environmental Program (UNEP) and the preparation of the World Conservation Strategy by the International Union for Conservation of Nature and Natural Resources (IUCN). Many other organizations such as the Club of Rome, the World Watch Institute and the World Wildlife Fund (WWF), along with individual scientists and futurists such as E.F. Schumacher, Hazel Henderson, Rachel Carson and Paul Ehrlich, have contributed significantly to the body of knowledge, the global debate and new paradigms of thought considered essential for effective change.

Rachel Carson's Silent Spring dealt with the growing toxic legacy of industrial society. By 1972, the Club of Rome's Limits to Growth heightened (possibly overstated due to errors in limits to growth projections) the awareness that humans could not continue at the rate of population, development and consumerism growth without resource depletion. Ehrlich (1968) popularised the concept of zero population growth, while Barry Commoner, as described by Johnston (1991) focused on technological change and the resultant rapid depletion of resources and pollution growth. 
Despite their differences, the writers included a focus on environmental degradation, economic inequalities, unbridled growth, equal rights for women, political freedoms and earth-centred politics, which have become core elements of sustainable development.

The precursor of sustainable development came to the Canadian scene from a number of sources, but most importantly through the efforts of Thomas Adams who was planning advisor to the Canadian Commission of Conservation in 1909. Adams was a leading exponent of Ebenezer Howard's ideas on land use and town planning incorporated in the garden city movement in England (as described by Beevers, 1988). The Commission embraced not only resource conservation and wise land use, but also urban planning and public health, all of which were seen as distinct but closely related aspects of public well being.

Adams's conviction that the physical well being of people is the resource from which all others derive value, made explicit the relationship between social welfare, housing, the environment and urban planning. His initial interest in housing and health was expanded to include a concern for harmonious arrangements among land uses, the provision of wide streets, the division of residential districts based on housing "class" (i.e., as a pre-cursor to zoning) and the need for public parks, playgrounds and open spaces (Sarrinen, 1979).

\section{Development of Concepts of Sustainability}

Although Adams's work embodied many of sustainable development's key ideas, the need for sustainability he expressed was reinforced at a global scale by several African-based conferences in the mid-1960s with an aim to safeguard 
wildlife habitat (the epitome of the conservation movement at that time.) The International Union for the Conservation of Nature (IUCN) conferences also recognized that African rural development had limits imposed by soil, climate, and water, inhibiting abilities for self-development. European environmentalists (motivated to protect wildlife populations against drought and from the great white -largely European- hunter) encouraged African governments to follow the conservation movement in their national development plans, knowing that large land reserves required for animal habitat could only be protected from people's use for grazing, hunting and food supply if improved management techniques could lead to self-sustaining food production.

Consequently, the IUCN stated that conservation management must be based on a combination of prevention and cure,

"...the management (which includes survey, research, administration, preservation, utilisation) of air, water, soil, minerals and living species including man, so as to achieve the highest sustainable quality of life..." (McCormick, 1989: 46).

These and other background events led eventually to the "Priority Requirements" of the World Conservation Strategy (IUCN, 1980) as outlined in Table 2.1 
TABLE 2.1 Priority requirements of the World Conservation Strategy (IUCN, 1980)

A. Ecological processes

1. Reserve good cropland for crops (para 5.1).

2. Manage cropland to high, ecologically sound standards (para 5.3).

3. Ensure that the principal management goal for watershed forests and pastures is protection of the watershed.

4. Ensure that the principal management goal for coastal wetlands is the maintenance of the processes on which the fisheries depend (para 5.6).

5. Control the discharge of pollutants (para 5.8).

B. Genetic diversity

1. Prevent the extinction of species (para 6.1).

2. Preserve as many kinds as possible of crop plants, forage plants, timber trees, livestock, animals for aquaculture, microbes and other domestic organisms and their wild relatives (para 6.4).

3. Ensure on-site preservation programmes protect:

- the wild relatives of economically valuable and other useful plants and animals and their habitats;

- the habitats of threatened and unique species;

- unique ecosystems;

- representative samples of ecosystem types (para 6.8).

4. Determine the size, distribution and management of protected areas on the basis of the needs of the ecosystems and the plant and animal communities they are intended to protect (para 6.10).

5. Coordinate national and international protected area programmes (para 6.12).

C. Sustainable utilization

1. Determine the productive capacities of exploited species and ecosystems and ensure that utilization does not exceed those capacities (para 7.1).

2. Adopt conservation management objectives for the utilization of species and ecosystems (para 7.2).

3. Ensure that access to a resource does not exceed the resource's capacity to sustain exploitation (para 7.3).

4. Reduce excessive yields to sustainable levels (para 7.4).

5. Reduce incidental take as much as possible (para 7.5).

6. Equip subsistence communities to utilise resources sustainably (para 7.6).

7. Maintain the habitats of resource species (para 7.7).

8. Regulate international trade in wild animals and plants (para 7.8).

9. Allocate timber concessions with care and manage them to high standards (para 7.9).

10. Limit firewood consumption to sustainable levels (para 7.10).

11. Regulate the stocking of grazing lands to maintain the long-term productivity of plants and animals (para 7.11).

12. Utilise indigenous wild herbivores, alone or with livestock, where domestic stock alone would degrade the environment. 
A few years later, the term "sustainable development" was first brought to global attention by the World Commission on Environment and Development (1987) stating that:

"humanity has the ability to make development sustainable to ensure that it meets the needs of the present without compromising the ability of future generations to meet their own needs." (WCED, 1987:43).

The Bruntland Report, entitled Our Common Future was a landmark document in terms of drawing international attention to issues of global and local sustainability and enunciated several guiding principles for sustainable development. Comments and observations by the author of this thesis are included in brackets.

1. A political system that secures effective citizen participation in decision making. (A definition for "effective" was not provided, as to whether it means involving a majority of the population or directly influencing the final decision.)

2. An economic system that is able to generate surpluses and technical knowledge on a self-reliant and self-sustaining basis. (We assume the surpluses are for the world's public and not corporate shareholders.)

3. A social system that provides for solutions for the tensions arising from disharmonious development. (A definition of "disharmonious" was not included, but it is assumed that much more than aesthetic conflicts are implied. Social tensions are evident in many forms of global and local scale development currently underway.) 
4. A production system that respects the obligation to preserve the ecological basis for development. (Fundamentally limiting, since at the extreme this means no growth. If there is a real obligation, then the responsibility must ultimately rest with someone -government or private industry -a debate far from resolution.)

5. Technical systems that can search continuously for new solutions. (And, hopefully, apply the solutions without creating new problems. This implies a system of monitoring and testing so as to gauge the success or failure of new technologies.)

6. International systems that foster sustainable patterns of trade and finance. (A very politically divisive -left versus right, principle.)

7. An administrative system that is flexible and has the capacity for selfcorrection. (Bureaucratic and labour union self interest may be major disruptive forces. For example, unwillingness to change "tried and true" practises, or simply delaying of corrective measures often serves to frustrate initiatives and advancement.)

Since the publication of these principles in the WCED's report the idea of sustainable development has gained mainstream acceptance (or at least has become a mantra for enlightened environmentalists) and is given central attention in many political agendas as well as the mass media. The above principles, when analysed in everyday language, become mission statements for sustainability, summarized as follows: 
1. Sustainable development does not necessarily mean "no growth". At the same time, it does not mean growth according to traditional economic measures. Sustainability requires a new approach to development, and the creation of cost and environmental accounting and auditing methods that can properly measure biophysical resources, impacts and risk assessment. Of course, the science, knowledge and understanding of biophysical resources is constantly evolving, so such measures must evolve as well.

2. Social inequities contribute to the continued degradation of natural systems. Environmental impacts, cyclically, precipitate further social and economic deterioration. Sustainable development implies a merging of social, economic and environmental factors into decision making and risk assessment.

3. Technology is a key interface between humans and other aspects of the natural world. Sustainable development requires new investment in science and technology, and the development of new and different technologies.

Further, we can conclude that the fundamental principle of sustainable development is that the support of the health, welfare and quality of human life for future generations is part of, and linked to, the diversity, productivity and quality of the ecosystem. 


\section{Sustainability: The Debate About Meaning}

Studies indicate that present rates of population growth and resource consumption are not viable over the long term - projections exceed the carrying capacity of the planet (Ottawa Citizen, 2000).

Some of the generally accepted basic elements of this dilemma are discussed below (along with the author's counter arguments in brackets):

- The stock of non-renewable resources on the earth is finite; (but technological developments continually lead to a redefinition of resources. This is as much a cultural and scientific concept as a physical fact of an element or chemical compound.)

- Ecosystems have limits; (but ecosystems do not remain static, since evolution is a fact of nature).

- Some natural assets, such as unique landforms and areas of outstanding beauty, are irreplaceable; (although they degrade naturally over time).

Sustainability depends on maintaining and improving the well-being of people and ecosystems together.

Although the WECD defined the concept of sustainability, we must ask what are some more finite requirements for the accomplishment of sustainable development in practise, particularly at the local level? Although these vary widely among researchers in the field, some supposedly constant principles are summarized by Selman (1996: 14-16). 
1. A Public Trust Doctrine - places a duty on the state to hold environmental resources in trust for the benefit of the public.

2. Precautionary principle - where there are threats of serious or irreversible damage, a lack of full scientific certainty shall not be used as a reason for postponing cost-effective measures which, given the current understanding of the problem, are thought to prevent environmental degradation.

3. Principle of Inter-generational equity - which implies that one generation should "pass on" the earth to the next one, in at least as good a condition as it was inherited.

4. Principle of Intra-generational equity - stating that all people currently alive have an equal right to benefit from and improve their quality of life (i.e., presumably to a western or North American standard) from the use of natural resources, no matter where in the world they are located (i.e., equity between countries).

5. The Subsidiary Principle - which deems that decisions should be made by the communities affected, or by authorities closest to them.

6. Transfrontier responsibility or the "polluter pays" principle, which requires that costs of environmental damage be borne by those who cause them. Sustainable development in one locale or country cannot be achieved at the expense of environmental conditions elsewhere. We must accept responsibility for the impacts of our activities on air and water quality, biodiversity and natural resources. Part of this 
responsibility will probably be in increased cost of various consumer products which have damaged the environment as a result of their production.

These somewhat simplified, constant performance principles for sustainable development have been widely scrutinized on a global basis for many years. Due to several conflicts in philosophy and ideology, the ambiguities arising from the debate have made it difficult to translate the theories of sustainability into practice. Risk assessment, for example, when applied in its simplest form, would take the stance that total avoidance of all environmental impacts would mean society should do nothing at all, and as a result civilization as we know it would end!

As an integrative term, sustainable development attempts to pull together various subjects - environment, economics and societal goals. However, we may not yet possess the negotiation and mediation skills required to resolve the conflicts inherent in these broad topics and conflicts which represent the major difficulties in the advancement of sustainable development today, as expressed below.

1. For inter-generational equity to be realized, reusable resources should not be consumed at a rate that is greater than their regeneration rate; waste discharge should be maintained at, or below, the assimilative capacity of the natural ecosystem; exhaustible and reusable resources should be priced according to their replacement value, and reduction in the stock of exhaustible resources should be compensated with 
increased stocks of renewable resources. However if regeneration rates are managed as opposed to "natural", what is the environmental price of management? (e.g., fresh water supply for irrigation). Further, if we assume the assimilative capacity of a natural ecosystem at the point of input is zero, damage at the point of input is fully attributable to the environment. Exhausting supplies of resources requires assessing the risk of such actions, either at a pre-determined rate, or absolutely. Alternatively, finding or developing other resources for use may be possible. Increasing stocks of renewable resources may result in other environmental impacts, from such practices as intensive agriculture.

2. There is a perceived failure to take into account intra-generational equity. Sustainable development, as a goal in national and international policy debates...

"has drawn attention to the issue of inter-generational equity... but ultimately it will fail to halt environmental degradation unless matched by a comparable concern for social justice or equity within the present generation" (Boyce, 1995:12-17).

However, to date, there has been no demonstrable link between environmental conditions and social justice and equity. In developed countries, difficult choices must be made in times of economic downturn, when employment often takes precedence over the environment. Similarly, impoverished countries aspire to improving their quality of life, often resulting in conflicts between nature conservation and economic development. Issues such as biodiversity and landscape 
conservation, versus "rights" to resource development and exploitation and local benefits from use of resources must be further debated.

3. Another debate focuses on the issue of freedom vs. control. Can we trust the democratic, market based decision process to "do the right thing" for the people involved and for global sustainability, or will central controls and legislation become necessary? Can we depend on democratic society, or the state for that matter, to choose difficult courses of action in the interest of future generations? If society at large embraces three simple principles of wise stewardship, possibly we can depend on it to make the difficult choices. These are:

- Do not pollute and destroy your own "home" environment/ecosystem.

- Do not pollute and destroy others' environments/ecosystems.

- Apply the "golden rule", whereby you " do unto others...", since everything is connected to everything else.

4. Those promoting sustainable development do not necessarily preclude economic growth. Others argue that the environment cannot continue to support such growth. Our Common Future (WCED, 1987) stated that technology and social organization can both be managed and improved to make way for a new era in economic growth. Some, such as Turner (1993) believe that this new era might bring disastrous results, wherein sustainable economic progress places ever increasing demands on an 
already stressed environment, eventually pushing the environmental price to the point where economic progress is unsustainable. The other option - massive, global redistribution of wealth, is undoubtedly a concept with which the majority of the wealthy will never agree!

Wilbanks (1991: 541-556) goes on to ask the following questions.

5. Can sustainability be more effectively achieved when organized on a centralized or decentralized basis? Should sustainable development be applied at a national, regional or local scale, and what is more important, the power and resources of large groups, or the social structure and local knowledge of smaller ones? Sustainability at one scale might not be so at another.

6. On the issue of reformism vs. revolution, is it realistic to think that we can respond to the challenges posed by sustainable development by making incremental changes in policy, institutions and preferences (a slow, deliberate process) - or will true sustainable development require more revolutionary changes in how we do things on the earth?

7. The subsidiary principle becomes problematic if not impossible when determining the appropriate level of decision making for environmental issues of international significance (e.g., the James Bay project). The cost of transfrontier responsibility ultimately trickles down to the end consumer, allowing corporations often to rely on repair of environmental damage through public taxes, not from their profits. 


\section{Sustainability: Is it Practicable Politics?}

Turner (1993) argued that sustainability was being used as a mediating term to bridge the widening gulf between developers and environmentalists, and that the concept was deliberately vague and self-contradicting, so as to confound political or academic definition.

However, the term has "stuck" since 1987, and, in my opinion, it seems that neither public figures nor private corporations can afford to ignore it, as it is well known that the "greening of society" has political force and powerful public relations and marketing implications. We have created an environmentally sensitized democracy (superficially, at least as long as it is pain free and costs nothing) in the industrialized world, yet we have not discovered the means of mainstream acceptance and implementation.

What we do know is that putting global sustainable development into practice probably requires a re-structuring of international arrangements and transforming economic thinking as well as undertaking formidable decisions regarding North-South economic and technology transfer. The critical paradox seems to be that the "concept" of sustainable development is more encompassing than the tools (e.g., the aforementioned mediation and negotiation skills) we have at our disposal to promote its cause. The scale of rethinking, restructuring and de-politicizing institutions, economies of people and international organizations required to achieve sustainable development is formidable. If we can pause momentarily to think back to earlier references to a "mechanistic world view" and the subsequent fragmentation of today's society, it is easy to 
understand why a holistic view is not yet widely embraced by society at large. Personal observation and experience demonstrates that fragmentation or specialization is central to the modern professional working process, and represents a triumph of reductionist thinking. We now have a social predicament, as our legacy of work in isolation from the "system" has valued material things, which are quantifiable, and discounts spiritual things, which are more difficult to measure. However, economics, ethics and even aesthetics (in this day of allpowerful public opinion polls) can be reduced to some measurable scale. We don't have the will, it seems, to turn such power of opinion over to the pollsters: elected politicians would never agree! We need a different world view, a healing view, one that assesses the risk of not pursuing material goals against the risk of not pursuing ethical environmental goals. The answer may lie in recognizing the value of relationships - that things exist in an interdependent and interactive relationship with everything else. Systems relationships are dynamic, constantly changing and adjusting to work together. In essence, we need to change our thinking to a systems approach, where indications of health are rooted in the quality of the relationships between and among the parts.

Therefore, acceptance and implementation of the concept of sustainable development implies social evolution in which change is accepted as a process, where the notion of adjusting relationships requires society's creative energy for the future. Sustainable development strives to respect society and environment and contributes greatly to a unified world view, predicated on the notion of holism i.e., behavior of a system depends on how the individual parts interact as 
functional components of the whole - at a local to global scale. Within the western world, Christian-rooted notion of a unified world view, individuals - their relationships to each other, nature and their communities - have value and are valued. It is this combined sense of personal and contributive value that makes sustainable development a workable proposition for the future, provided that individuals and society at large can change. This valuation/decision process must work within democracy and in this sense most of the change must be directed by the people from the bottom up - at the grass roots level (Vojnovic, 1994: 11).

Decades of dispute about the need for effective environmental management and sustainable development is at the very least helping to arrive at a consensual position. Several of today's environmentalists and political leaders are advocates for sustainable development, and believe that we can have both economic growth and environmental protection. (Serageldin, 1994: 2). This has become a central tension within the contemporary environmental movement, and is the basis for a potential split between the remnants of the ideological left and those who would support the "greening of capitalism" - not necessarily mutually exclusive intellectual options, as will be demonstrated by Fodor (1999) later in this chapter.

\section{Sustainability: Governmental Activity}

Internationally, specific sustainable development issues have been on the agenda at events such as the 1992 Earth Summit in Rio de Janeiro, the 1995 meeting of the Intergovernmental Panel on Climate Change, the June 1997 UN 
Special Session as Sustainable Development in New York, and the December 1997 meeting of world leaders in Kyoto on climate change.

In Canada, a National Task Force on Environment and Economy was set up in 1987 to foster and promote sound economic development. This led to the formation of the National Round Table, subsequently mirrored in all provinces and territories. By 1996, the office of the Canadian Commissioner of Environment and Sustainable Development was established, and, by the end of 1997, twentyeight federal departments had tabled sustainable development strategies. To date, several municipalities across Canada have incorporated sustainable development policies into their updated official plans. (Government of Canada, 1998:5-8)

For example, a Royal Commission in Ontario adopted a bioregional/ ecological perspective in arguing that sustainable development must support "natural capital" such as forests, food lands, clean air and water, by "living off the interest, not the capital" (Royal Commission on the Future of the Toronto Waterfront, 1992).

It is generally acknowledged that social inequity both within and between countries, has been growing since the 1970s (Johnston, 1994:148). Poverty, for example, is often found to be both a result and cause of local environmental degradation. Some would argue that global wealth is at the cost of global environmental degradation, yet environmental protection is ultimately required for economic stability. While social justice, environmental protection and economic prosperity are goals in themselves, they are interdependent with respect to 
sustainability-one cannot be maintained without the others. This triad of social, economic and ecological factors must therefore be addressed in any reversal of the trend to degradation. Progress toward change will depend on more than a singular, although worthwhile, effort, to, for example, preserve forests, recycle materials or build better pollution control technologies.

From what we have reviewed so far, the pursuit of sustainable development can best be understood as a journey. Guided by a need for better decision making, this journey is an exploration of new ways of thinking and acting as we strive for solutions that integrate economic, environmental and social concerns.

For those with a desire to find ways to steer a new course, one of the central challenges is that the scope of change and specific measures necessary are not well understood or agreed upon. The issues are complex. As we have seen, the science necessary to unravel cause and effect and remedy is not well developed, and many of the research questions do not fit neatly into a single professional discipline or government mandate. Furthermore, effective research to determine solutions - even to adequately understand the issues - often requires long periods of time, sometimes generations.

Even though the barriers to achieving sustainable development might not be overcome in the near future, it should be recognized that attaining the second best - advancing towards sustainable development and prolonging ecological and social stability in light of the physical limitations - is not a trivial alternative. The pursuit of the core equity requirements (especially intra-generational) would 
bring about considerable improvements in both human and ecological terms.

Future generations can then build on these improvements as they themselves reconceptualize the problem, and perhaps even establish a more widely accepted solution.

However, for many, sustainability will continue to be an impossible ideal. Can improved practices, possibly resulting from the test cases referred to previously or as proposed in this thesis at a local community level, make a difference in a world where capitalism and consumerism are seen as ultimately unsustainable? If all ecological "capital" is used up in the process, what will future generations have as "raw materials" to work with?

"Living ecosystem" resources might, with time and assistance, have some re-generation capacity, but "hard", non-reusable and mineral resources are either combusted as energy sources or used to create products which are ultimately discarded. In both cases, there is considerable financial impact in the "renewing" or "recycling", if these are to be the sources of future raw materials.

Even though well intended and informed, the global community may never achieve the condition of sustainability. However, humankind can advance a step closer to sustainable development, thereby prolonging the notion of social and natural/ecological stability.

"No organization - in Canada or around the globe - has a definitive view of what a sustainable development strategy should contain. No organization knows precisely what the road to sustainable development looks like. However, travellers moving toward sustainable development do identify one essential prerequisite: an articulated commitment to continuous learning, improvement and innovation" (Government of Canada, 1998:5-8). 


\section{CHAPTER 3}

\section{LOCAL AND URBAN SUSTAINABLE DEVELOPMENT}

\section{Evolution of the Concepts}

Having critically reviewed the background and key issues in the sustainable development debate, the relationship to and potential role of the concept in urban and suburban development and the problems inherent to urban growth are now explored.

The natural environment is a topic in which public interest has varied greatly. A decade ago, the economy was thriving, and from personal recollection, environmental concerns rated highly in public opinion. This was the time of Exxon Valdez, Chernobyl, the Green Plan and the Earth Summit in Rio de Janeiro - major events that tended to focus popular attention.

Surveys such as one by Environics International (1998) ranked the environment as a much lower priority, competing for attention with other worthy causes such as the economy, deficit reduction and national unity.

However, if environmental issues are currently low in public opinion, this by no means decreases stress on the global environment. For example, between 1989 and 2000 the world's population increased by about 800 million with relative growth in greenhouse gas emission, ozone depletion, and so on. Most of this growth occurred in developing parts of the world, (especially in cities) where the need for economic growth is a dominating reality. The World Watch Institute, in its State of the World 2000 report, said "Global economic trends during the 1990s 
were remarkably bullish, but environmental trends were disastrous" (Ottawa Citizen, January 2000:C14).

The report noted that from the economist's viewpoint the 20th century brought spectacular technological achievements, boosted employment and has helped fuel the longest peacetime expansion ever in the United States, but ecologists see the expanding global economy outgrowing earth's ecosystems. Vast quantities of fossil fuels are being burned (which might alter the climate, either adding to or reducing natural trends) rather than using clean, reusable (i.e., sustainable) sources of energy.

Meadows (1972), in a report on the predicament of mankind for the Club of Rome, reviewed an inventory of global environmental stress evident up to the 1970s. The report reveals how little we've learned, much less accomplished, in the last three decades.

Global sustainability can only be partially linked to the local level, in that some global objectives cannot be addressed at a local or municipal scale. (e.g., mass production systems or international trade and finance patterns). At best, local communities can contribute to some aspects of global sustainability, many of which are tied to the environmental problems relating to urban expansion.

A sustainable city (to be more fully defined later in this chapter) should protect people, provide shelter and a healthy environment and offer opportunities for employment and cultural expression. Since most cities are expected to triple in size over the next generation, it is important that the world community take concrete action. Examples include practices such as materials' recycling and 
reuse; waste reduction and exploration and introduction of renewable energy resources. Ultimately, the planning, implementation and management of transportation, energy and solid waste strategies must be appropriate for human health and environmental quality, if "mega cities" are to be liveable environments.

Over the last two centuries of urbanization, especially since 1854 and Thomas Crapper's invention of the water closet toilet and the introduction of sanitary sewers, environmental conditions in cities in the western and industrialized world have improved dramatically. The process was often slow, but over time, many epidemic diseases were controlled and the supply of clean water and the removal of wastes has become (almost) expected. (Canadian exceptions such as Victoria and Halifax still dump untreated sewage directly into the ocean, challenging the assimilative capacity of the ecosystem discussed earlier in this chapter). The risk of fire has been contained, and standards of comfort and cleanliness have risen to unprecedented levels. Many of the improvements and policies introduced in the period 1890-1914, and in the years following WW II, which once were radical innovations, have long since become routine in most cities in the western world (e.g., chlorination and fluoridation of the potable water supply.) A new wave of innovation is needed again, however, since cities now confront a range of problems, which are not so easily alleviated by conventional strategies. The environmental problems we now see in some of the largest cities such as Mexico are indicators that cities can no longer generate solutions to their own problems. Large, well managed cities like New York, London or Toronto seem to handle infrastructure and transportation problems well, but have much 
more trouble with landfill, recyclables and other "end products" of human life. In fact, many cities (in North America) have a growing list of regional and local problems that compromise their prospects for development, even though cities are where most of the expertise to solve such problems is concentrated. For example, even the very first cities exceeded the carrying capacity of their bioregion. Their "ecological footprint" (Rees, 1992:121-130) is an estimation of the area of land and resources required to sustain that city based on an assessment of requirements. The higher the material standard of living, the larger the footprint becomes, impacting a finite amount of productive land and non-renewable resources. Ultimately, some would argue, certain economic activities are non-sustainable, as exemplified by current requests for the diversion of Canadian fresh water for irrigation in the American mid-west.

Although much of the research and literature to date focuses on sustainable development at a global level, it is the culmination of activities at the local level which eventually accumulate to global problems. The call for more sustainable cities results from events such as rapid peripheral growth at low density (land consumptive and expensive to service) and abandoned and degraded inner city sites (normal, economics-driven change experienced by most cities).

Canada's Commissioner of Environment and Sustainable Development stated in the spring of 1998 that he was troubled by the federal government's 
performance to date stating that "while Canada has demonstrated vision, it is failing to implement it..." (Government of Canada, 1998:5-8).

He recognized that the challenge of "making sustainability happen" remains, and that the real challenge is to find ways to encourage, facilitate or even force the multitude of changes in local, day-to-day activities and decision making required to move toward sustainability. However, if we wish to move the "sustainability mission statements" reviewed earlier in this chapter to an effective level, we must strive to develop these into objectives and operational definitions with environmental indicators. Ultimately, cities, towns, communities and neighbourhoods should be designed and implemented with the above in mind, to help achieve the global vision.

We need local action on urban/suburban environmental issues that will work to revitalize cities and enable them to support economic and social development into the millennium. European and third world cities may have similar or very different problems - a subject for investigation not undertaken here, since our focus is the North American city, and greater Ottawa and Nepean specifically.

The major components of a healthy liveable (i.e., sustainable) city, as put forward by the Metro Toronto Planning Department in 1991 are as follows:

- Environmental Integrity - Clean air, soil and water and a variety of species and habitats maintained through protection that ensures sustainability over the long term; 
- Economic Vitality - A broad based, competitive economy responsive to changing circumstances and able to attract new investment so that opportunities for employment and investment will be available in both the short and long term;

- Social Well-being - Safety and health, as well as equitable access to housing; regional, community and neighbourhood services; recreation and cultural activities.

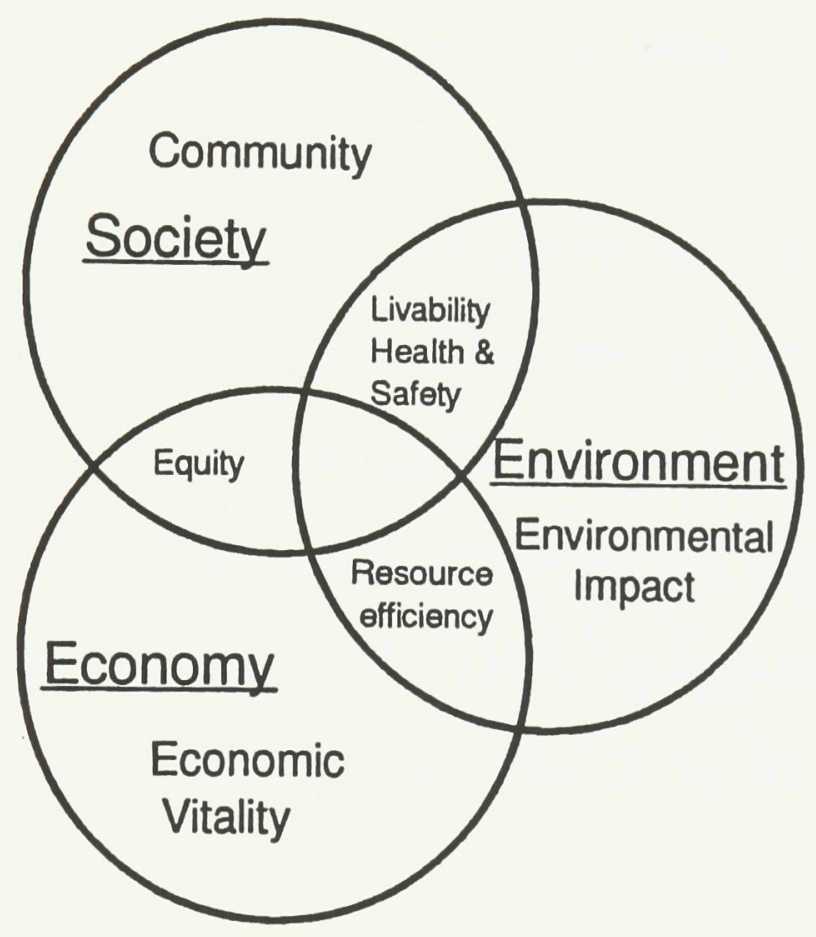

FIGURE 3.1 SUSTAINABLE DEVELOPMENT FRAMEWORK CMHC (1991): 11

One can hear echoes of the Bruntland report's guiding principles in these broadly stated objectives. Figure 3.1 attempts to graphically express sustainable development, but gives equal weight to each component. Those in wealthier western and industrialized countries often demonstrate an intra-generational bias by arguing that the environment /biophysical component should be more 
prevalent, reminding us again that environmental popularity is often linked directly to economic well-being.

Toronto's growth situation a decade ago demonstrates why its City planning department was exploring quality of life in their region. An area of 33,000 ha. of rural land were converted to urban use in the decade 1976-86. Between 1981-86, 36ha. were developed for every 1000 population, yet densities decreased. While the inner city supported 6000 persons per sq. $\mathrm{km}$, the greater Toronto area supported 1376 persons per sq. km. (Metro Toronto Planning Department, 1991).

If trends continue unchecked, it is expected that over $40 \%$ of that region's new housing development will occur in those communities that are the most remote from the regional centre where very expensive infrastructure services have yet to be developed. The construction of new roads, sewers, stormwater systems and other services threaten the existing environment, especially the natural resources and features of the region that make it so attractive in the first place.

Adaptability has always been a key variable in the evolution of urban areas, especially relevant in today's unpredictable economic and social climate. Although there is a vision (as described in the next section), we do not really know what conditions will be like in cities in 50 years time, but what seems obvious is that energy use, transport and consumption is likely to be different from now. Without adaptability we cannot design to accommodate these changes in a sustainable way. 
Politicians and planners need to re-think how we build and move about in our cities and towns, but it is individual values at the local level (as will be discussed further in the next chapter) that will drive social changes. The sustainability of cities in the global environment requires our evaluation of humanity's place in the world and a collective deepening of our responsibility to the earth and future generations.

Ultimately, we must ask ourselves whether the current level of materialism and consumerism can service the transition to a sustainable world (Brown and Jacobsen, 1987:38-56).

The physical resources consumed could be recycled, but at a considerable energy cost. This implies a need for increased research efforts into alternative energy sources.

It may be that we collectively must accept a lower standard of living (as defined by the consumption of material goods) and exchange it for higher quality of life as demonstrated by good health, social well being and the long-term enjoyment of a stable ecosystem (Campbell, 1997:126-129).

Some would question if these are, or should be, mutually exclusive goals. Eben Fodor, on behalf of the Institute for Southern Studies, ranked the environmental and economic health of all 50 American states, using 20 indicators for each category. Nine of the states in the top twelve on the environmental scale also ranked in the top twelve on the economics scale, drawing the conclusion that "The states that do the most to protect their national resources also wind up 
with the strongest economies, and the best jobs for their citizens" (Fodor, 1999:20-21).

What can we learn from such "local success stories" that can contribute solutions to the global problem?

At a time when rapid urban growth in Latin America and Asia Pacific regions is calling for infrastructure development estimated to cost one trillion dollars within the decade, the need seems obvious: it is up to cities in the industrialized world to demonstrate that economic growth can be advanced while pursuing more sustainable forms of physical and social development than what has been accomplished over the last century (OECD, 1996).

\section{Vision Of A Sustainable Community - Evolution and Principles}

Numerous visions have been put forth by planners and urban visionaries for the creation of a "good" or "better" community, but what kind of place would a "sustainable community" be? To date, there is no universally agreed-upon definition.

There are, however, several recent community "movements" that have parallels with the global sustainable development perspective, such as the "eco" or "green" communities, "healthy" communities, "garden" communities and "new urbanism" movements (CMHC, 1997:5-12).

The concept of good governance, which refers to the establishment of fundamental conditions of law, economic stability, social welfare, infrastructure 
investment and environmental protection, also has parallels with the core precepts of sustainable development.

The green or eco-city evolved from the landscape planning movement which arose in the early part of the 1800 s, and evolved further from the urban ecology movement during the 1960 s and 70 s. In his influential book on ecological site planning, "Design with Nature" (1971), lan McHarg proposed a way of looking at the entire urban ecosystem as a whole, realizing human potential was dependent on a healthy environment where humans and natural processes were integrated.

The healthy or liveable city concept has its roots in the public health movement of the mid 1800 s, and, viewing the environment from a human perspective, uses human physical, social and mental health as a basis to address the inter-relationships between environmental and social degradation.

A healthy city is designed, built and managed to truly contribute to the health and well-being of all its inhabitants. The Ontario Healthy Communities Coalition, defines a healthy community as one that:

- provides a clean and safe physical environment;

- meets the basic needs of all its residents;

- has residents that respect and support each other;

- involves the community in local government;

- promotes and celebrates its historical and cultural heritage;

- provides accessible health services;

- has a diverse, innovative economy; 
- exists within on a sustainable ecosystem (Royal Commission on the Future of the Toronto Waterfront, 1992).

The goal of the compact city movement is to increase the efficiency of cities through compact urban form, a mix of land uses and efficient public transit. The amount of land required for further development can thereby be reduced as can related servicing costs.

Collectively known as the new urbanism (Bookout, 1992: 22-25) from its emergence in the 1980s, and advocating "neo traditional planning and design", this currently popular movement relies on principles based on traditional, historic urban form to create "urban villages" with the socially and economically vital neighbourhoods advocated by Jane Jacobs (1961). Typically, development is arranged around a "main street" or town square and comprises a variety of housing types, commercial and community uses, all concentrated in a compact, pedestrian scale plan.

In summary, each of these planning movements has a particular focus. The green city takes an environmental perspective, the healthy city has a humanist perspective and the compact city focuses on the mechanics of urban design. The neo-traditional community embraces many of the principles of the other movements.

The original, global concept of sustainable development, along with many of the ideas of the current planning movements, provides a foundation for a vision of a sustainable community. 
The goals of sustainable community development are to create communities that have healthy natural areas; that use land efficiently and are compact; that have safe, vibrant, accessible neighbourhoods; that are designed for efficiency in resource use, transportation and servicing, and are equitable, affordable and fiscally responsible (CMHC, 1999:17-20).

An empirical review of sustainable development projects identified nine categories of common characteristics and performance proportions, which are objectives for community planning. These are set out in Table 3.1 with suggestions as to how to actually achieve the objectives, which contribute to a more sustainable community. Again these do not have operational definitions although process and procedure statements are provided. 


\section{TABLE 3.1 CHARACTERISTICS IN PLANNING AND DESIGNING FOR A SUSTAINABLE RESIDENTIAL COMMUNITY AND NINE PERFORMANCE PROPOSITIONS}

1. Community (Design): Social fabric consciousness, developmental spirit and concrete objectives, stewardship roles defined and evolved, high group sensitivity to residents' satisfactions.

- Attend to community design in concert with land use and housing design.

2. Land and Community Space: trade-offs from private space expectations to community spaces in earliest planning phases; early attention to urban design-spatial composition to achieve agreeable community spaces, ground linkages and networks.

- Develop community management commitments-beginning with user-participant planning and design at the initial stages (at least) of a project.

3. Waste Management: Disposal, recycling and refuse programs, and local organization. - Minimize and control waste (from households and businesses, and from production processes of enterprises, including environment and landscape cleanups, and regulation of waste disposal and pollution discharges on the community site) and establish local refuse and recycling programmes and facilities.

4. Transportation: "calm" traffic systems and street sizing, emphasis on pleasurable street environments and person mobility.

- Minimize both the on-site generation of vehicle trips and the nefarious impacts of transport on community life and environment.

5. Community-based Food Production:

- Provide area for private gardens, allotments, greenhouse production units, and/or contractual associations for community purchases from nearby farm producers.

6. Housing and Other Built Forms: Land-use allocation/plan-making and design of housing forms proceed in concert with each other.

- Use building materials that optimize ecological soundness or "retums "(design, production, transport and construction); includes programs and considerations for achieving useful life, refuse and retrofit of existing buildings, and refuse or selective disposal of materials in post-demolition or post-construction contexts.

7. Resources Conservation: in all aspects of design and housing technologies, procedures and routines for household practices, and community education programming.

- Minimize energy consumption; use renewable energy. Minimize water consumption. Minimize waste. 


\section{Sustainable Development at the Local Level}

During the 1970 s and 80 s, environmental literature and news items were dominated by international and global issues - a necessary emphasis if politicians and big corporations were to be concerned with the seriousness of the environmental damage then being done.

But the local dimension was largely neglected. What could the average person, as an individual, really do about environmental problems? Thinning of the ozone layer was seen as huge and remote, and global and national strategies were seen as abstract and far removed from the average person's realm of influence. Consequently, the distancing of the person from environmental events reduced feelings of direct responsibility, and increased feelings of ineffectiveness. Rifkin (1991: 121-136) has argued that local communities, through their collective effects on society, act as catalysts for change at local, regional, provincial and national scales.

However, over the last 20 years, many examples of grassroots environmental actions led conservation-minded agencies to popularize the slogan " Think globally ... act locally ". Although sustainability can be considered at a number of scales - from the overall city/region to the local community and ultimately the individual household,

"sustainable development must be implemented where people are able to learn, feel and be empowered to act - at the local level. Sustainable development must be integrated into policies and decisions in local communities. It is imperative that we address the fundamental causes of our problems at the roots - our thinking and our behaviour at the local community level" (Maser, 1996: 165). 
This section explores four inter-related areas of activity where the impact of decisions are demonstrated at the local level. The author's suggestions (drawn from research, readings and personal experience) to improve the mechanisms and contribute to more sustainable development, follow.

\section{Governments}

As a direct result of Agenda 21 (United Nations, 1993) national governments had to produce sustainable development strategies, and these in turn required regional and local levels of government to respond.

New provincial policies calling for ecosystem-based, sustainable planning are now implemented through planning instruments such as official plans and zoning by-laws enacted at the regional and municipal levels. Through their official plans, each municipality can guide new development and urban renewal. In North America, there are initiatives at all levels of government and in the private sector (Province of Ontario, 1997).

\section{Suggestions for Governments}

New development should be based on a mixed-use concept of housing, jobs, commercial and social amenities. Residential development and intensification should be located away from sources of pollution such as industrial zones. Municipal and regional policies and infrastructure planning could ensure greater integration of local and regional public transit systems; increase the quantity and quality of public transit services; implement an extensive network of bike lanes and efficient pedestrian linkages directed towards the reduction of 
vehicular trips, air pollution concerns and improved safety. A long-term shift away from private vehicle use will depend on the interplay of public and private sector policies that will enable the public to reduce its dependency on the automobile. Within the Regional Municipality of Ottawa Carleton, transportation planning policy as well as changes in land use policy (spelled out in the Regional Official Plan of 1994), are intended to improve the appeal of rapid transit and encourage a mixture of commercial, business and residential activity.

\section{The Planning and Design Community}

Community planning is not the prerogative of any one particular profession or discipline; rather, it is a very multi-disciplinary activity, often involving the investment community, land surveyors, urban planners, civil engineers, architects, landscape architects, and various other environmental specialists. However, all the professions involved have weaknesses and/or specific interests of their own that should be recognized.

Urban planners in the past have paid little attention to ecological aspects, but this is now beginning to change. Planners, in general, have little knowledge about ecosystem functioning or impacts, and they lack the critical tools and resources to help them incorporate more ecologically sound principles into their plans.

Engineers have taken a narrow, mechanistic approach to transportation and infrastructure design. Landscape architects, in my opinion, have spent way too much time trying to restore their interpretation of nature to the urban 
environment, at the expense of relating to the economic and social aspects of human intervention and the natural environment.

The introduction of the concept of sustainability has given renewed vigor and justification to the most basic tenets of planning, such as protection of prime resources, local relevance, and social equity.

Some local strategies are based on a "top down " approach of expert decision -support methods ", while others are adopting a "bottom up" approach, more visionary and consensus building. However, as agreement on environmental indicators improves, and terms such as "carrying capacity " become more clearly defined, a more standardized approach to sustainable planning may emerge. I suggest it will be subject to constant adjustment and refinement.

Suggestions for the Planning and Design Community

Over the past decade professionals involved in urban planning have begun to broaden their scope to include each other's areas of expertise in the search for workable, acceptable community planning alternatives. All those involved on the "front line" of urban planning need to continue to be open minded, to comprehend and synthesize issues of urban design, ecosystems, social ethics, economics and politics into a more complex whole - to build healthy sustainable communities.

The idea of a sustainable community, however, is much more multifaceted than these points can express and there is no rapid solution, or indeed, 
at this time, any agreement over optimum future patterns of settlement, production or development. Basically, places need to be planned and managed for optimum quality of life, (as defined by health, happiness, mental well-being, and so on in Table 3.1) and people must at least be willing participants if not the motivation for regulation in the transition to sustainable development.

Recognizing that settlement pattern, resource consumption, infrastructure demands and buildings have a direct relationship to the size of a community's "ecological footprint", there are some basic planning policies at a local level for consideration:

- Discouragement of dispersed, single-use residential areas or any significant development highly dependent on (often individual) trips by automobile;

- A mix of housing typologies;

- Some degree of spatial concentration (not necessarily centralization) of community activities such as residential, commercial and work places;

- The location of moderate to high densities of development well served by efficient and economical public transit services (CMHC, 1996).

At the local level, planning regulations are still one of the strongest tools to ensure environmentally responsible development. For planning to be a genuine contributor to sustainable development it must be rigorously checked against consistent and coherent criteria for sustainable development, such as those to be described in the next section. 
Finally, regions are quite distinctive assemblages of ecosystems, and therefore approaches to development (e.g., extent of settlement and landscape conservation) vary from place to place. The quest for the more sustainable localities will require imaginative and continued informal debate.

\section{The Business Community}

Earlier in this chapter, we discussed the central challenge of sustainable development, attempting to reconcile economic, social and environmental objectives. There is growing pressure on private sector business and industry to accommodate ethical environmental principles. Agenda 21 of the United Nations (1993) sought to:

- Encourage the concept of stewardship in the management and utilization of resources by entrepreneurs;

- Increase the number of businesses engaged in enterprises that subscribe to and implement sustainable development policies.

While many businesses may be reluctant to conform, there is little doubt that sustainable issues are permeating the private sector. In some cases, the "green advertising veneer " is being supplanted by the adoption of sustainability as a basic principle of business strategy and accounting (Government of Canada, 1998:10-12).

However, in today's planning and land development environment, both municipal authorities and the development industry are somewhat uncertain about their roles and their capacity to advance the notion of sustainability within 
the context of community planning and development. Currently there are several factors in the Canadian context, which help to explain this uncertainty.

First, the "operational" meanings of sustainable development and planning-design criteria are still not sufficiently well defined and empirically demonstrated.

Second, the private sector has argued that existing inflexible municipal procedures, zoning, onerous levels of "public participation", tightly defined site engineering requirements and site development standards make it almost impossible to innovate in any meaningful way, within an acceptable timeframe such that normal product delivery timetables will not be adversely affected. There are, therefore, concerns that sustainable development planning requirements will further complicate an already difficult process. Personal experience has demonstrated a great deal of municipal, interdepartmental disagreement when it comes to even the slightest variation from "standard" planning procedures, usually slowing or halting the review and approval process.

Furthermore, there is an overwhelming perception (well founded, in our experience within the Regional Municipality of Ottawa-Carleton) that marketdriven, consumer preferences rule. The development industry, politicians and bureaucrats are loath to divert from current community forms because consumers may not purchase innovative built-forms, or neighbourhoods that are different in character from what is usually seen in the market place, or which might add to development costs (and sale price). 
Suggestions for the Business Community

A national round table on environment and economy in 1995 (Pathways to Sustainability, 1995: 39-47) found that some leading members of the corporate world were expanding their scope of sustainable development reporting. Their motivation came from expanding environmental and ethical awareness and the rising environmental standards of society at large. Also, many recognized that economic benefits often paralleled environmental improvements, especially in longer term and international, competitive arenas. At the very least it was, and still is being recognized that sustainability is an agent of change to be dealt with signaling a certain maturation in the environmental movement. The actual implementation and monitoring of more sustainable communities is but one strategy to provide the guidance required by the private sector.

\section{The Private Citizen and Household}

Individual behaviours contribute to environmental health and climate. And because we, as individuals, collectively comprise local communities which ultimately form the global village, we can serve to minimize global environmental impacts of our activities by changing our individual behaviours. Over the past century, environmental resources and amenities have been increasingly threatened and such real, day-to-day quality of life issues are most frequently voiced at the local level, e.g., in the media, at community meetings or at municipal councils. Personal experience at the provincial, regional and local level over the past three decades has demonstrated that the pendulum of public 
interest has now swung well to the side of the interventionists. No longer are environmental concerns the bailiwick of the perennial neighborhood activist. Today, we see the general level of civic mindedness heightened across the community. " Baby boomer " parents are coming to grips with the world they will pass on to their children.

Suggestions for the Private Citizen and Household

At the local level, education, organization and action empower individuals to influence their own destiny through a self-determined democratic process. If they get involved, they can influence the decision making process.

For example, local communities and households now demonstrate their concern for conserving resources, better waste management and recycling, and impacts of various forms of land development. Over the last decade we have seen the popularization of collective initiatives and actions which lead to increased interest and participation in environmental stewardship. More work in this area is needed for more widespread achievement of local sustainability.

Public spiritedness and concern for sustainable development issues at a local level can readily be harnessed, as long as citizens feel that they have genuine impact on local governments and are not just providing volunteer labor for some token results or futile battles against determined, wealthy and politically connected corporations.

Public awareness of global agendas, national programs and policies should continue to become more mainstream due to ever improving 
communications and invaluable technology such as the Internet. These improved linkages serve to provide viable comparative information as support for local sustainable development issues, helping to strengthen and lend purpose to local causes, many of which still require provincial legislation to enable them to be realized.

For community residents to truly support and demonstrate neighbourhood sustainability, those in leadership positions need objectives and operational indicators. Information is needed to demonstrate the comparative health of the local ecosystem. Activities undertaken in the community must provide for basic needs and enhance quality of life. Do they stress or restore the ecosystem? Comparisons of sustainable initiatives to other "global" activities allow the community to measure success in meeting goals such as local development plans or zoning modifications (CMHC, 1993:5).

\section{Applications in Local Community Planning}

In the recent Canadian context (since 1995), after the preparation of an environmental agenda for the country called "Canada's Green Plan for a Healthy Environment" (1990), work continues toward the evolution of a common set of urban sustainability indicators, relating to global sustainability, but which reflect local realities and possible initiatives.

The need for sustainability indicators arose from questions as to the real progress (or lack of progress) of sustainable development in Canada, since without some means of meaningful, credible measurement, progress could not 
be charted, the existing situation assessed, goals set and plans advanced, with any degree of assurance.

The Organization for Economic Co-operation and Development (1994) and the Canadian Indicators Workshop (1995) defined an indicator as a statistic or parameter that, tracked over time, provides information on trends in the condition of a phenomenon and has significance extending beyond that associated with the properties of the statistics itself (CMHC, 1995 and 1996).

Sustainability indicators have also been described as small pieces of information reflecting the status of larger systems. They have the capacity to make complex systems understandable, and thereby assist communities in determining their economic, social and environmental condition, where they are going, and how far they are from chosen sustainability goals.

An indicator should be more than just a simple statistic or measurement, since indicators provide a summary of a condition or problem and permit observation of progress or change. This progress can be measured over time or against benchmarks, targets or visions of the future.

Sustainability indicators link the social, environmental and economic elements of a proposal or initiative, have an overlying equity component, and relate directly to society's vision for future sustainability. At a global scale, these indicators are expressed in the following Table 3.2 in which environmental elements appear under I (Ecosystem) economic issues and are in II (Interaction), and social concerns are set out under III (People). Most of these do not have operational definitions. 


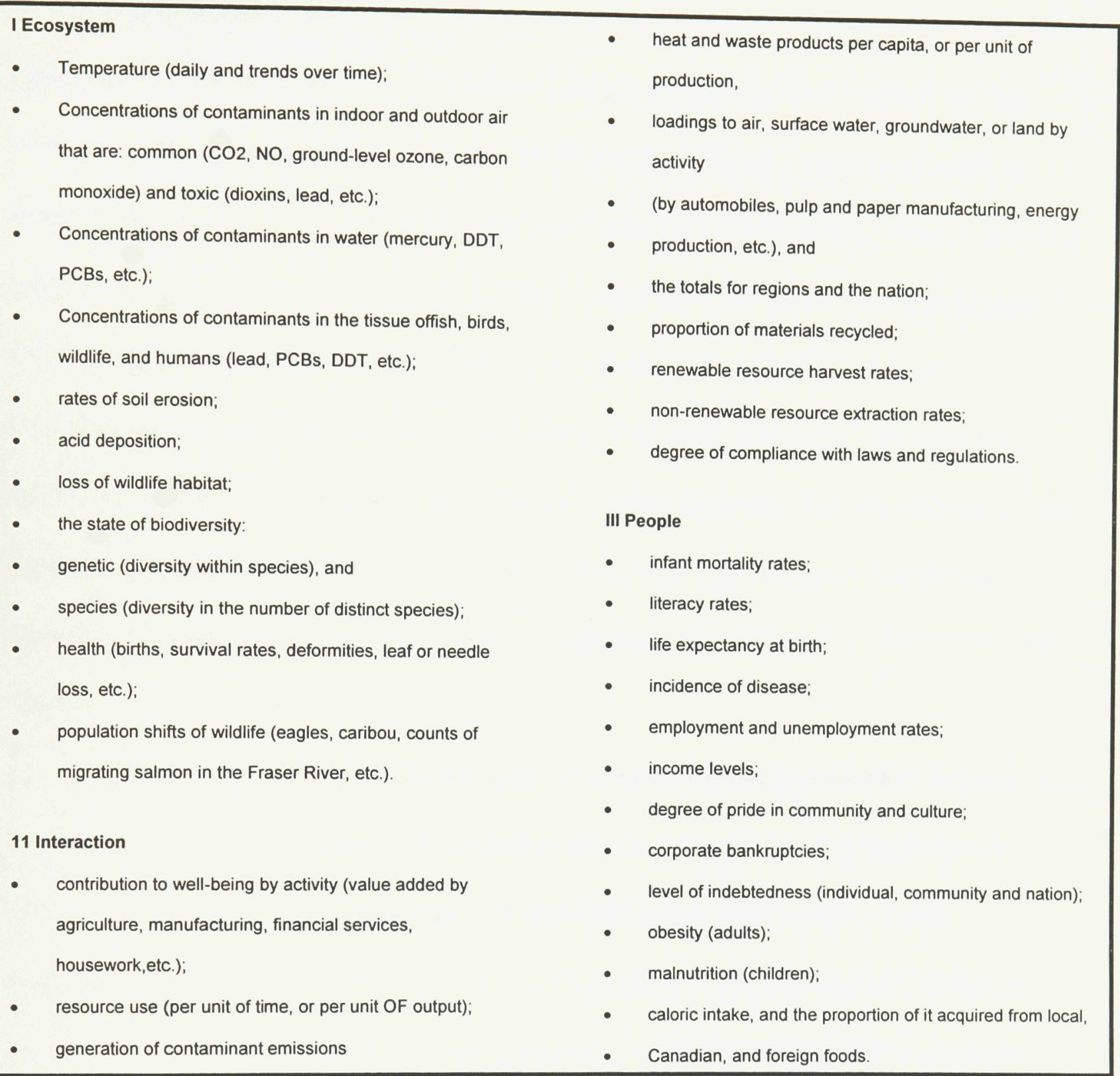

Table 3.2 - A Partial List of Rudimentary Indicators, "Pathways to Sustainability" (1995): 39-47

To relate these indicators to the local level, social indicators might include accessibility to affordable housing or recreational opportunities; unemployment levels or access to jobs are economic indicators, while water quality, consumption rates or non-renewable resources versus renewable energy resources are environmental indicators. 
Sustainability indicators might, over time, be referred to by urban planners, government officials, senior bureaucrats and decision makers, citizen groups, non-government organizations, interest and lobby groups, media, educators, private industry and the general public to assist them in efforts to design and plan healthier, more sustainable communities. Therefore, the needs and expertise of the users is an important consideration in the choice, development and explanation of indicators. Efforts to develop coherent, standardized indicators continue today at municipal, provincial and national levels, but regardless of the type of indicators selected, it is important that the community be the primary source of sustainability indicators and implementation (Mitchell, 1995 1:11, Hart, 1996).

Before discussing the application of sustainable development indicators at a community level, we should first define what we mean by "community". A human community is a social network of interacting individuals, usually concentrated into a defined territory, involving customs and shared modes of thought (Johnston, 1994:80-81). People have some attachment to a place of residence, and some degree of local autonomy. They share interaction locally, as well as with larger society. They have an interest in their local environment, (community), and events which might change that environment.

A community, given this definition, could be based on ethnicity, gender, religion, geography, politics or shared interest and objectives.

More communities today are assuming responsibility for many aspects of their own future, which serves to strengthen the sense of unity. However, from 
personal experience it can be argued that there is a distinct need for more tolerance and collaboration and less self-interest within communities. For example, issues such as education, taxation, delivery of services or new development issues often rapidly divide community interest groups. In this sense, in part, society demonstrates a deeply seated mechanistic worldview. Sustainable development will rely on the re-creation of a sense of local community to balance material objectives with the spiritual.

Substantial changes may be required in existing power relationships, the re-ordering of some cultural values, reform in governments and institutions and a re-consideration of the social effects of economic growth. Rees and Roseland (1991:15-26) defined guidelines against which our progress over the last decade can be measured.

1. Advancement of sustainable development principles (both operations and actions) will most likely come from trial and error - demonstration projects that provide "proof", resulting from implemented work. Further research regarding key measurable indicators is needed to monitor the success of initiatives as implemented in actual constructed projects.

2. In the absence of economic and costing data, or a theory on how sustainability factors can be integrated into plans and designs of sustainable communities, it is improbable that proposals for innovation will be implemented to any degree by the industry, no matter how well researched and promoted by government research agencies. 
3. Municipalities have a vital role to play in the advancement of sustainable development, through arrival at an internal consensus on what are desirable and feasible innovations; development of a common purpose between public and private sectors towards sustainable development; public and industry education and awareness programs; sharing of cost saving initiatives with other stakeholders, and imposing barriers or economic disincentives on projects and processes that are not ecologically sound.

The characteristics for sustainable community planning as expressed by Perks and Van Vliet (1993) in Table 3.1 have progressed between the early 1990 s and the present to a current statement of principles (which continues to evolve). These principles are generally accepted by today's planning and professional community involved in sustainable development and research, and are summarized in Table 3.3. 


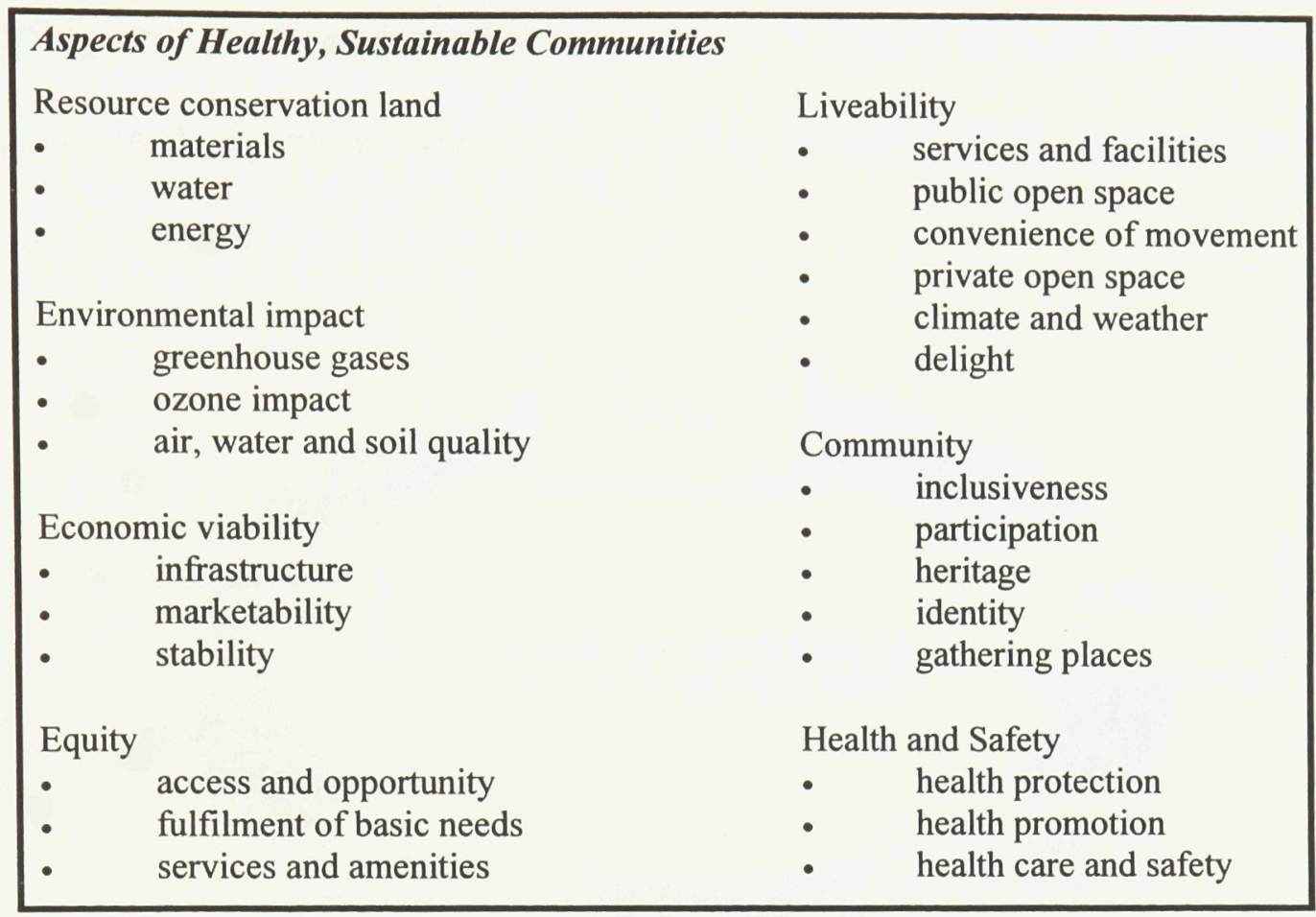

TABLE 3.3 ASPECTS OF HEALTHY, SUSTAINABLE COMMUNITIES (CMHC, 1997:4)

If we recognize that there appears to be a willingness to advance the cause of local sustainability, we must also be able to assess our progress over the next decade, and beyond. A process of assessment must be able to be measured (repeatedly) to determine trends; be interactive, adaptive and responsive to change, because systems are complex and change frequently. Future evaluations must have an adjustable framework, goals and indicators as new insights are gained, and must assure the feedback of collective learning to decision makers, because sharing of lessons is crucial to the process.

Mr. Brian Emmett, the Canadian Commissioner of the Environment and Sustainable Development, Canada, at a lecture at Carleton University November 12,1998 presented a similar view of an improved strategy for his own department. He discussed the inextricable connection between policy and 
planning and the "lower profile" business of implementation, evaluation and reinvestment of lessons learned into policy re-formulation, as expressed in Figure 3.2 below.

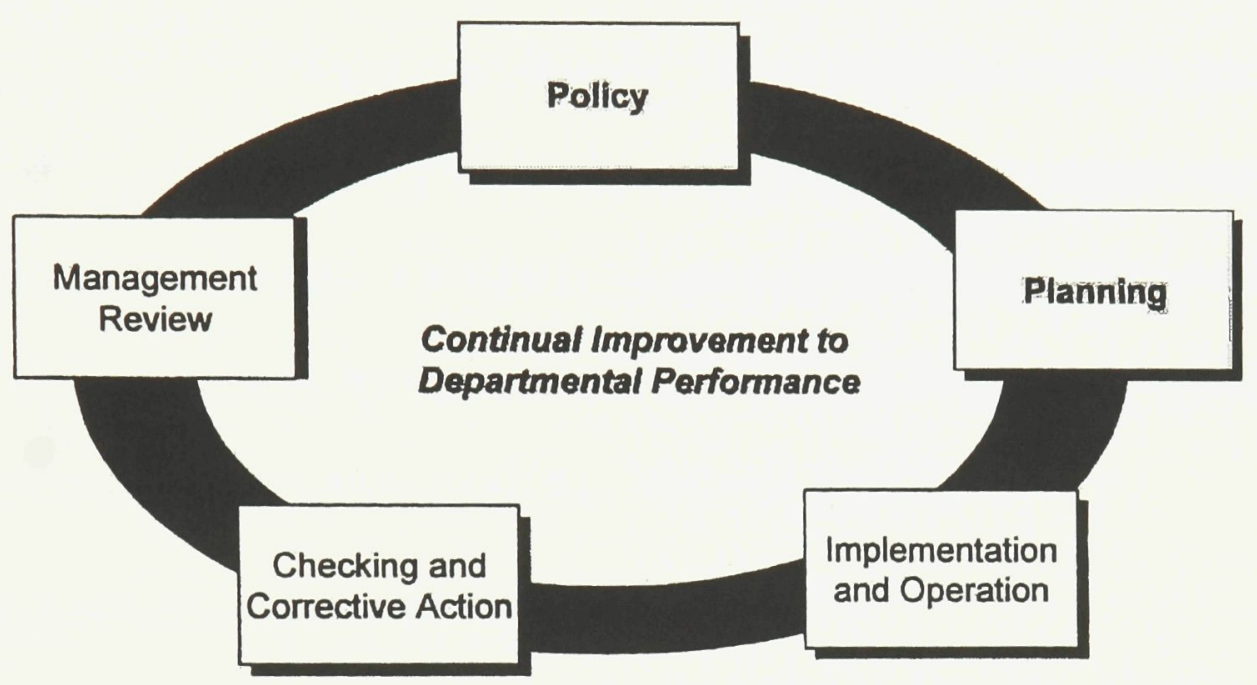

Figure 3.2 SUSTAINABLE DEVELOPMENT STRATEGY 


\section{CHAPTER 4}

\section{CASE STUDY BACKGROUND AND METHODOLOGY}

This chapter describes the political influences which created the opportunity for this case study, identifies the site and provides a description of its characteristics, potentials and limitations. Study objectives are set out in detail, together with a description of the tasks to be undertaken to realize the objectives. A chronological description of events has been intentionally employed so as to convey an appreciation for the evolution of concepts and their modifications in response to input and criticism as the work progressed.

\section{History and Political Framework}

The questions and thought processes that laid the foundation for this case study actually began in the fall of 1997, when the term "sustainability" was first used on related project work undertaken by the author with $\mathrm{CMHC}$ 's research division. Sustainable development as a concept became more common in working dialogue over the following two years.

This thesis has provided an opportunity to more thoroughly explore and understand the global origins and significance of the paradigm, so as to expand upon and complement the use of the term by CMHC - the leading national community and housing research organization.

In early 1994 , the City of Nepean assumed a lead role in the advancement of a Master Development Plan for an approximately 340 hectare (840 acre) land assembly (Figure. 4.1) located between Fallowfield Road on the north perimeter, 
Strandherd Road on the south, Woodroffe avenue on the east and Greenbank Road on the west.

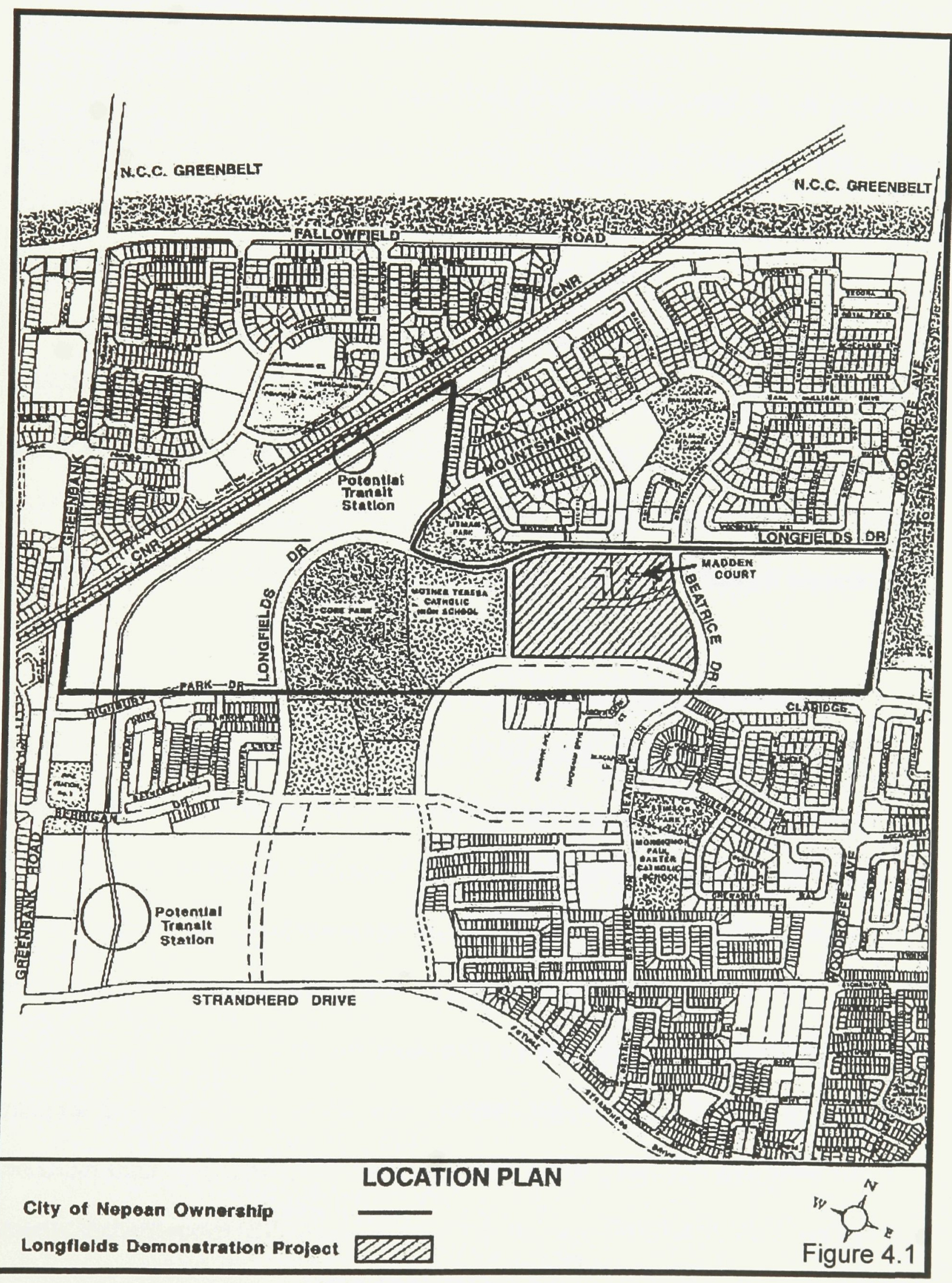


The land assembly comprised the lands of several owners, among them the City of Nepean with approximately 100 hectares (247 acres), much of which is currently under active development.

The firm of Larocque Levstek Consulting Services, (with G. Larocque as partner in charge) worked with the Planning Partnership (Toronto) in 1997-1998 in the preparation of the above mentioned Master Plan, which incorporated many of the "new urbanism" planning and design principles.

The City's land holding was, from the outset, envisioned (by the Planning and Development Department), in part, as an opportunity for case studies and demonstration projects for innovations in land planning, development forms, open space systems, and so on. This is based on conversations with Mr. Jack Stirling, Commissioner of Planning and Development for the City of Nepean, 1998.

In the past, the public sector has often taken a lead role in terms of research and development for new community planning, development and construction. For example, the Centrepointe community in Nepean, and the Carson Grove project in Gloucester are public sector initiatives where many current planning and land development concepts are demonstrated. Other examples exist on a national basis, as will be described later.

The author wished to continue an involvement with the development of the community and advance to the more detailed planning of a neighbourhood within the City's overall master planned "Longfields" community. Consequently, an unsolicited approach was made to the Planning and Development Department in 
January 1999. A proposal was finalized and subsequently accepted, to undertake a case study project.

Subsequently, CMHC was contacted, since this national organization is mandated to undertake research in many areas, among them land development and housing.

Sustainable development and more sustainable communities had been identified by CMHC (1998-99:98) as a "high priority" topic for 1999 and into the new millenium, wherein the design of sites must apply sustainability concepts to the details of site planning, material selection, design of site infrastructure systems, and related site development approaches.

In this regard, several studies have been completed to date, or are ongoing across North America. Three communities in Nova Scotia explored sustainable residential land use planning in 1993. A project in Calgary, Alberta, in 1996 tested consumer reactions to more sustainable suburban design. The Regional Municipality of Ottawa Carleton studied multiple housing for community sustainability in 1998. Currently, a study is ongoing at CMHC identifying the barriers to sustainable real estate development in Canada, while the South East False Creek neighbourhood in Vancouver undertook a sustainable design charette in 1999. Surrey B.C. has recently completed work similar in nature to this case study, but focusing more exclusively on environmental and biophysical sustainability (CMHC, 1998-99).

Further afield, Robert Thayer (1994) described the 1970s Village Homes project in Davis, California as an early convergence of several aspects of 
sustainable development. The 28 hectare (70 acre) site includes 220 clustered solar homes in a naturally drained open space system with community gardens and orchards. The bicycle and pedestrian oriented neighbourhood fosters improved community and social interaction.

Another tangible example (developed by a landscape architect) is the Institute for Regenerative Studies at the California Polytechnic University at Pomona. The late John Lyle (1992: 265-272) developed and implemented a Master Plan for the 137 hectare (340 acre) Landlab, dedicated to education and research in the sustainable use of resources.

The Earth Centre (Thompson, 1999:60-69), a 162 hectare (400 acre) demonstration of sustainable living, opened in April 1999 in South Yorkshire, England. Funded by the Millenium Commission, it will be fully complete by 2002 . CMHC made it clear that studies leading to actual, implementable project (where results could be measured against sustainability indicators and quantified) would be supported and encouraged by $\mathrm{CMHC}^{\prime}$ s research division.

However, affordability (as expressed by the impact on the cost of housing to the public) continued to be an underlying concern in all CMHC sponsored research projects.

After analysis of the overall land servicing schedule, current regional development trends and other municipal concerns, Nepean's Planning and Development Department identified a 12 hectare (approximately 30 acre) site suitable for such a case study within their overall land assembly. 
The site selected bordered a growing community, was surrounded by infrastructure, and was estimated to be two to three years from market demand, allowing appropriate time to complete the case study. (See Location Plan, Figure 4.1)

Although funded by the City of Nepean, CMHC has expressed an interest in possibly sharing the results of this case study and possibly funding future stages. The Regional Municipality of Ottawa-Carleton's Research and Planning Departments must ultimately review and comment on municipal development applications. Consequently, municipal, regional and to a limited extent federal levels of review are involved.

\section{Objectives and Tasks}

The principal objectives for the case study as introduced in Chapter 1 may be more fully specified as follows.

1. To research and develop the concept and practical "implementable" planning and design guidelines for a 12 ha. / 30 ac. neighbourhood demonstrating sustainability strategies. Such sustainable development initiatives and approaches will be based on on-going or completed research projects, as well as new ideas created by this particular study.

2. Assess the actual costs of a more sustainable neighbourhood concept plan as compared to a conventional subdivision layout to show how construction costs of concepts proposed ultimately affect affordability. A life cycle cost exercise will compare long term investment requirements by the City, and explore the financial impacts of sustainability initiatives. 
3. The study will test the reaction of the public (average citizens in the marketplace) as well as the development industry, and the professional community (especially those in the review and approval process) to the more sustainable community design that will evolve from this case study. There is a need also to identify the current barriers to sustainable development, some of which will be revealed in this case study.

4. Advancing towards more "mainstream acceptance" of a community form which meets clear sustainability targets is a key objective of the case study. The exploration of the scale of initiative, and the pace at which such concepts may be introduced for realistic implementation, must be understood so as not to deter acceptance by the private sector investment and development community, since, in the current investment climate, it is they who may deliver more sustainable living, work and play spaces to the wider public.

5. Study results will be used as feedback in the learning loop of sustainable development research currently underway. Results may be used to advance discussions and changes to site planning guidelines, development policies and zoning and other regulations at a municipal (City of Nepean) and regional (Regional Municipality of OttawaCarleton) level.

These objectives acknowledge that the physical design of the built environment is only one aspect of the sustainable community design process. Infrastructure design concepts, social and economic realities, conservation and 
environmental opportunities are evaluated within the context of existing City regulations and financial considerations.

Also the study tasks required the involvement of other professional disciplines. An architecture and urban design firm, as well as civil engineering expertise, were brought onto the study team, and will be referred to as "study team" throughout the ensuing text. The study was directed by the author of this thesis, who also provided environmental and development planning, physical geography and landscape architectural input to the study.

A time frame of 12-18 months was set for the completion of tasks and delivery of the case study, which provided enough lead time to complete the study before the land was to be marketed. Funding arrangements between the City and the study team were finalized. An advisory or working committee comprising City department representatives was formed, from Planning and Development, Public Works, Engineering and Parks and Recreation. This "working committee" as described throughout the following sections, was assembled for each case study progress review meeting, and provided critical review and commentary as the work schedule advanced. The author acted as study team co-ordinator and became the principal municipal liaison for the case study on a day-to-day basis.

\section{Site Inventory and Analysis}

After a review by the study team of current sustainable development research, and documents obtained from $\mathrm{CMHC}$, the Federation of Ontario Municipalities, the Government of Canada, university library and the internet, 
collection of site data was carried out, including an inventory and analysis of the existing conditions of the study site and environs.

Much could be said here regarding the decision by the City of Nepean and the Regional Municipality of Ottawa-Carleton to encroach onto former agricultural lands for the expansion of the south urban community (within which the case study lands are located). A review of this decision, which pre-dated this case study by many years, will not be undertaken here. It is the opinion of the author that such a review will not serve to further the case study process or results.

However, the resultant environmental change of these lands (from old growth white pine forest first to viable agriculture and now to "greenfields" awaiting development) is indeed a local-scale reflection of many of the environmental issues which will continue to challenge global sustainability.

Similar peripheral expansions (often onto agricultural lands) is typical of many Canadian cities, and this trend is expected to continue, barring major legislative changes regarding land use (typically a slow and difficult process.) The opportunity of planning, constructing and monitoring a more sustainable neighbourhood on such a "typical" greenfield site was one of the major areas of interest to $\mathrm{CMHC}$. Lessons learned, it was felt, could potentially be transferred to other similar sites so as to extend the educational process and awareness of how to develop such lands in a more sustainable fashion.

Surrounding land uses consist of existing residential development to the north, comprising a mixture of two storey homes, north of Longfields Drive (Figure 4.1). This road is presently a two lane collector road in a thirty metre wide 
right of way, incorporating traffic calming measures, a recreation path and sidewalk which link the community to transit services, schools, parks and commercial services. Existing transit stops are located along Longfields, with major transit stations planned for the community $650 \mathrm{~m}$ north west of the case study site. As the area develops, transit services will be extended to other roads on the site perimeter.

The north east corner of the study area is occupied by Madden Court, a two storey residential development. Since the case study surrounds this existing development on two sides, due consideration must be given to the integration of vehicular and pedestrian movements, infrastructure extension, green space linkages and other such impacts of a new development on an existing neighbourhood. The remainder of the east and south perimeters is currently open, undeveloped land slated for future residential expansion.

To the west of the site, the new Mother Teresa Secondary School (Figure 4.1) generates daily pedestrian, vehicular and bus traffic for hundreds of students and staff. The school site incorporates active sports amenities and green space shared by the community.

Topography varies only $0.5-1 \mathrm{~m}$ across the site, providing for natural drainage towards the east and northwest. The site is poorly drained, and remnants of old agricultural drainage ditches are still present. Percolation tests were completed, and the results made available to the study team. Groundwater levels were roughly $1 \mathrm{~m}$ below the surface, within a silty-clay layer. 
Soils are fairly uniform across the site, the overburden consisting of topsoil ranging from 75 to $180 \mathrm{~mm}$ in depth underlain by sensitive silty clay, silty sand and sand till on the west of the property. Bedrock is found at roughly $3 \mathrm{~m}$ below the surface. (Detailed geotechnical reports were made available to the study team by the Engineering Department.) The agricultural capability classification of the soil is class 2 , wet, in recognition of the requirement for artificial drainage.

The master drainage scheme for Longfields has identified the need for stormwater management, and a pond is designated, incorporated within a neighbourhood park just east of Beatrice Drive(Figure 4.1).

Stormwater management ponds and related facilities will serve to control the quantity and quality of post-development runoff, to maintain stormwater flows at pre-development rates. Water borne sediments are settled out to help prevent downstream siltation, while, in the case of permanently wet ponds, water quality is improved through nutrient uptake by aquatic and riparian plants. As well, such facilities can reduce erosion downstream of new development. The City of Nepean Engineering Department directed that the case study site be graded to lead storm and melt water to a storage pond, which leads to and outlets into the City's major water quality treatment facility before entering the Rideau River via the Barrhaven Creek. In this case, the storage pond serves also as an active park space, and consequently will be sodded or seeded for turf cover.

The area was once used as pasture, and secondary growth vegetation cover today consists of scrub growth of willow, dogwood, alder, and small elm and ash. No locally or regionally significant vegetation was observed. 
The widest dimension of the case study site is oriented roughly in a northeast to south-west direction, offering road alignment, site plan and unit orientation opportunities for passive solar integration.

Since the entire area is relatively flat and open, both prevailing, cold, north-west winter winds and cooling summer breezes sweep unobstructed across the site.

The existing Utman Park, and the newly developing Core Park (Figure 4.1), are within walking distance of the case study site and provide active recreation amenities, in addition to the schoolyards in the vicinity. Other new schools for the area are in the planning process or under construction.

Existing municipal services (sanitary sewer, water, electrical, gas, telephone and cable) surround the site on Longfields, Claridge and Beatrice.

In terms of a development program for the site, preliminary discussions with City Departments confirmed a preference for a mix of built forms, densities and unit types, with affordability to be a key consideration. Further, some form of commercial development fronting on Longfields was suggested, as was a "modified grid" street pattern. This program responded to the "neo-traditional" Master Plan vision for Longfields, as previously described in this Chapter. 


\section{CHAPTER 5}

\section{DEVELOPMENT OF THE CONCEPT PLAN}

\section{Working Sessions}

In this section, the planning process is described in detail so as to demonstrate the current level of awareness regarding sustainable development in the City's Planning and Development Department, as well as to identify how concerns evolved in the process which might become barriers to the sustainable development initiatives being proposed in the concept plan.

The development of the case study concept plan relies on the critical input and comments from professionals with a variety of expertise on both the study team and municipal working committee.

As previously discussed, it is this interactive process which will ultimately evolve a realistic concept plan supported by the working committee. Through this process, considerable time and expense is saved in that the concept plan is not advanced too far before being thoroughly reviewed by municipal professionals and adjusted as necessary.

Initial Meetings

The initial working session in early March 1999, reviewed the background, history and current status of sustainable development in Canada, described earlier and as set out in project descriptions and literature. The study team provided a framework for sustainable community development practises, a further development of the concepts earlier expressed in Figures 3.1, Table 3.1 and 3.3. The case study objectives and study team's experience and capability 
FRAMEWORK FOR PRESENTATION OF SUSTAINABLE COMMUNITY DEVELOPMENT PRACTICES (PHYSICAL DIMENSION)
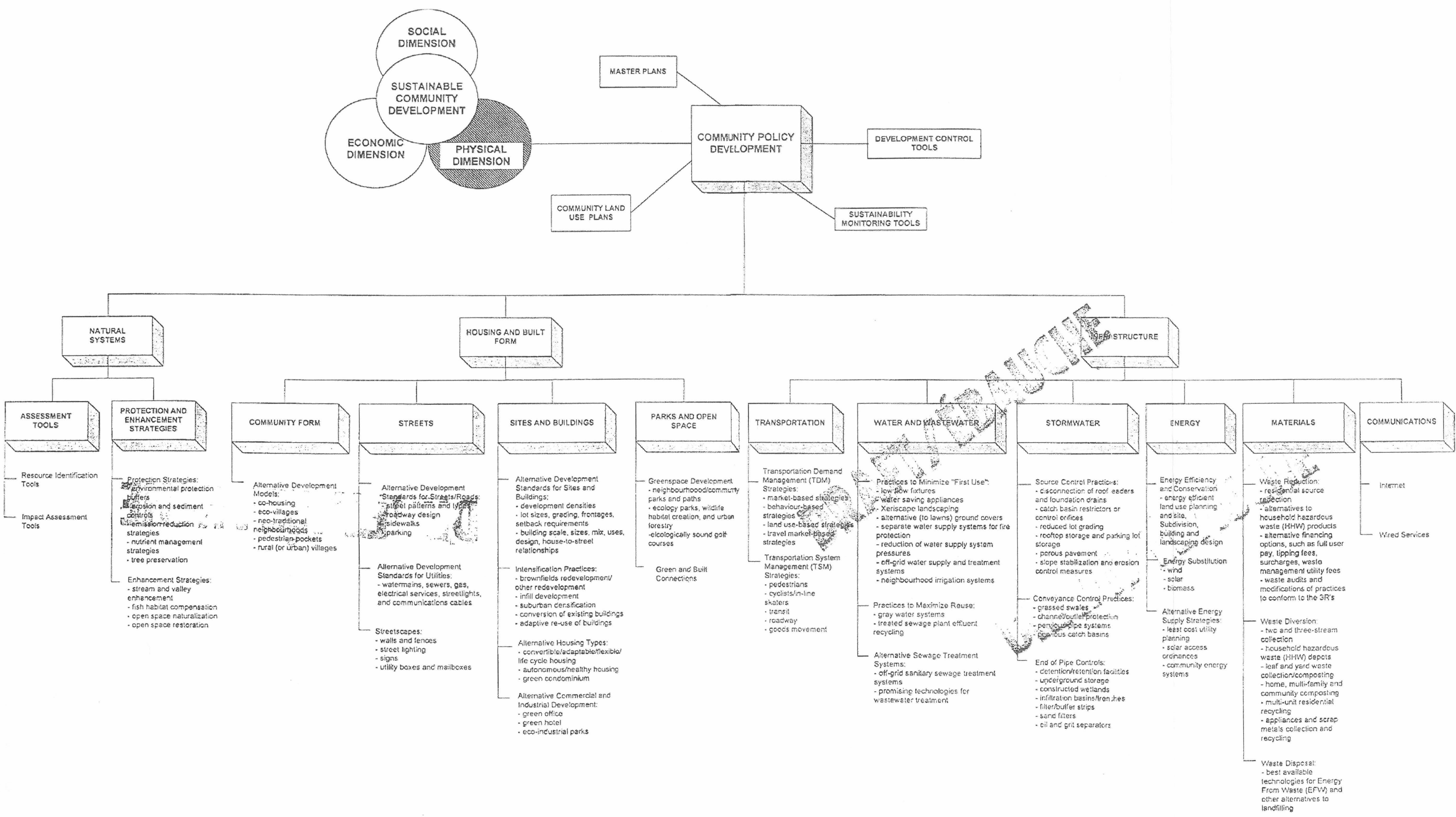
led to a focus on the physical dimension of sustainability. The framework, Figure 5.1 , illustrated the relationship between social, economic and physical aspects of sustainability, but for this initial working session, was used to illustrate an approach to the physical dimension.

Physical geography was integral to the assessment of the physical dimension of community sustainability, wherein climate and microclimate, drainage, site geology and soils, water table, stormwater management, water and air quality and other such issues as described in Figure 5.1 were to be investigated.

Some of the earliest comments revolved around concerns for street pattern and community form. The City's Public Works representatives expressed concerns for snowfall storage and handling in higher density forms of development, as well as a need for closer liaison with utility companies regarding the design of reduced dimensions and alternate standard street cross-sections. Engineers on the working committee offered for consideration alternate stormwater management concepts under review from the Niagara area.

An initial series of sustainable development initiatives was suggested at this session. These initiatives were drawn from the combined experience of the study team as concepts deemed practical enough so as to be considered for implementation. As well, study team discussions regarding the physical dimension of sustainable community planning (Figure 5.1) resulted in this first suggestion of several proposed sustainability measures. The initial list included: 
1. A variety of mixed-use forms and unit types to provide for a wide range of buyer income and to demonstrate social mix and improved streetscape;

2. Alternate stormwater management using a linear swale system as opposed to the standard stormwater management pond;

3. Alternate (reduced) standard road dimensions, setbacks and lot sizes;

4. Design to maximize passive solar opportunities;

5. Other microclimate (energy substitution) potentials like windbreaks, cooling and shading;

6. Landscape diversity and reduced maintenance practices;

7. Community involvement and stewardship of common open spaces;

8. Universal site accessibility;

9. Reduction of vehicular trips by providing alternate travel opportunities: pedestrian and bicycle linkages and transit use.

Social housing mix and built forms were the focus of the next working session, during which the City expressed a preference for more dense forms of development within the typical low rise suburban environment. Built or planned examples from the Ottawa-Carleton region were analyzed, and lowrise forms yielding up to 22-25 units per acre were investigated. Many of the concepts discussed implicated a more flexible approach to zoning. Preferred land use direction and more specific architectural design guidance was provided by the municipal working committee. For example, a preference for more seniors' housing, special needs residential units, limited care projects, and affordable 
voiced over the private housing court concept, within which internal roads and services are privately funded and maintained. This concept was specifically developed to demonstrate possibilities for infill development on difficult or oddly shaped residual land parcels, and to test alternative, flexible zoning approaches. It was felt that purchasers must be made aware of the long-term road and infrastructure repair and replacement costs of such schemes.

Progression of the Work

Over the next two months, each professional discipline on the study team continued with the research and feasibility testing of a variety of sustainability initiatives. Discussions with the City helped focus on concepts most likely to gain departmental support, thereby removing barriers. The evolving list of concepts offered specific built form ideas leading to an improved social mix and contributing to affordability, while new site engineering and infrastructure concepts were presented and reviewed.

A preliminary concept plan for the neighbourhood illustrated typical applications of the sustainable development initiatives together with land uses, pedestrian and vehicular circulation patterns, open space and landscape development approaches.

Reactions to the material reviewed at this stage included a recurring concern for the number of initiatives being proposed, and whether the approval agencies and development community would perceive the study as overly 
"experimental" resulting in a protracted review and approval process, and ultimately seen as too high risk in the market place.

Ensuing discussions also revealed a concern that sustainable development initiatives being proposed might have a negative impact on the timing and marketability of the City's lands. The study team was reminded that the City's underlying objective was the sale of the case study area lands. The study team took from this that, at this time, the advancement of community sustainability came second to revenue generation. In other words, financial return was, and is still, highest priority at the local level.

The preliminary site plan concept review elicited further comments regarding improvements to the modified grid street pattern to ensure more "diffused" traffic and pedestrian access. The linear stormwater management swale was seen as providing an orientation opportunity within the neighbourhood, and as many streets as possible should contact this "greenway". A community centre would provide a neighbourhood focal point, as well as local disaster relief support if properly equipped. Front yard setbacks might be reduced or waived entirely to encourage development of units fronting onto collector roads (e.g., Longfields), so as to improve streetscape and remove sound attenuation wall requirements. (These are regional and provincial regulations which set down acceptable noise levels in rear yard outdoor use amenity areas.) Street patterns and rear lanes should be laid out to allow for continuous, unobstructed routes for snow removal and garbage collection. The requirement for service and emergency vehicles to back up, turn or negotiate any additional 
movements, which might entail additional work for or endanger unionized employees, has long been and continues to be a controlling factor in community street plan layouts.

Site engineering reviews expressed a concern for the minimal (less than $1 \%)$ existing site gradient, and relatively impermeable soil conditions. These realities will have a direct effect on several sustainable development initiatives and practices being proposed. Currently the Works Department policy is to ensure positive drainage away from development areas.

Various water and wastewater management techniques were reviewed, including technologies for wastewater recycling and reuse, water conservation and rainwater cistern systems. After analysis, it was concluded by the study team that most of the current technologies require installation as part of a very large community area to result in any noticeable benefits. As well, many are very climate sensitive, and unless in the ground or inside a building would be impractical to implement in the Ottawa area.

Currently, standarized regulatory requirements for water re-use technology in Canada do not exist (CMHC, 98-101). Systems (such as grey water re-use for irrigation) require plumbing modifications to separate sink and shower water from toilet water. Also, in some areas, additional treatment may be required, since Ministry of Environment regulations currently prevent discharge of grey water, which will eventually be picked up by storm sewer system and discharged (in many municipalities), directly to natural water courses. These systems function in the summer, but would need to be reconnected to the 
conventional sanitary sewer in winter months. Other systems such as the use of untreated water for fire fighting requires another separate (from potable) water distribution system; the benefit of this is realized mainly at the water purification plant. The additional costs of a dual system are obvious. This case study is too small to capitalize on any of the benefits from this type of system. After this assessment, it was decided that neighbourhood water and wastewater technologies for this specific site would not be further considered. However, inhouse systems or cistern systems could be included by builder developers within certain built forms, or in the central community building, if so desired.

The linear greenway and bioswale concept must be designed to handle a 50 year storm event. Currently, many stormwater ponds provide double use as active park spaces, which led to a discussion regarding active and passive recreation demand. Parks and Recreation personnel evaluate community need and supply, and depending on demographics and growth projections might recommend passive forms of open space over active parks especially if alternate choices for active recreation exist in the vicinity. Finally, Works personnel confirmed that snowfalls could be removed once per season from denser environments, but would be stored in place where streetscape space allowed. Dead-ended (culs-de-sac) roads are to be discouraged due to their inefficiency and negative impact on pedestrian and transit connectivity

\section{Revised and Refined Concept}

A further revised concept was presented in late June 1999. 
Site engineering comments directed that lower gradients to slow runoff rates from yards and gardens could be allowed at the normal $2 \%$ away from structures, but reduced to $1 \%$ in swales leading to site stormwater inlets. This initiative decreases the rates of flow to stormwater storage areas, and allows for more absorption back into the soil instead of runoff. It was underscored that the silty-clay soils do not easily release water, and that serious structural damage can occur if yards and foundations are not properly drained.

A shallow system was deemed best for the exfiltration trench initiative, since deep trenches would flood out in the clay soils. However, there is no desire to substantially lower the ground water table which would result in consolidation of the lower clay soil levels, where further foundation damage could result. It was noted, however, that subject to soil conditions, the exfiltration system, if successful, might reduce downstream stormwater pond and treatment requirements and pipe sizing, thereby helping to balance out the added cost of exfiltration system construction. The City also speculated as to whether such a system might reduce provincial design and regulatory requirements for stormwater management if ultimately applied on a larger scale, but no further investigation of this possibility was undertaken at this time.

The study team was further instructed by the City Engineering Department to verify the low point along Beatrice Drive so as to co-ordinate the drainage scheme and link the linear greenway/bioswale to the stormwater management pond located east of Beatrice. In this way the linear system proposed works in concert with the pond, and, by collecting stormwater from Beatrice Avenue might 
allow for the shifting of the stormwater management pond further eastward. This new location is more central to the land area served, reducing costs of stormwater infrastructure and allowing for improvements to the overall master land plan.

Concluding comments from the working committee confirmed that streets were to be dimensioned at a minimum right-of-way width of $17.5 \mathrm{~m}$ with a sidewalk on one side, to conform to the new city standard. Rear lane dimensions would result from a more detailed site plan filed with a development application. Pedestrians were to have higher priority throughout newly developing communities, under the "new urbanism" mandate.

Several comments were made in regards to architecture and built forms proposed at this stage, such as a preference for "offset" garages. These designs shift garages to the side of the house, thereby opening up the main entrance visually to the street, as well as providing more window surface for passive solar gain. This is accomplished by introducing a wider, shallower lot shape. Questions regarding economies of scale for various density forms were explored. A desire to have an area of the site appropriate for lower cost housing was expressed. A commercial site was identified on the north-west corner of the study area, in response to requests from Planning Department representatives on the working committee. They also wished to include in the study area a commercial location away from a main arterial road (the customary location), so as to test the success of smaller scale, pedestrian accessible neighbourhood commercial services. 
A note of caution from both Planning and Works Departments was expressed, in that it was felt that many of the "community stewardship" initiatives being proposed might be of interest to only approximately $25 \%$ of the general public. This was drawn from a history of resident involvement in City sponsored stewardship programs, and phone calls and other communication with the councillors' and mayor's office. It was felt that this was a direct reflection of residents' current attitude toward environmental improvement when it involves any impact on personal life style such as physical work, time consuming community activism or personal cost.

Methodology Modification

An important change in direction for the study methodology occurred at this point in the study.

Although the study team felt that the list of sustainability initiatives being considered was minimal, the municipal working committee reacted negatively, expressing a concern that there were possibly too many concepts being proposed for inclusion in one development project. Their preference was for only a few clear, comprehensible new ideas. They felt that the chances of implementation would be greatly improved if approval agencies and the private sector were convinced of the cost-benefit of any initiatives. Once constructed and deemed successful in the marketplace, it was felt that their lead would be followed by others in the development industry. This was seen as key to the advancement of sustainability in new development at the local level, which is 
largely a product of the private sector. The study team was directed to focus the initiatives which would, with little or minor difficulty, be acceptable to the approval agencies, the development community and ultimately, the homeowner. Concerns were expressed over the possible cost of any new initiatives compared to conventional development approaches.

At this point, it was unclear to the study team as to whether a certain level of resistance to sustainable development had been identified (i.e., the direction from the working committee to reduce the number and variety of initiatives being proposed, and cost concerns), or whether there was a perception that the review and approval process for this case study neighbourhood was about to become more complicated than for a conventional subdivision.

In order to get past this potential barrier, the study team reduced "new" sustainable development initiatives to two or three site development ideas, and fewer built forms and architectural concepts.

However, many of the initiatives being proposed were actually very familiar to approval agencies and the development community as "best management practices", well established "better ways" of doing things that have, over the last few decades, been assimilated into good community design (e.g., solar orientation). These best management practices are all contributors to healthier communities and sustainable development and so, rather than eliminate them from the list, graphics and presentation materials were reorganized to clearly separate "new concepts" being introduced by this case study, and "best management practices" to be incorporated. The study team felt that future 
presentations to politicians, the public and the development community would benefit from a more complete picture of the full spectrum of initiatives being incorporated.

Circulation of Preliminary Report on Working Sessions

The preceding (approximately 7 months) working period and the resulting concept plan for a more sustainable neighbourhood were summarized in a report for circulation to, and comment by, all City Departments represented on the working committee. At this stage, minimal comments were fed back to the study team, reflecting the fact that most relevant comments had already been made and accommodated during the working sessions and incorporated into the summary report and concept plan.

However, the author was surprised at this stage by the rather sudden interest in the topic of sustainable communities, expressed by the City's Environment Committee, composed of citizens and politicians. A full presentation of the case study was made to the environment committee on their invitation, followed some weeks later by a similar presentation in a region-wide public forum, round table discussions and workshops. Public reaction to the case study was gathered during a public "open house" held at Nepean City Hall, October 30, 1999.

\section{Concept Plan and Sustainable Development Initiatives}

Resulting from the study team's work and critical review comments by the municipal working committee as described to this point, the concept plan as 
illustrated in Figure 5.2 was prepared. This graphically descriptive plan, together with its details, legend and notes, proposes a community form incorporating various sustainability strategies.

A graphic or large poster format $(1 \mathrm{~m} \times 1.2 \mathrm{~m})$ was specifically chosen for the concept plan since, from experience, the private sector development community has little initial patience for "in-depth" descriptions of development opportunities. Rather, one has around two to three minutes to make an impression and capture the interest and imagination of the typical developer/investor, and a well organized graphic format is one way to do this quite successfully. However, a written report was prepared and provided a detailed descriptive text of the case study.

The illustration of the concept plan in Figure 5.2 is now further described. An extension of Kilbarron Road from Madden Court to the west acts as the major east west access, while a larger principal entry road connects Claridge Drive to Kilbarron, offering vistas over a central community park. The northwest corner of the site consists of a mix of residential, commercial and retail land uses. South of Kilbarron, a variety of built forms and lot arrangements are set out on a modified grid, providing opportunities for traffic dispersal to collector roads on the perimeter. The existing Madden Court development to the north east has both road systems, pedestrian patterns and green spaces integrated into this concept plan. 


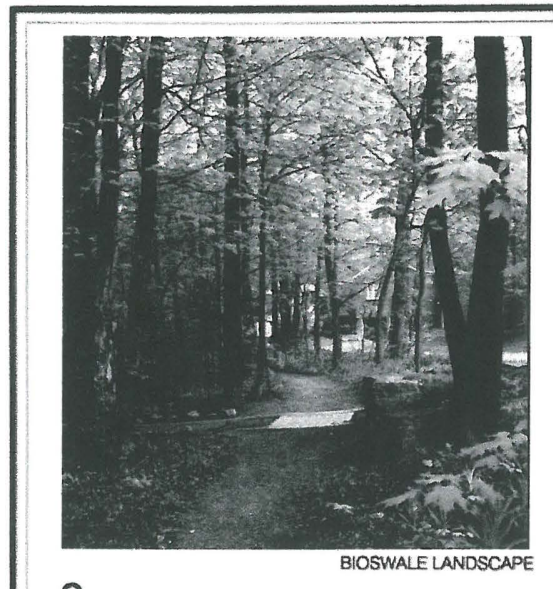

9

PLAN VIEW OF BIOSWAE / SWM IN UNEAR GREENWAY

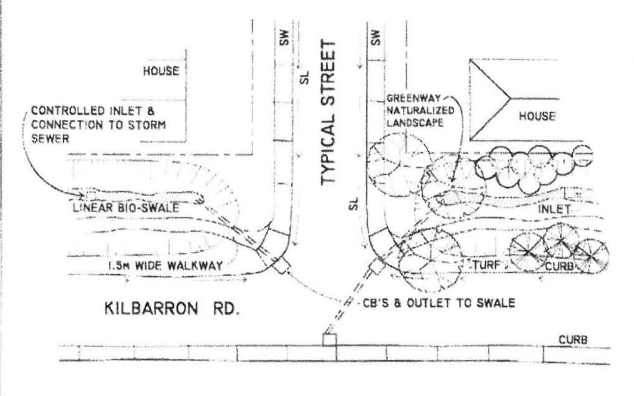

SECTION THROUGH BIOSWAE / SWW LNEAR GREEWUY

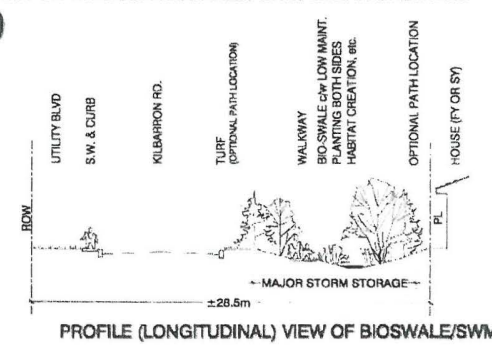

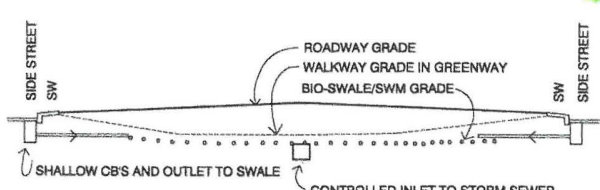

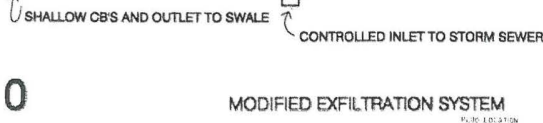

10

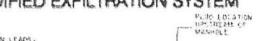

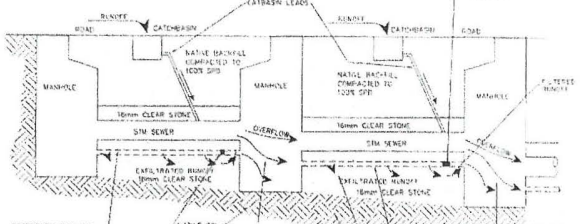

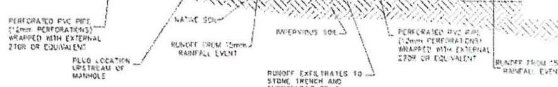

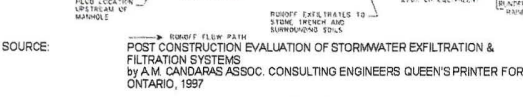

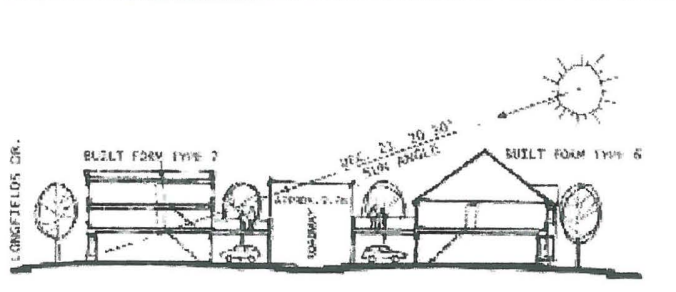

17
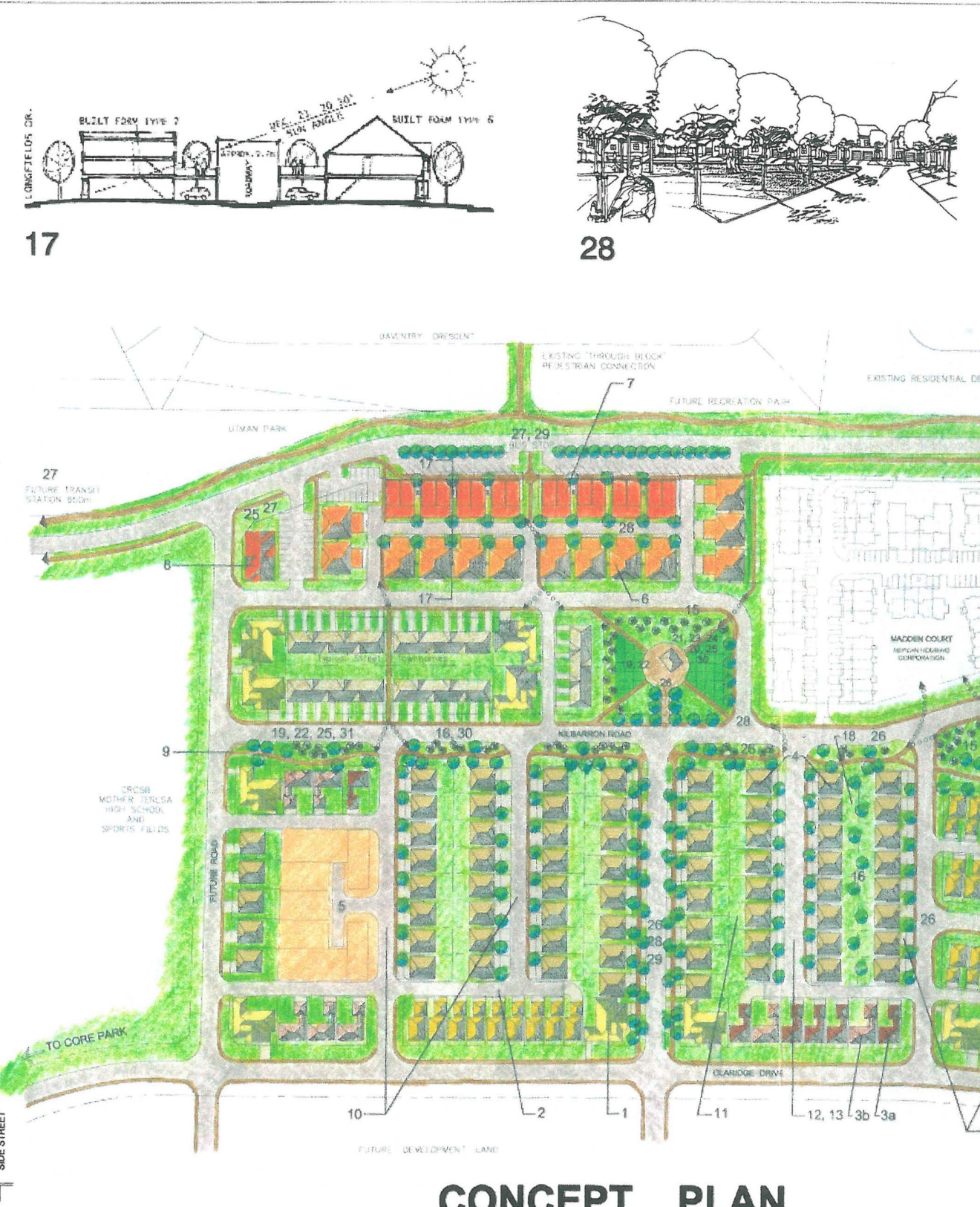

10

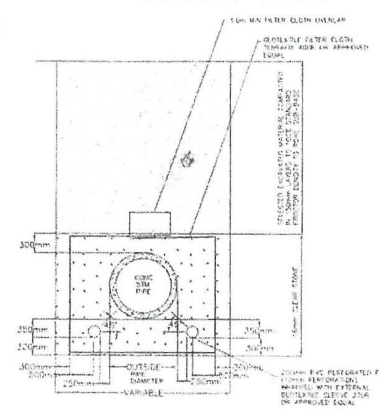

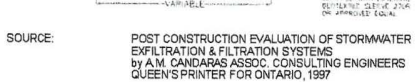

\section{CONCEPT PLAN}

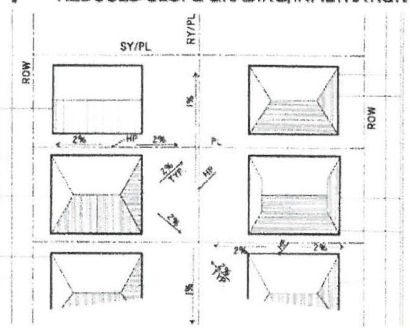

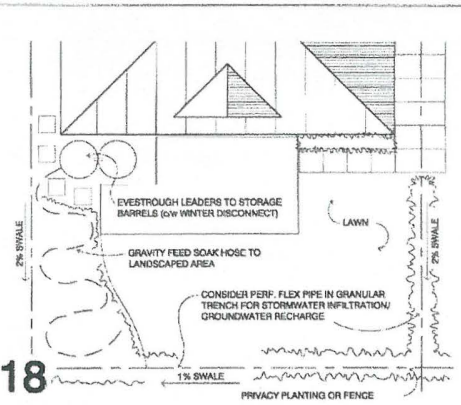

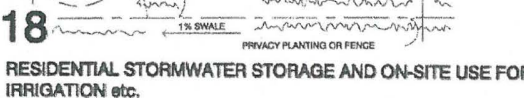
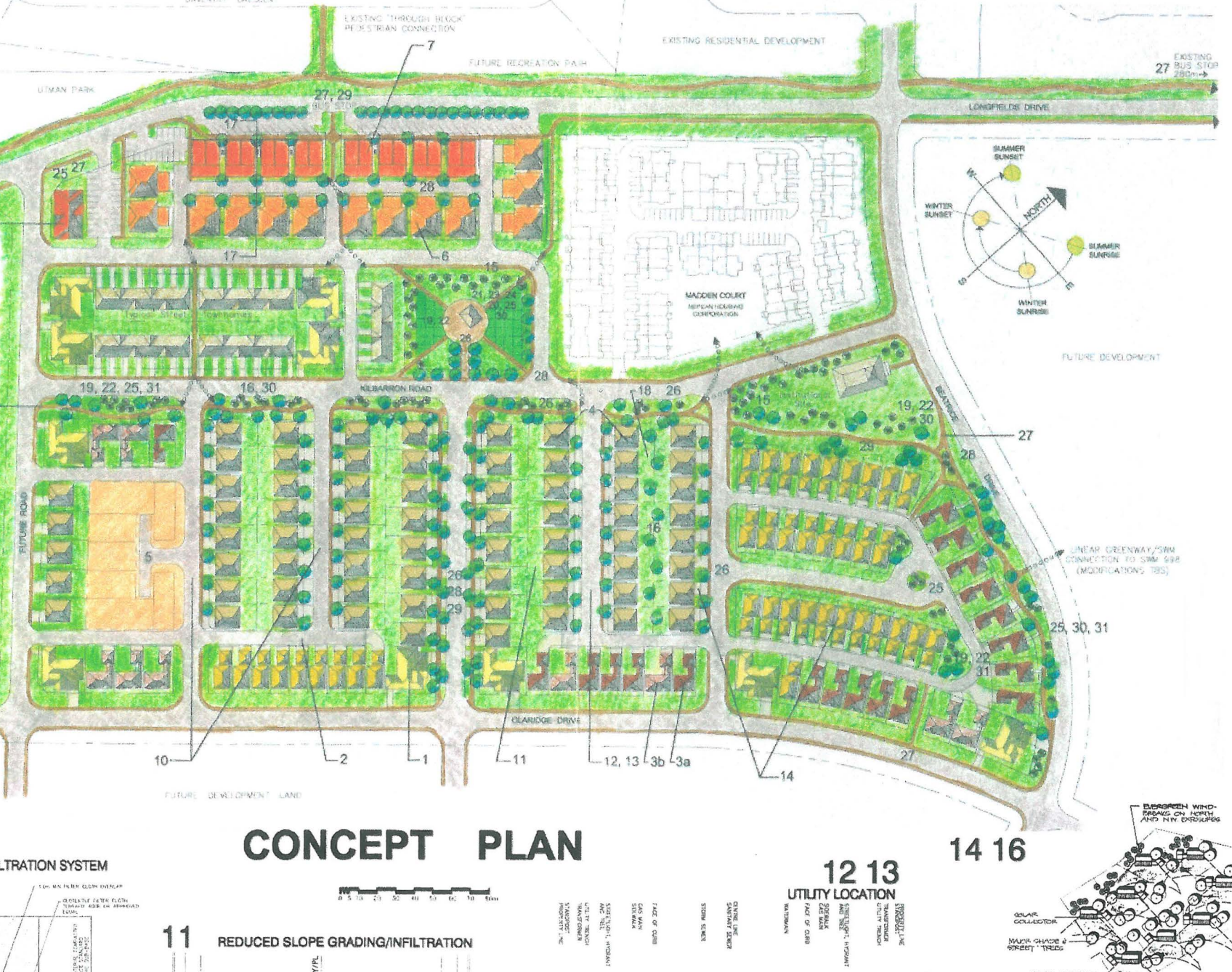

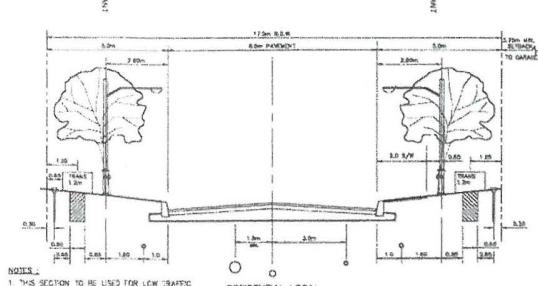

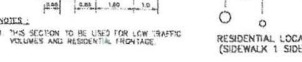

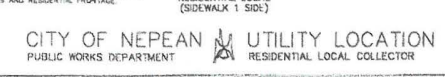

SUSTAINABLE DEVELOPMENT LEGEND BUILT FORMS / UNIT TYPES

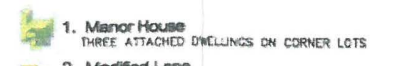

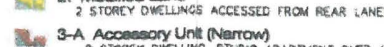

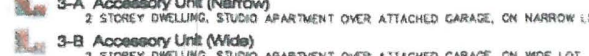

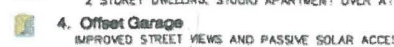

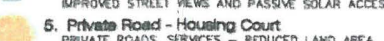

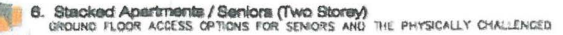

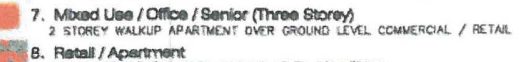

NEW SUSTAINABLE DEVELOPMENT INTTATIVES:

AND BEST MANT

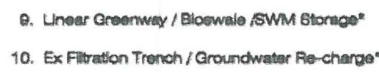

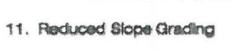

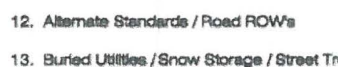

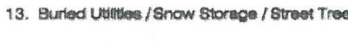

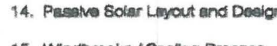

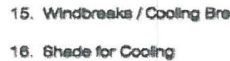

16. Ehasab tor Cooling

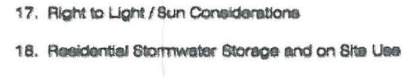

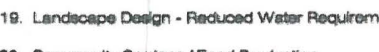

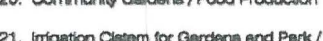

und

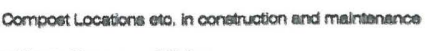

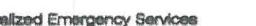

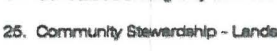

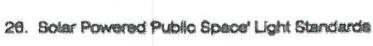

27. Aos

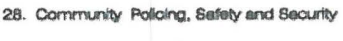

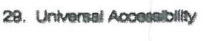

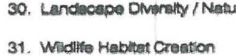

r. Mamoriam

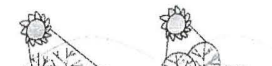

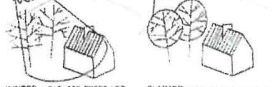

1416

$x^{2}=3$ \% 0.09 $\Rightarrow 00$

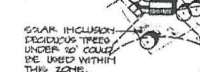

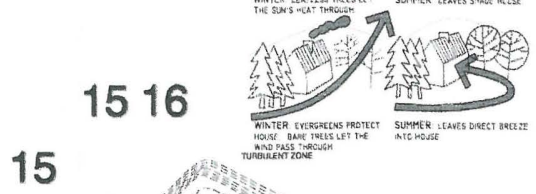

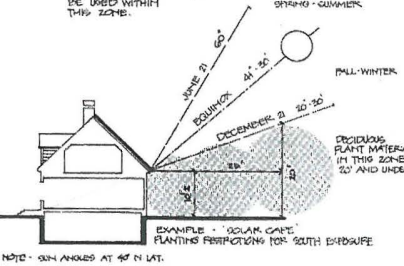

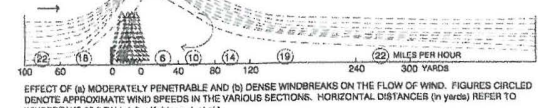
City of Nopean
LONGFIELDS OEMONSTRATION PROJECT

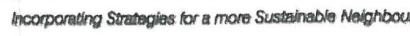

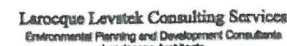


With reference to Figure 5.2, architectural and built form concepts are described as Numbers 1-8 and located using these numbers on the concept plan.

These unit types (further illustrated in Figures 5.3 to 5.11 ) are designed to address economic, social and environmental concerns. Architectural forms demonstrate universal accessibility, equitable integration opportunities for various age and income groups, community security, solar access and improved, more interesting streetscapes. The concept plan demonstrates efficiency of land use, variety of housing types and social mix. Various unit designs provide for family adaptability over time, infill densification and affordability. Commercial and retail integration with residential and home office opportunities, for example, reduce vehicular trip demands.

An overall density of approximately 10 units per acre or 25 units per hectare is achieved by the concept plan as illustrated in Figure 5.2

In addition to the architectural built form strategies, the major innovative sustainable development feature incorporated into the site's engineering design and landscape development is the linear greenway/bioswale parallel to Kilbarron, which offers an alternative approach (to the standard stormwater management pond) for stormwater storage and treatment while providing an inviting pedestrian linkage and passive recreation environment.

An infiltration/exfiltration trench system, which would be constructed as part of the standard storm sewer system is the other major initiative. These, together with a series of recommendations for healthier community design 
leading to a more sustainable neighbourhood, are summarized below and located on the concept plan, Figure 5.2.

All of the sustainable development initiatives (1-31 as listed on Figure 5.2) are described as having the potential of being further designed and constructed within the neighbourhood, and would be at the discretion of the City (as landowner) or choice of the private sector developer(s) constructing and marketing the community. However, (with certain reservations as outlined in Chapter 6) most are deemed as being realistic and acceptable for integration into the site planning and design process for a more sustainable neighbourhood in the Ottawa-Carleton Region. Again referring to the concept plan, Figure 5.2, "new" sustainable development initiatives specifically conceived for this case study are described in numbers 9 and 10 below. A series of other planning and design ideas generally referred to as "best management practices" follow in numbers 11-31. 


\section{URBAN DESIGN / ARCHITECTURAL STRATEGIES}

DENSITY INTENSIFICATION FOR LOW DENSITY NEIGHBOURHOODS

1. Manor House (25.4m - 3 Units - $600 \mathrm{~m}^{2}$ lot)

THREE ATTACHED

DWELLING UNITS ARE

CLUSTERED IN A MANOR

HOUSE' CONFIGURATION

ON A CORENER LOT. ONE

2-CAR GARAGE FACES

EACH STREET AND 15

SITUATED ADJACENT TO

THE DWELLING IT

SERVES. ENTRANCES TO

THE DWELIINGS ARE

SPACED APART FOR

MAXIMUM PRIVACY.

THIS APPFOACH ALLOWS

FOR MODERATE

INTENSIFICATION \&

ACCOMMODATION

OPTIONS IN A

PREDOMINANTLY SINGLE

FAMILY NEIGHBOURHOOD.

THE GARAGES,

ALTHOUGH VISIBLE FROM

THE STREET, ARE

CONTAINED BEHIND THE

FACADES OF THE HOUSE

IN ORDER TO REDUCE

THEIR PROMINENCE.
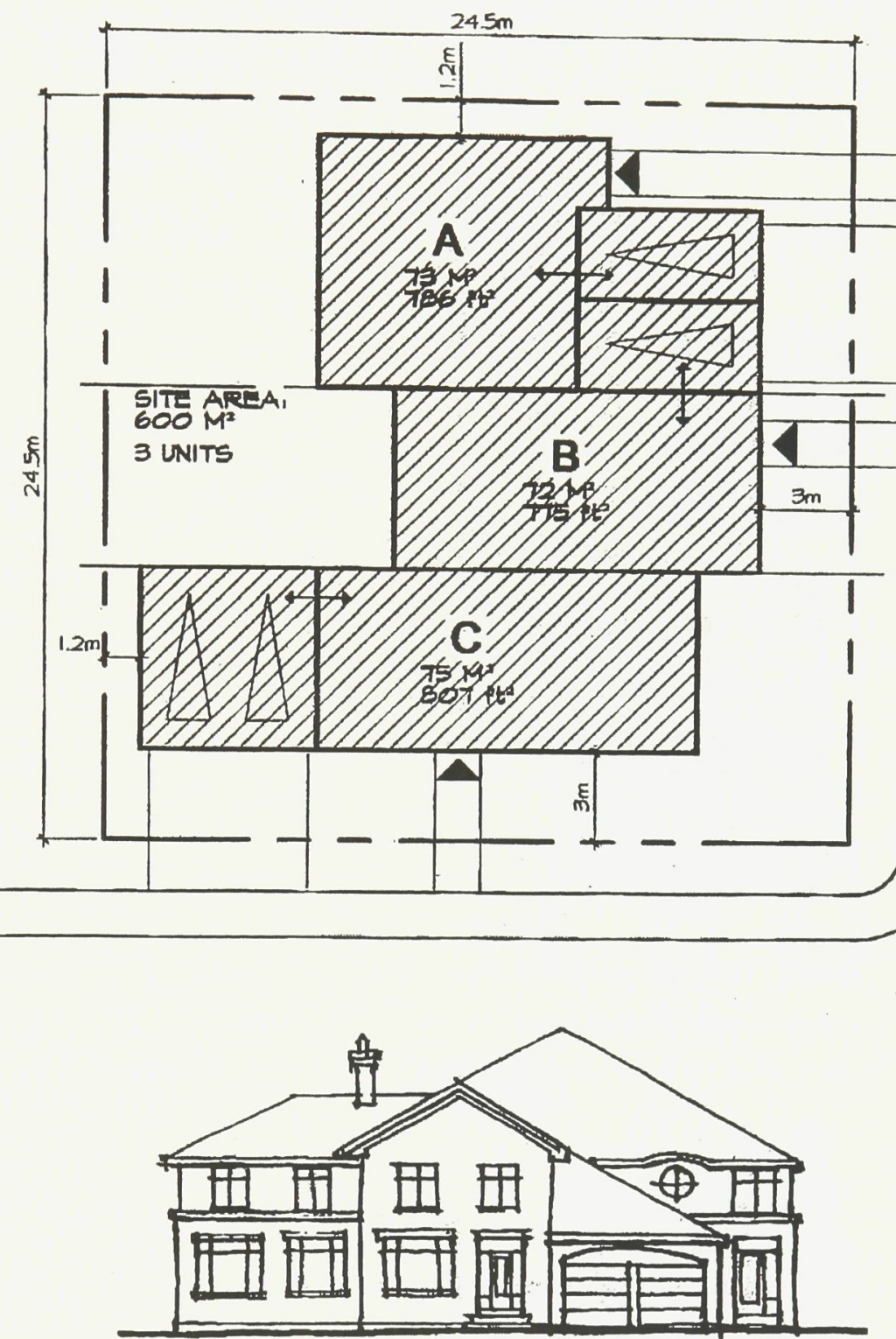

FRONT ELEVATION

BARRYJ HOBIN EASSOCATES ARCHITECTS 


\section{URBAN DESIGN / ARCHITECTURAL STRATEGIES}

DENSITY INTENSIFICATION FOR LOW DENSITY NEIGHBOURHOODS
2. Rear Lane Unit (IOm - $254 \mathrm{~m}^{2}$ lot)

A 2-STOREY DETACHED DWELLING IS SITUATED ON A NARROW LOT WITH A DETACHED 2-CAR GARAGE. THE GARAGE IS ACCESSED FROM A REAR LANE.

THIS STRATEGY ALLOWS FOR A STRONGER VISUAL RELATIONSHIP TO THE STREET. THE CHARACTER OF THE HOUSE CAN BE

PREDOMINANT WHILE REDUCING THE IMPACT OF THE CAR. IT ALLOWS FOR A STRONG HOUSE ELEVATION ON A SMALL LOT.
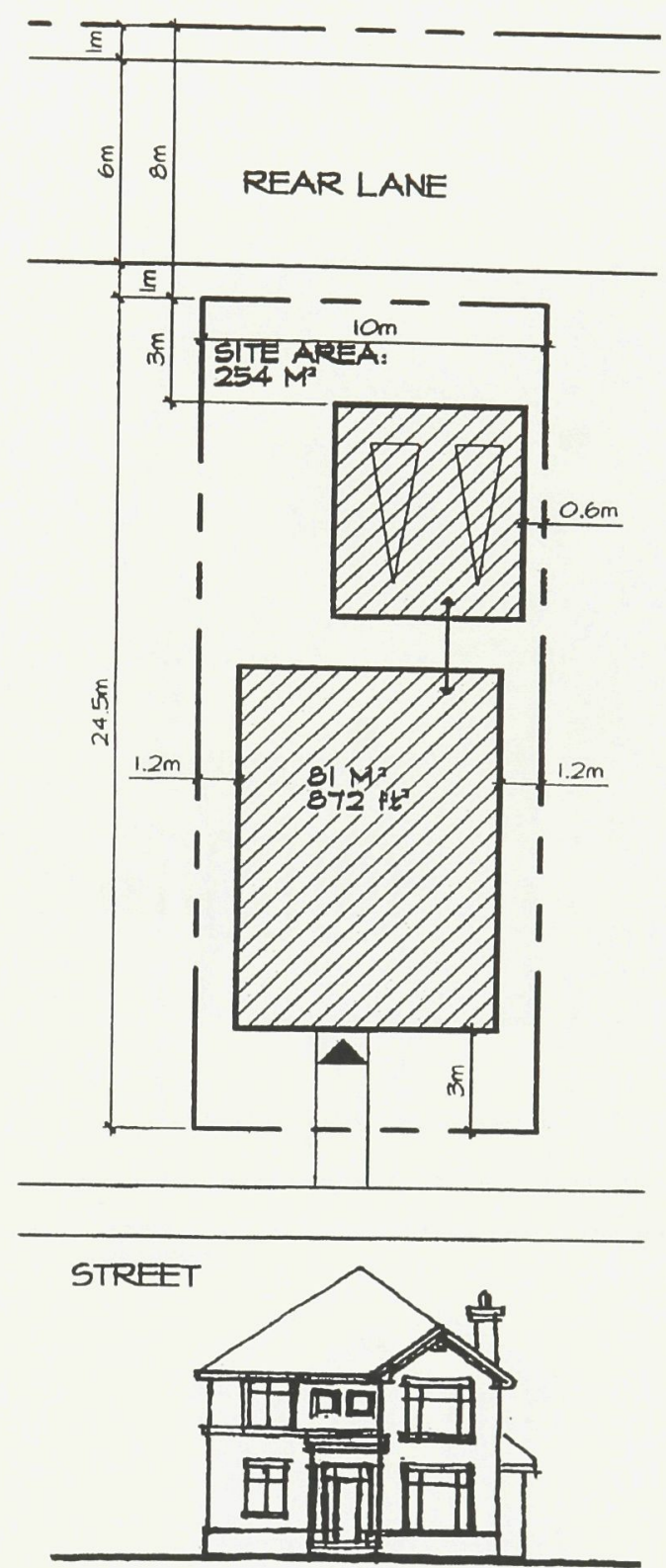

FRONT ELEVATION

BARRYJ HOBIN EASSOCAATES AROHITECTS

\section{Longfields Demonstration Project}

City of Nepean

Figure 5.4 


\section{URBAN DESIGN / ARCHITECTURAL STRATEGIES}

DENSITY INTENSIFICATION FOR LOW DENSITY NEIGHBOURHOODS

3 -A. Rear Lane Unit (12m-294m² lot)

A 2-STOREY DWELLING WITH ATTACHED 2-CAR GARAGE IS APPROACHED FROM A REAR LANE. A SECOND FLOOR STUDIO APARTMENT IS LOCATED ABOVE THE GARAGE AND HAS

PRIVATE ACCESS.

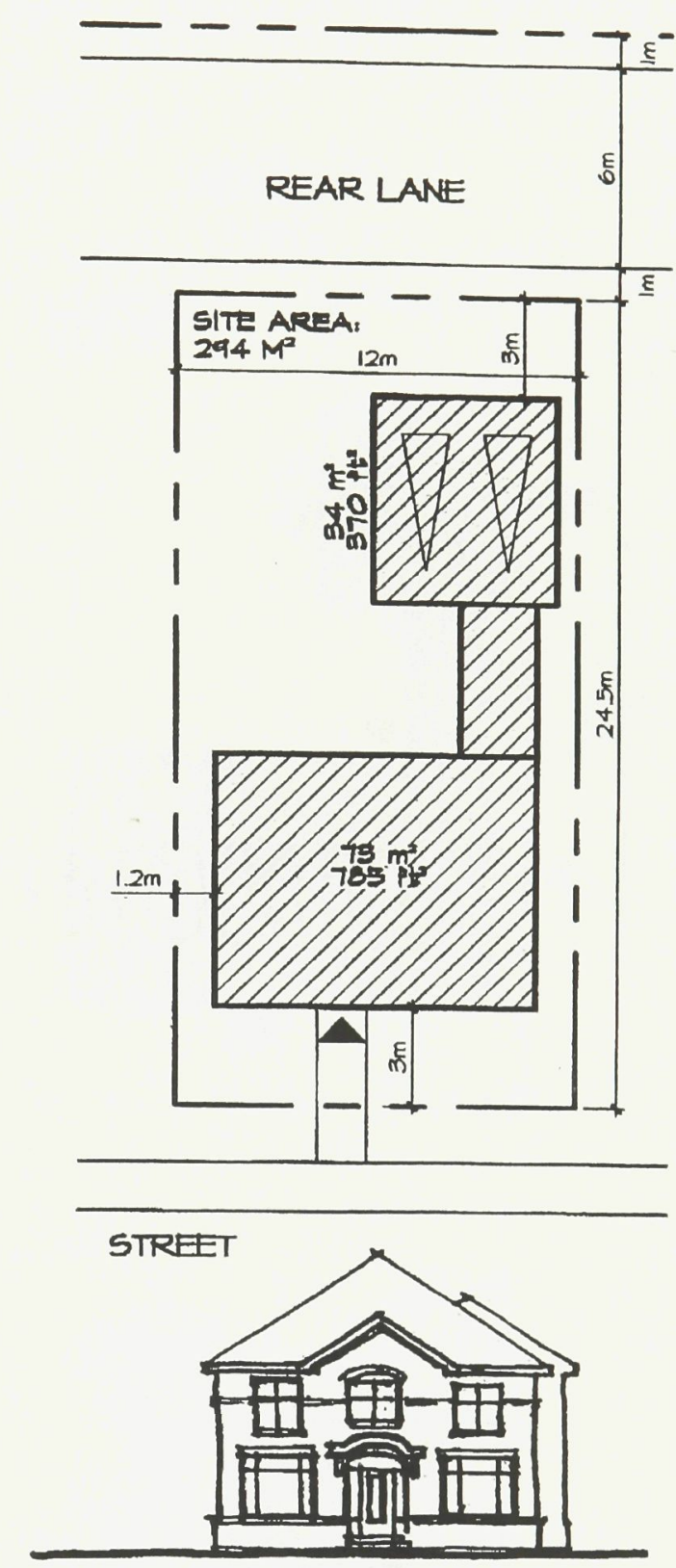

THIS APPROACH PROVIDES A VARIETY OF ACCOMMODATION OPTIONS FOR SINGLES. EXTENDED FAMILY. OR SENIORS WHILE MAINTAINING A SINGLE FAMILY HOME CHARACTER.

THE VEHICLE ACCESS LANE AT THE REAR OF THE PROPERTY PERMITS A FORMAL STREET FACADE WITH CONTINUOUS LANDSCAPING WHICH IS NOT OBSTRUC TED BY LANEWAYS AND PARKING GARAGES.

FRONT ELEVATION 
URBAN DESIGN / ARCHITECTURAL STRATEGIES

DENSITY INTENSIFICATION FOR LOW DENSITY NEIGHBOURHOODS

$3-B$. Rear Lane Unit (15m - 368m² lot)

A 2-STOREY DWELLING WITH ATTACHED 2-CAR GARAGE IS APPROACHED FROM A REAR LANE. A SECOND FLOOR STUDIO APARTMENT IS

LOCATED ABOVE THE GARAGE WITH PRIVATE ACCESS.

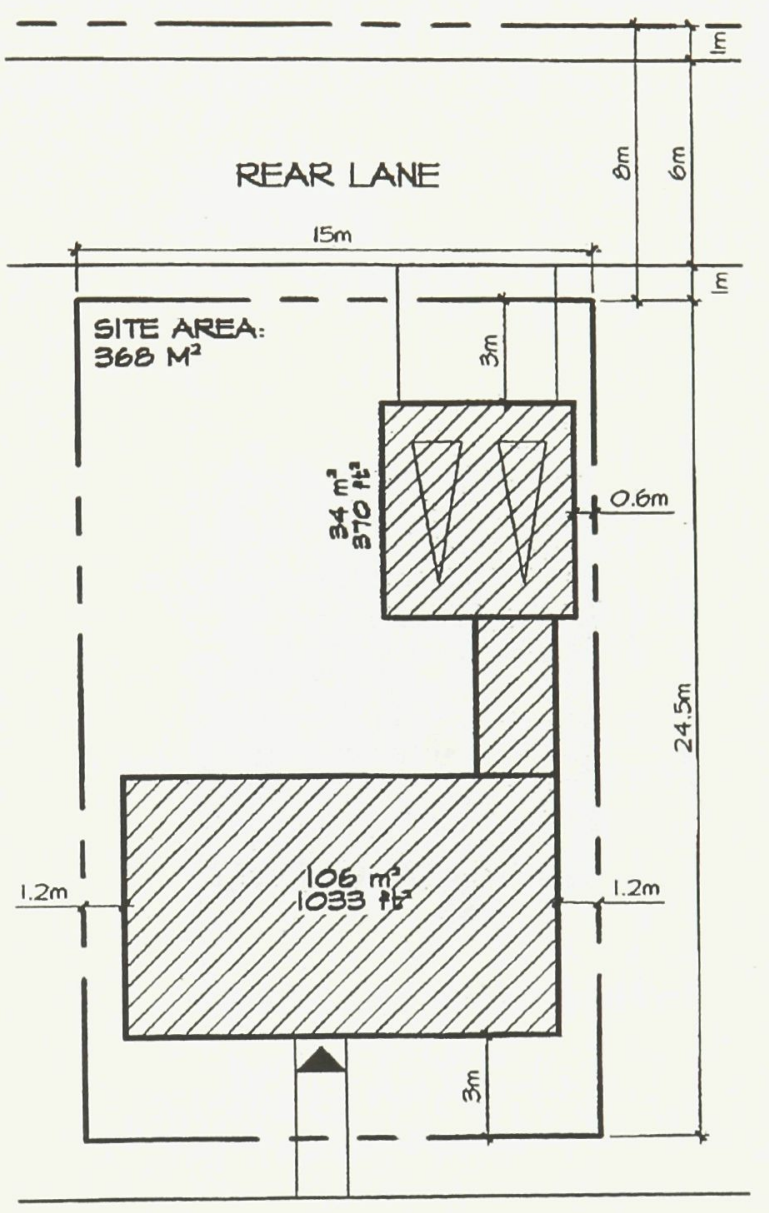

THIS APPROACH PROVIDES A VARIETY OF ACCOMMODATION OPTIONS FOR SINGLES, EXTENDED FAMILY, OR SENIORS WHILE MAINTAINING A SINGLE FAMILY HOME CHARACTER.

VEHICLE ACCESS FROM THE LANE AT THE REAR OF THE PROPERTY PERMITS A FORMAL STREET FACADE WITH CONTINUOUS LANDSCAPING WHICH IS NOT OBSTRUCTED BY LANEWAYS AND PARKING GARAGES.

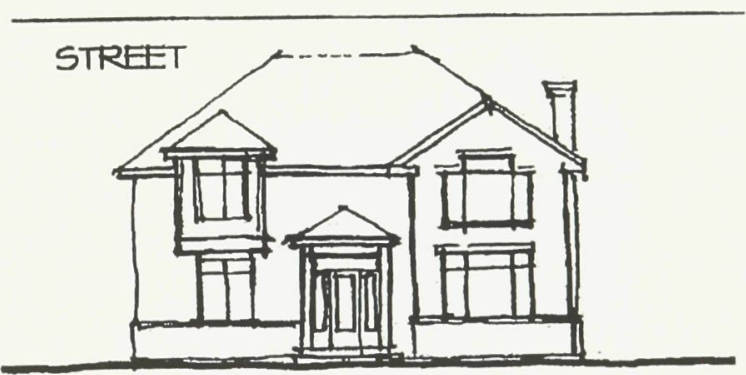

FRONT ELEVATION

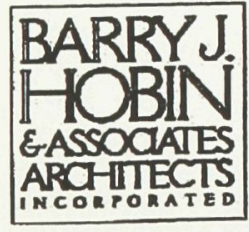

\section{Longfields Demonstration Project}

City of Nepean

Figure 5.6 


\section{UREAN DESIGN / ARGHITECTURAL STRATEGIES}

DENSITY INTENSIFICATION FOR LOW DENSITY NEIGHBOURHOODS

4 Offset Garage (Typ. $15 \mathrm{~m}-381 \mathrm{~m}^{2}$ lot)

A 2-STOREY DETACHED DWELLING WITH 2-CAR GARAGE FACES THE STREET. OFFSETTING THE GARAGE PERMITS A WIDER FRONT ELEVATION ALLOWING LARGER WINDOWS WITH VIEWS TO THE STREET.

THE IMPACT OF THE GARAGE IS LESSENED BY CONTAINING IT BEHIND THE PRINCIPAL FACADE OF THE HOUSE, AND IMPROVED SOLAR ACCESS
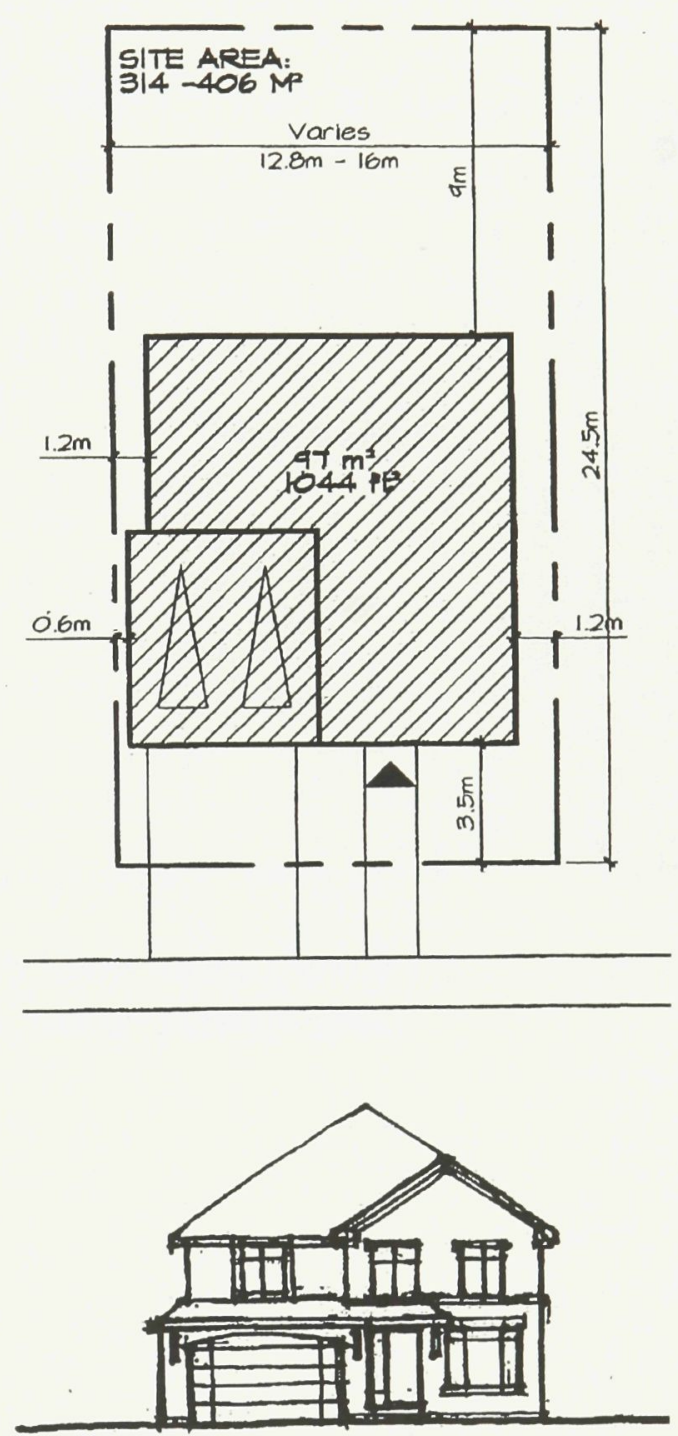

FRONT ELEVATION

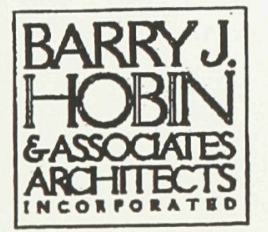

\section{Longfields Demonstration Project}

City of Nepean

Figure 5.7 
DENSITY INTENSIFICATION FOR LOW DENSITY NEIGHBOURHOODS

5 Housing Court - Private Rd.

THE PRIVATE ROAD APPROACH

FACILITATES A MORE EFFECTIVE USE

OF LAND AREA BY FURTHER REDUCING

THE LAND CONSUMED BY A FUBLIC

ROAD. THIS APPROACH IS MOST

APPROPRIATE FOR LAND WITH UNUSUAL

AMENITIES OR A DIFFICULT

CONFIGURATION.

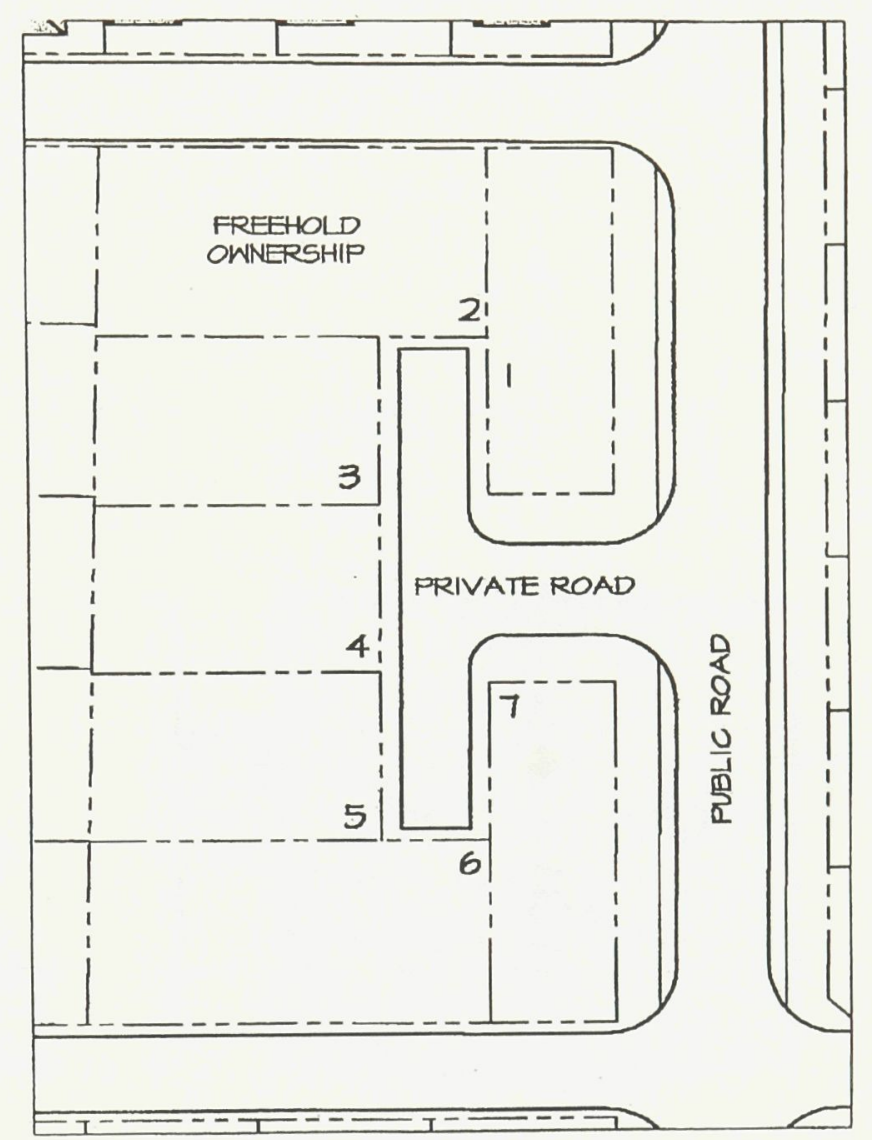

PRIVATE HOUSING COURT 
DENSITY INTENSIFICATION FOR MEDIUM DENSITY NEIGHBOURHOODS 6 Stacked Apartments: Seniors / Accessible

TWO SECOND STORY WALKUUP APARTMENTS WITH GROUND FLOOR ACCESS ARE LOCATED ABOVE GROUND-LEVEL APARTMENTS. PARKING IS CONTAINED IN CAR PORTS WHOSE ROOF DECKS PROVIDE OUTDOOR LIVING SPACE FOR THE UPPER DWELLINGS.

THIS HOUSE TYPE PROVIDES OPTIONS FOR

SENIORS AND THE PHYSICALLY CHALLENGED ON THE LOWER FLOORS AND FAMILIES ABOVE.
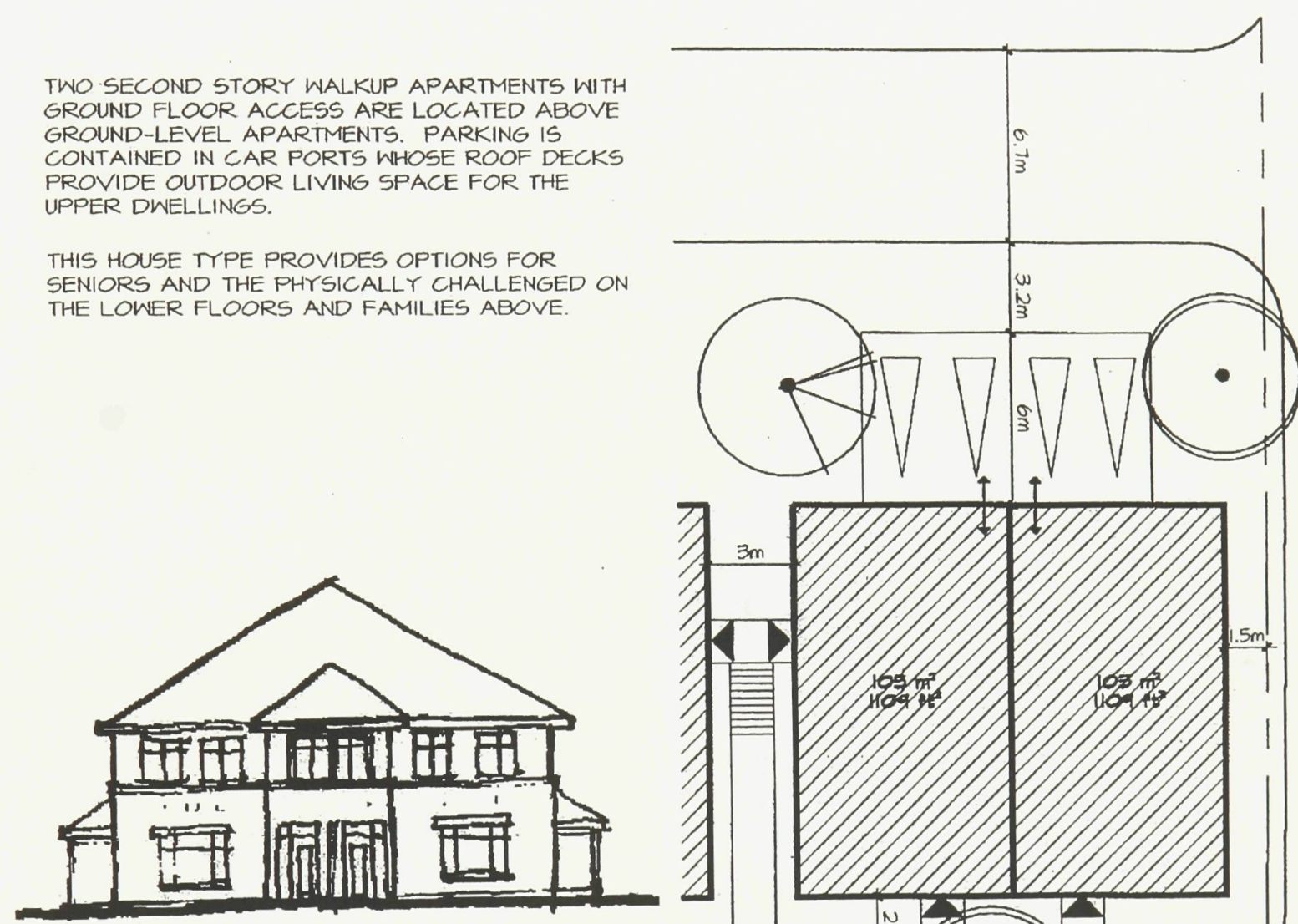

FRONT ELEVATION
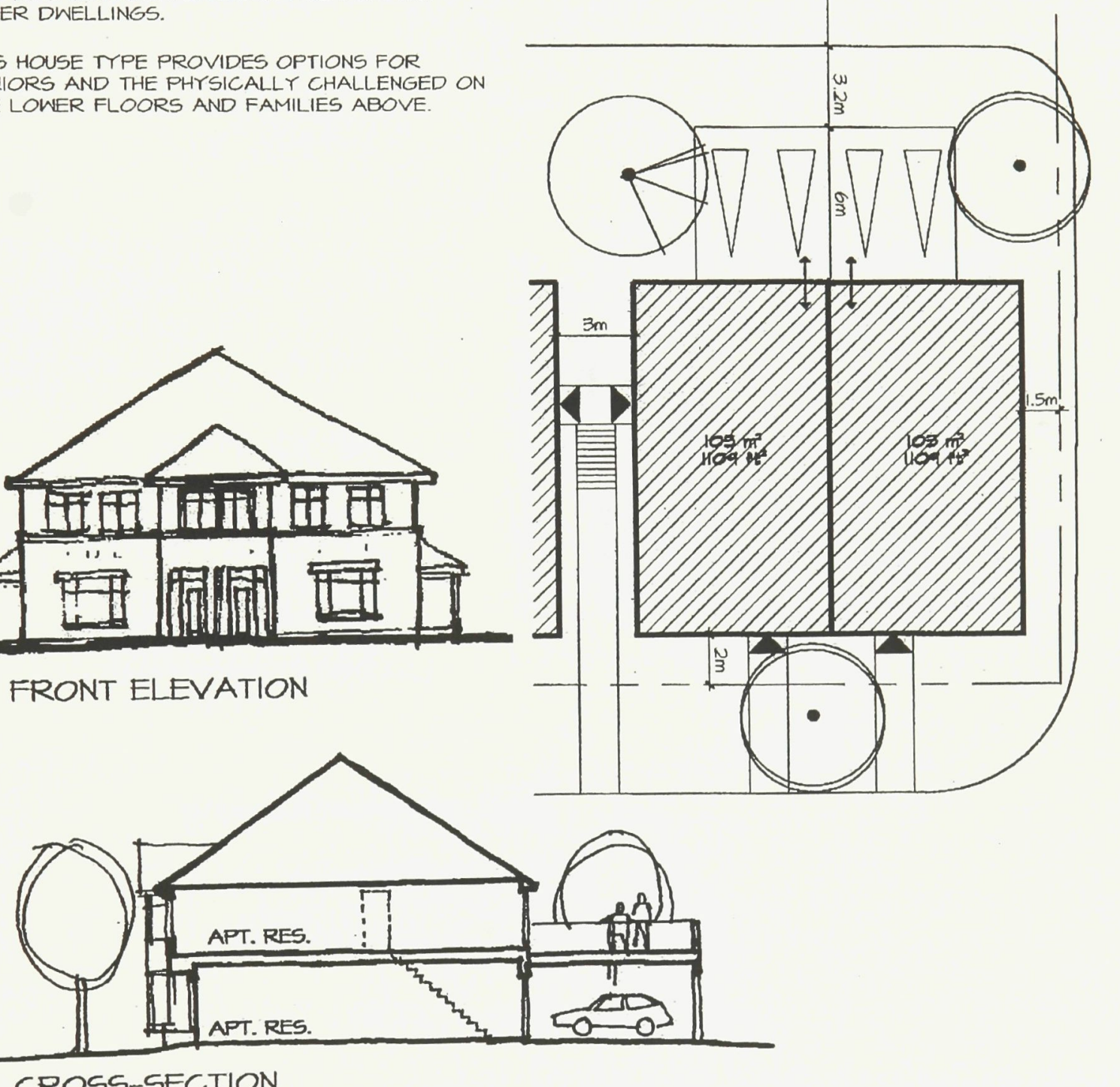

CROSS-SECTION

BARRYJ.  GASSOCAAIES ARCHITECTS 


\section{URBAN DESIGN / ARCHITECTURAL STRATEGIES}

DENSITY INTENSIFICATION FOR MEDIUM DENSITY NEIGHBOURHOODS 7 Mixed Use / Office / Senior (Three Storey)

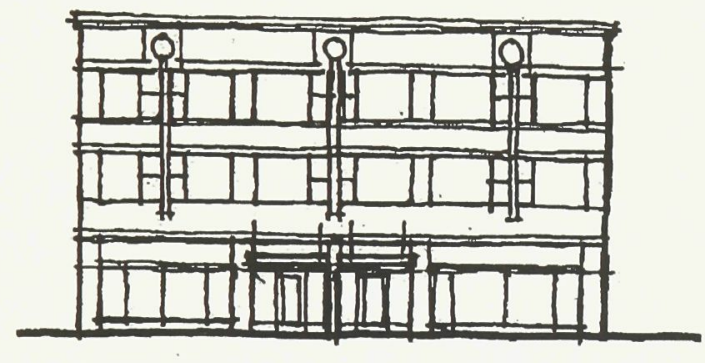

TWO 2-STOREY WALKUP APARTMENTS ARE LOCATED ABOVE GROUND-LEVEL

COMMERCIAL/RETAIL SPACE. PARKING FOR THE APARTMENTS IS CONTAINED IN CARPORTS WHOSE ROOF DECKS PROVIDE OUTDOOR LIVING SPACE FOR THE APARTMENTS.

THIS STRATEGY ACCOMMODATES A VARIETY OF USES AND GIVES VITALITY TO THE

STREETSCAPE. THE BUILDING FORM HAS A COMMERCIAL CHARACTER, YET PROVIDES PRIVATE RESIDENTIAL AMENITIES AND CAN BE EASILY ADAPTED TO A LIVE-IN OFFICE OR HOME INDUSTRY

FRONT ELEVATION

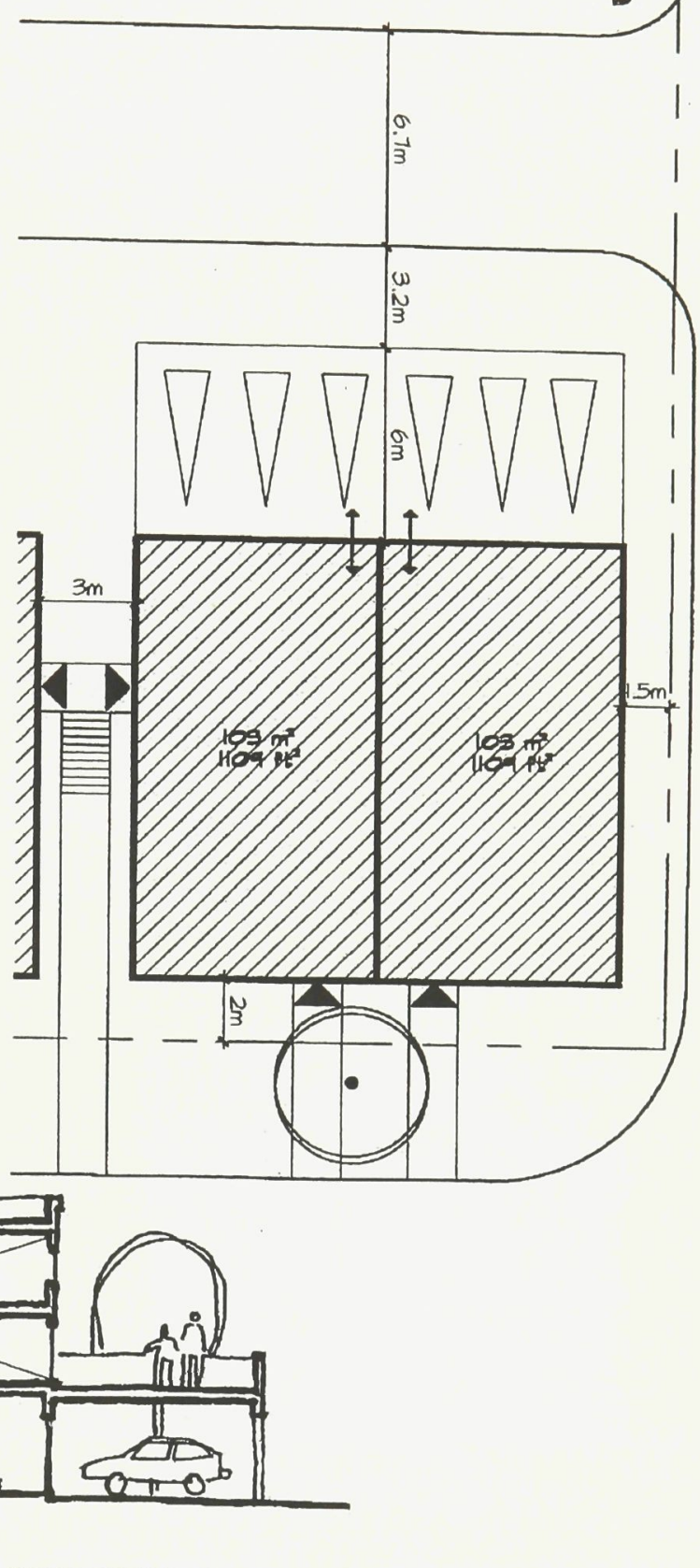

SECTION

BARRYJ. HOBIN EASSOCAAIES ARCHIIECTS
Longfields Demonstration Project

City of Nepean

Figure 5.10 


\section{UREAN DESIGN / ARCHITEOTURAL STRATEGIES}

DENSITY INTENSIFICATION FOR MEDIUM DENSITY NEIGHBOURHOODS

8 Retail / Stacked Townhomes

FOUR 2-STOREY WALKUP TOWNHOMES ARE LOCATED ABOVE GROUND-LEVEL COMMERCIAL SPACE. SURFACE

PARKING IS PROVIDED FOR TOWNHOMES AND COMMERCIAL SPACE.

THIS STRATEGY PROVIDES RESIDENTIAL INTENSIFICATION, AND OPPORTUNITIES FOR RENTAL UNITS WITH A VIEW TO THE STREET. THE COMMERCIAL COMPONENT IS CONTAINED IN A BUILDING FORM WHICH ENHANCES THE RESIDENTIAL CHARACTER AND VITALITY OF THE STREET.

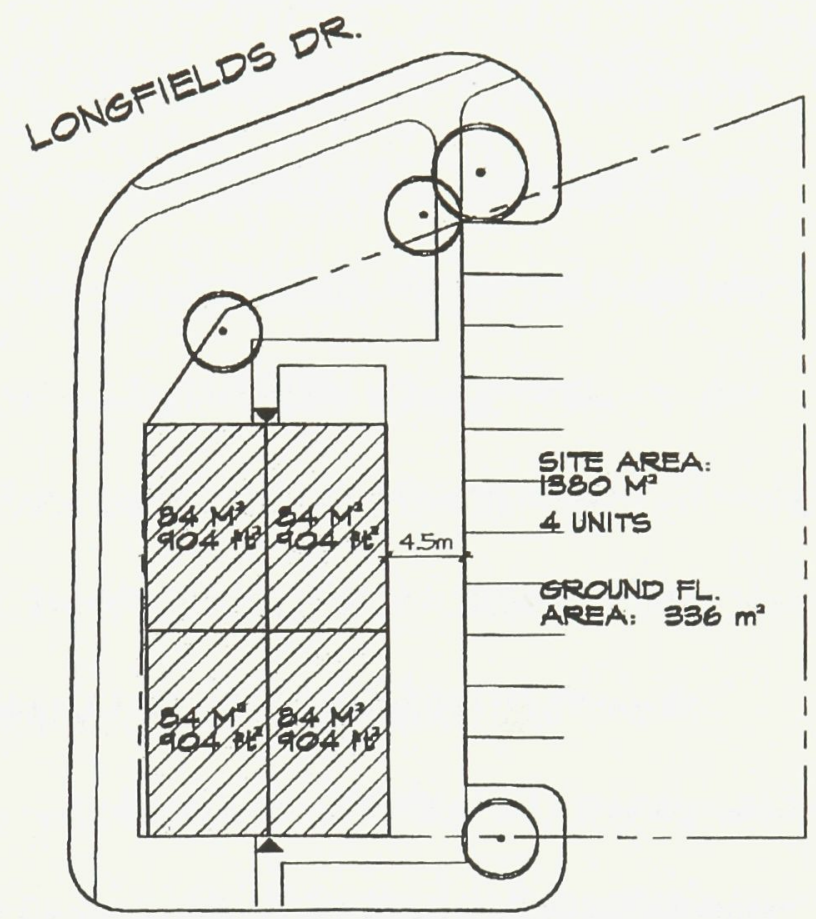

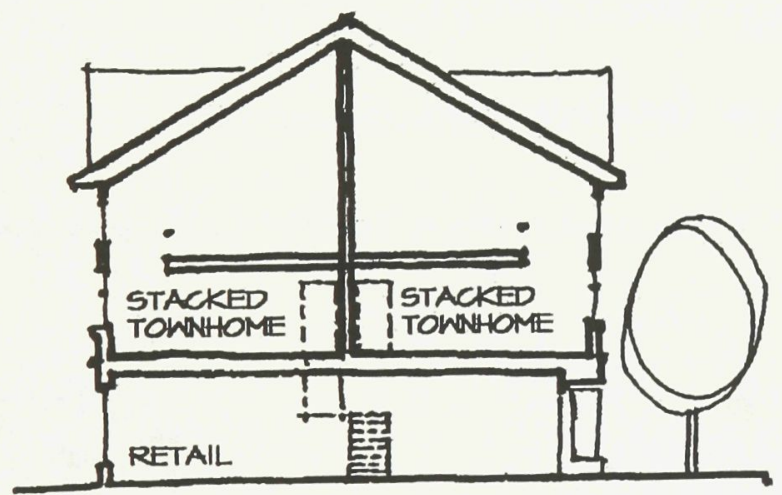

SECTION

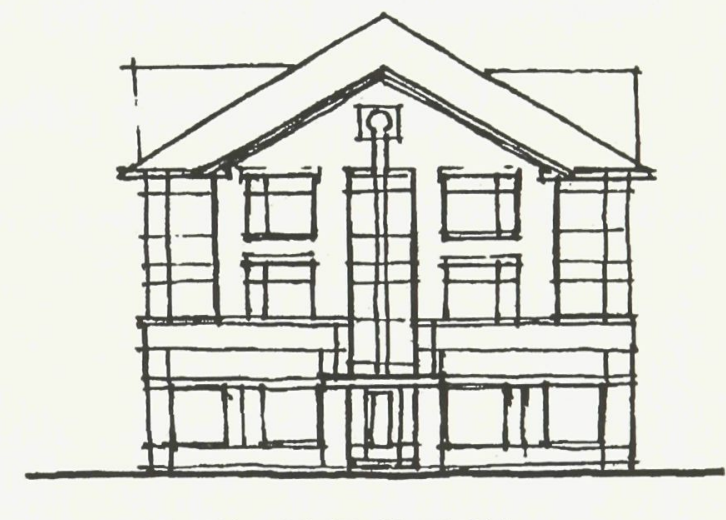

FRONT ELEVATION

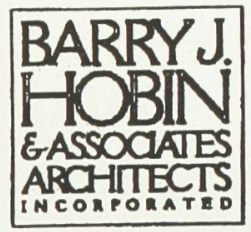

Longfields Demonstration Project

City of Nepean

Figure 5.11 
9. Linear Greenway Bioswale Stormwater Storage

(Figure 5.12)

Runoff from roads flows via shallow catch basins to a linear "bioswale" located within an extra wide right-of-way for Kilbarron Road. A permanently wet swale, approximately $1 \mathrm{~m}$ below the road, stores stormwater in excess of the 1 in 5 year event return. Wetland plants and trees help to create an inviting, linear park strip and walking environment, while the slow flows through the bioswale will be subject to filtration and nutrient uptake (e.g., nitrates, phosphates) by the specifically selected plant material. Water quality is thereby improved, ultimately outletting to the storm system through a control outlet on the swale. The system is intended to provide an alternative approach to the standard stormwater management pond and park approach seen elsewhere in the community where relatively rectangular areas varying from .5 to 2 ha ( 1 to $4 \mathrm{ac})$ are graded lower than the surrounding residential areas, and often provide within them active recreation amenities (soccer, softball) on open, grassed surfaces.

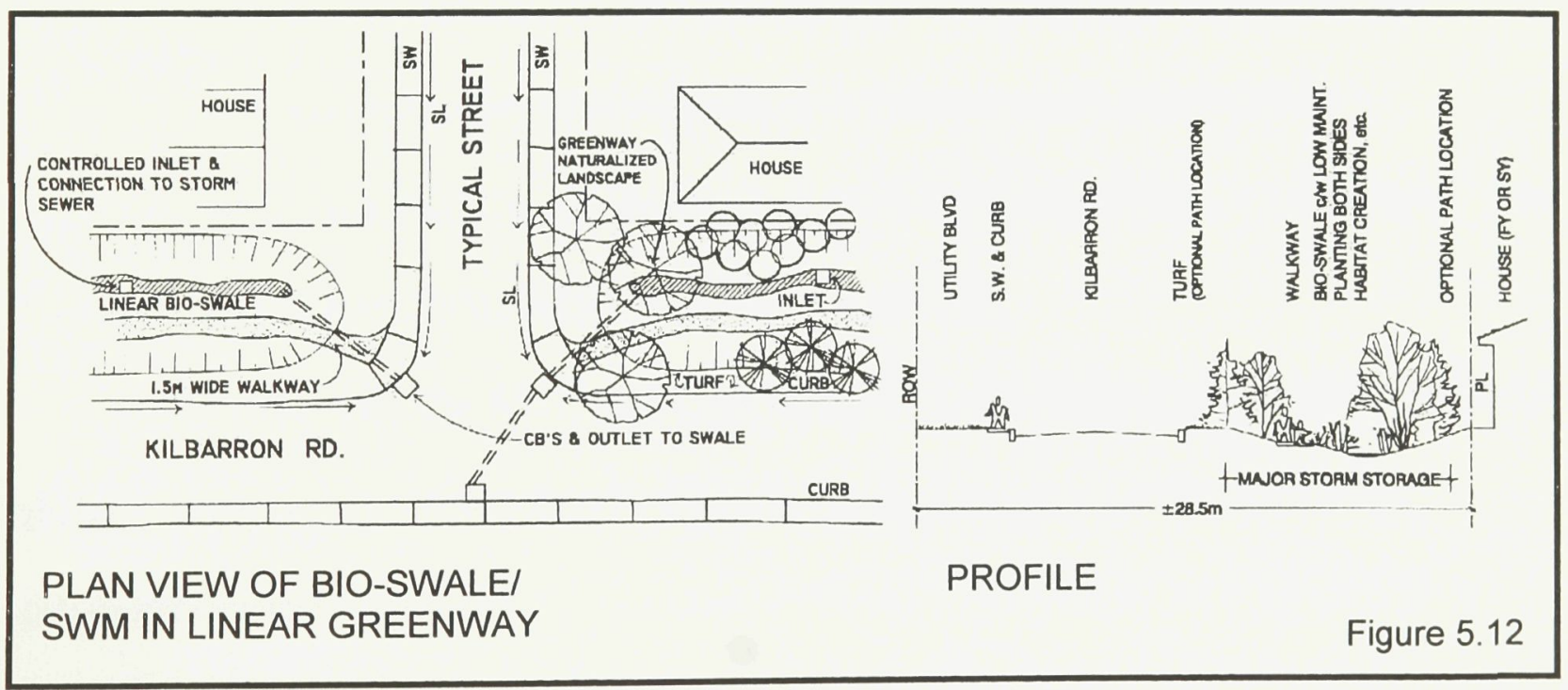


10. Exfiltration /Filtration Trench /Groundwater Recharge (Figure 5.13)

This initiative targets the lower flow, "normal" rainfalls often referred to as "first flush", minor events. These rainfalls and initial spring snowmelts typically carry the highest water-born pollution concentrations from roads, sidewalks and lawns directly to the municipal stormwater catchment system. This concept is being tested on a limited, experimental basis in Etobicoke, Ontario. The system consists of a typical five year design storm system with catch basins connected to the stormwater pipe. However, service accesses are constructed with sumps (approximately $0.5 \mathrm{~m}$ deeper than the sewer pipe.) Two $200 \mathrm{~mm}$ diameter perforated pipes with filter cloth socks are placed below the invert of the storm sewer and are connected to the sumps of the upstream and downstream manholes. A plug is placed in the perforated pipe, just above the downstream manhole. Clear stone wrapped in filter cloth is used as bedding and backfill around the storm sewer and the perforated pipes. Storm and meltwater flows from the streets are directed to the manhole sumps, where it moves to the perforated pipes below the manhole (lower than the main storm sewer).

As this "first flush" flow moves along the perforated pipe, it "exfiltrates" into the clear stone and percolates back into the ground.

The permeability of the existing soil and level of the ground water table will dictate whether an exfiltration or filtration system is used. If the soil is less permeable than necessary, the plug at the lower end of the perforated pipe is moved upstream to allow some of the exfiltrated flow back into the system 
through the perforations downstream of the plug. The flow re-entering the system has been filtered through the clear stone and may enter the next filter length. The process repeats until a filtered, cleaner flow eventually reaches the storm outlet. Maintenance on the system is completed by removing the plugs and using a typical sewer flush to remove any sediment build-up.

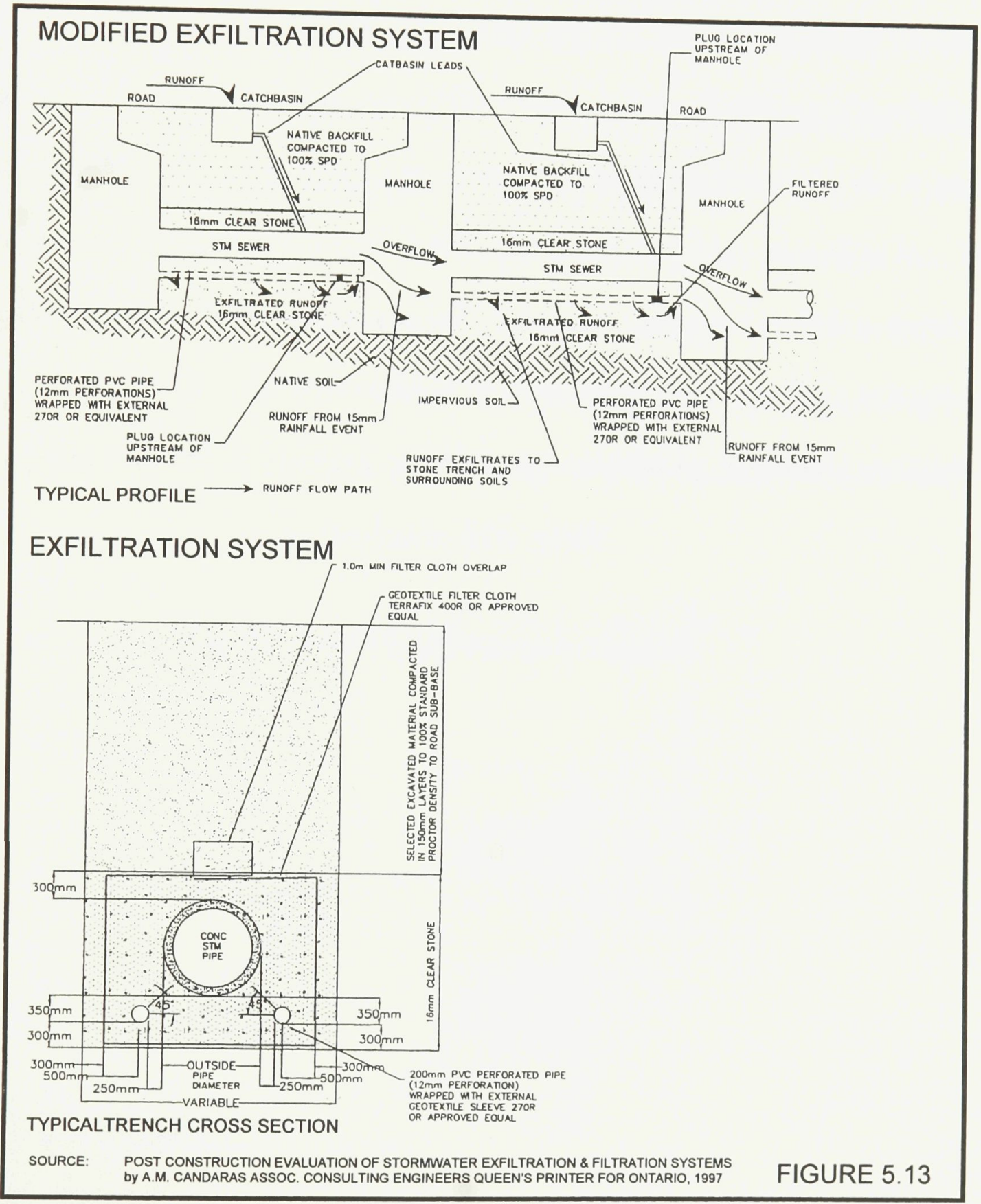




\section{Reduced Slope Grading/Infiltration}

(Figure 5.14)

Flattening lawn and grassed area grades slows surface flows, promoting infiltration and absorption of pollutants, and trapping of suspended solids, thereby cleaning up flows before they enter the storm system. Rear yard grades (away from the house) can be kept at the normal $2 \%$, but rear yard swales can be reduced to $1 \%$ to encourage absorption. Once again, existing soil conditions will affect the success of this approach. Given more permeable soils, the system may be enhanced if all eavestroughs discharge to the rear yard (see also No. 18) instead of directly to the storm system. However, surface filtration is limited by our northern climate, and past efforts to encourage road drainage into grassed swales has resulted in ponding on roadways caused by snow and ice banks along roads and across driveways in front yards.

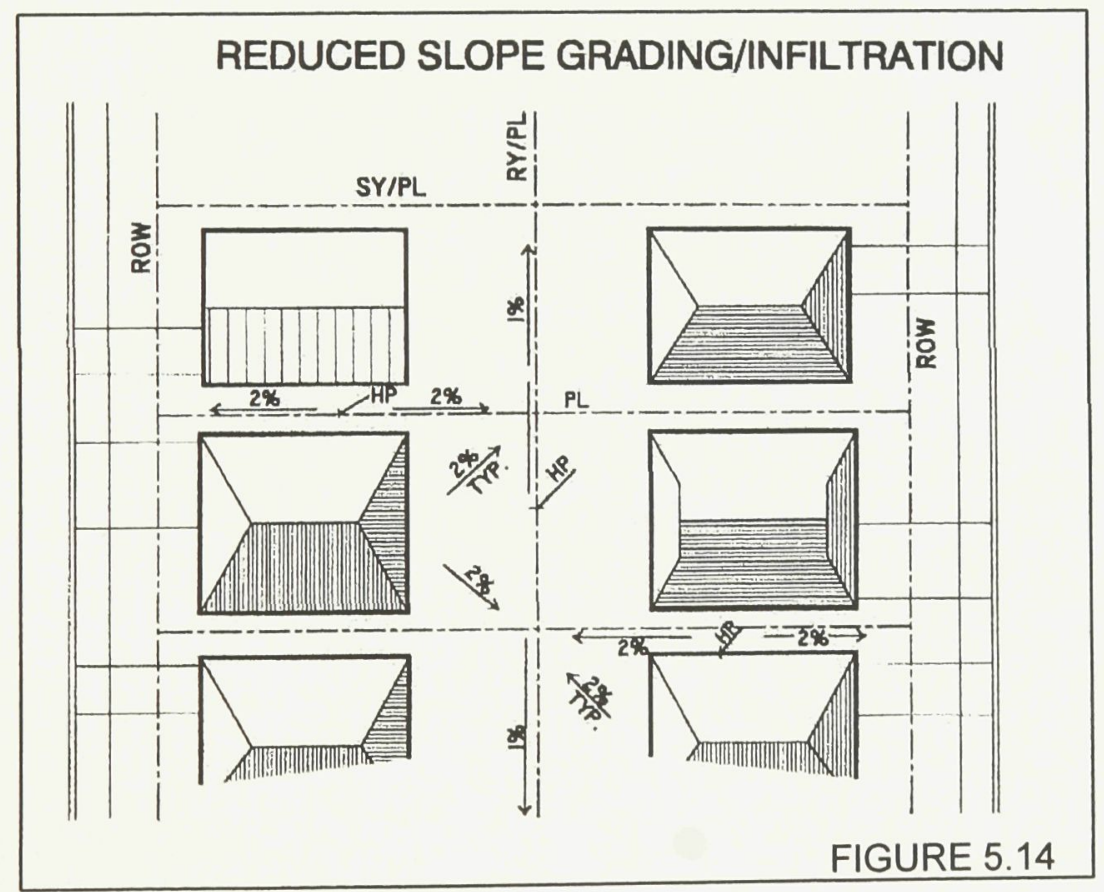


12. Alternate Standards Road Rights-Of-Way

(Figure 5.15)

Reduced right-of-way widths are less land consumptive, while at the same time contributing to a more intimate streetscape, street life and social interaction. Sidewalks, which will be maintained in winter, invite pedestrian activity and in many cases such standards can result in a more interesting architectural built form and community aesthetic. The $17.5 \mathrm{~m}$ wide right-of-way proposed with sidewalks on one side, conforms to revised Nepean standards. Twenty metres, with no sidewalk, has been the standard in all Regional municipalities for many years.

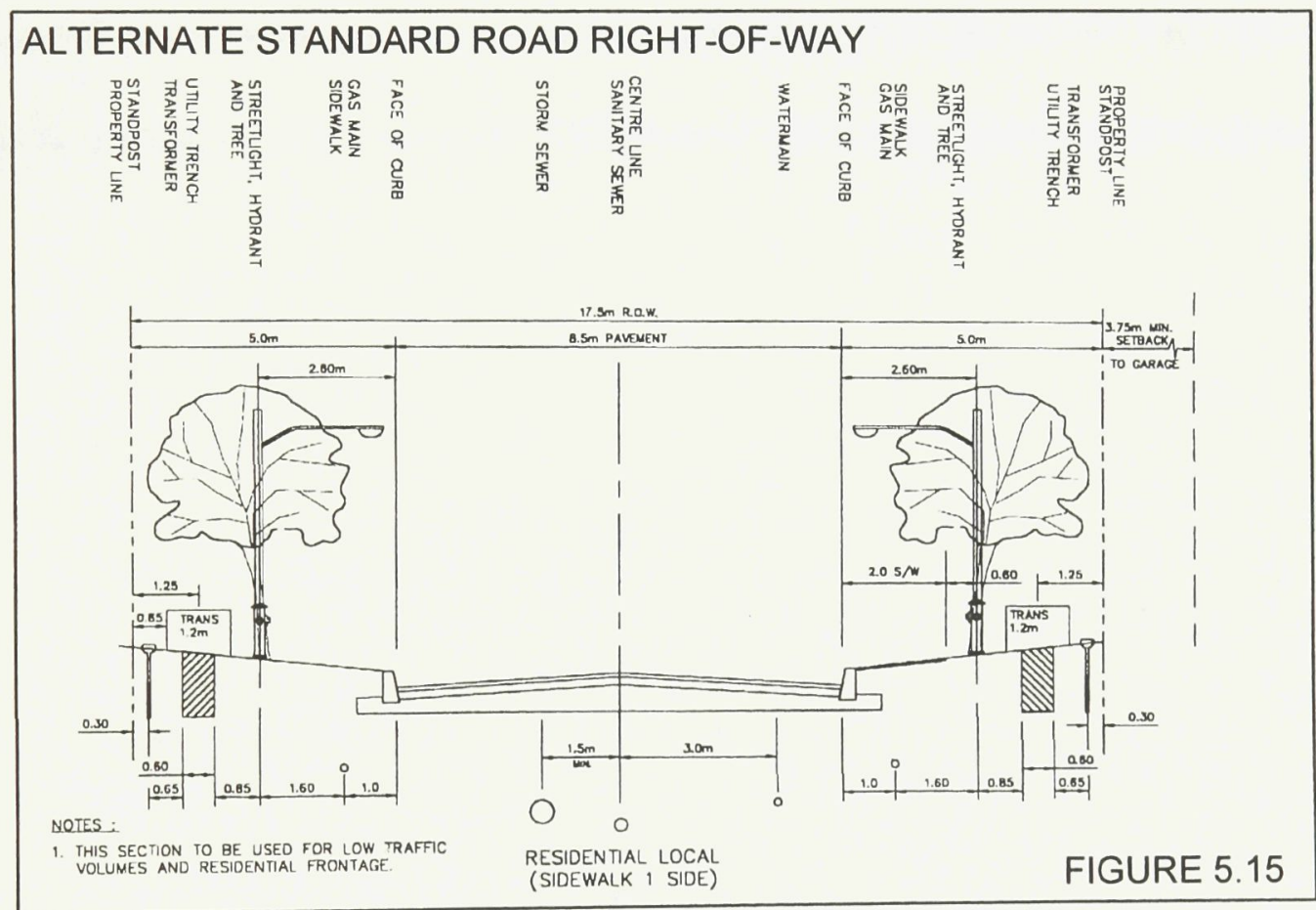




\section{Buried Utilities/Snow Storage/Street Trees}

Discussions between the Public Works Department, utility companies and community planners should continue in the co-ordination of buried utility locations, opportunities for street trees and the provision of snow storage, garbage collection and emergency services. So as to contribute to community sustainability, these functions must all be accommodated within a reduced width right-of-way, (or rear lanes in many new subdivisions) so as to be less consumptive of land. New maintenance equipment and labour techniques will probably be necessary, if streets and lanes are to be inviting, safe and fully functional in all seasons, since current equipment is generally too large for proper maneuverability in the reduced widths and turning radii being proposed. 
14. Passive Solar Layout and Design

(Figure 5.16)

East-west street orientations provide optimum solar access in as many cases as possible. For less favourable orientations techniques such as offset and separated garages "open up" the elevations of houses, increasing available window area for improved natural light and passive solar heating opportunities. Landscape design must not negate such opportunities, through improper tree selection and/or placement.

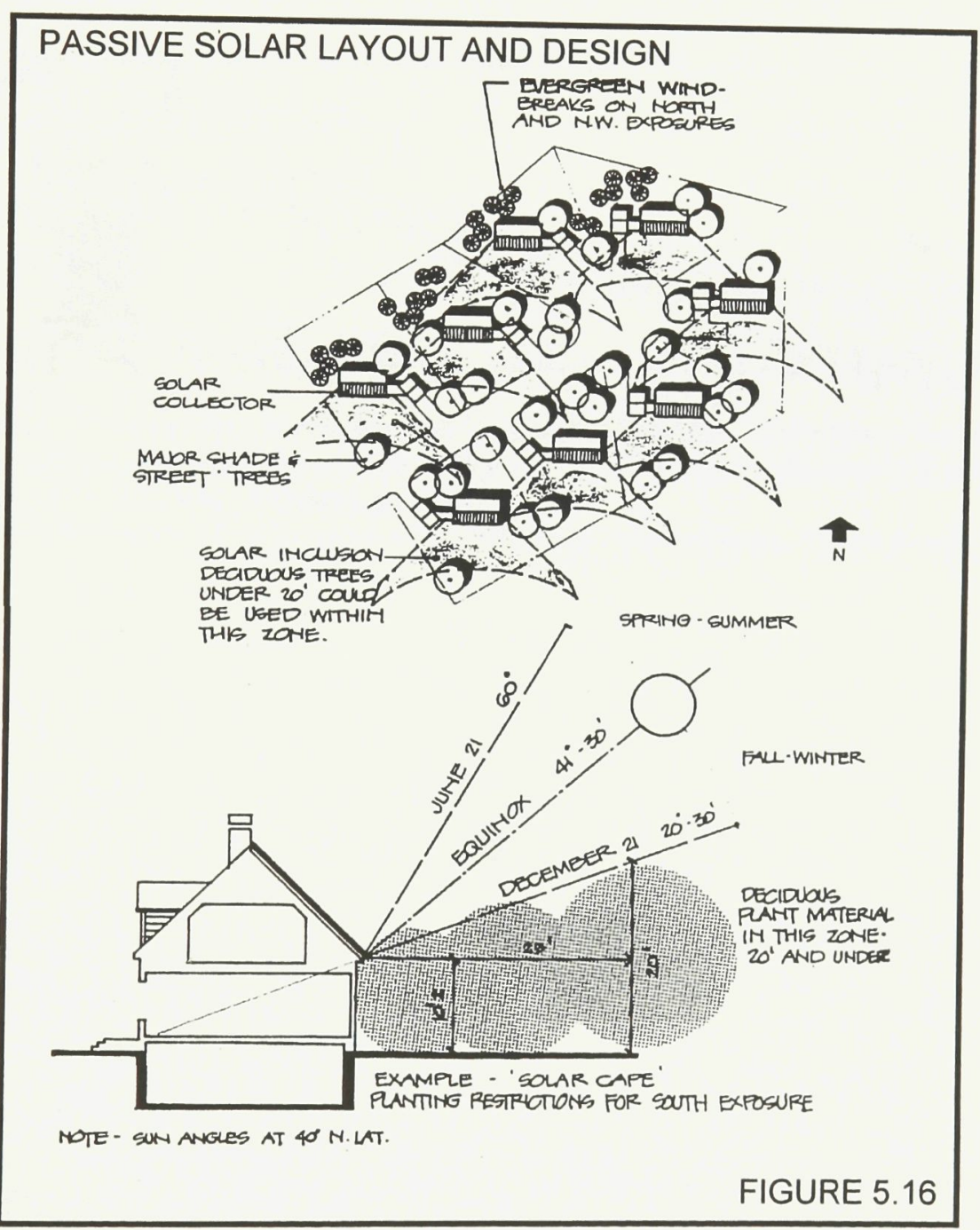


15. Windbreaks / Cooling Breezes

(Figure 5.17)

Recognition of the direction of prevailing, cooling summer breezes should influence both landscape design as well as architecture, as the effect on airconditioning requirements can be reduced. Similarly, proper mass plantings for winter wind breaks are difficult to achieve in more dense suburban environments, yet a few properly located coniferous hedges or clusters of trees can have a measurable effect, reducing both wind speed and heating requirements.

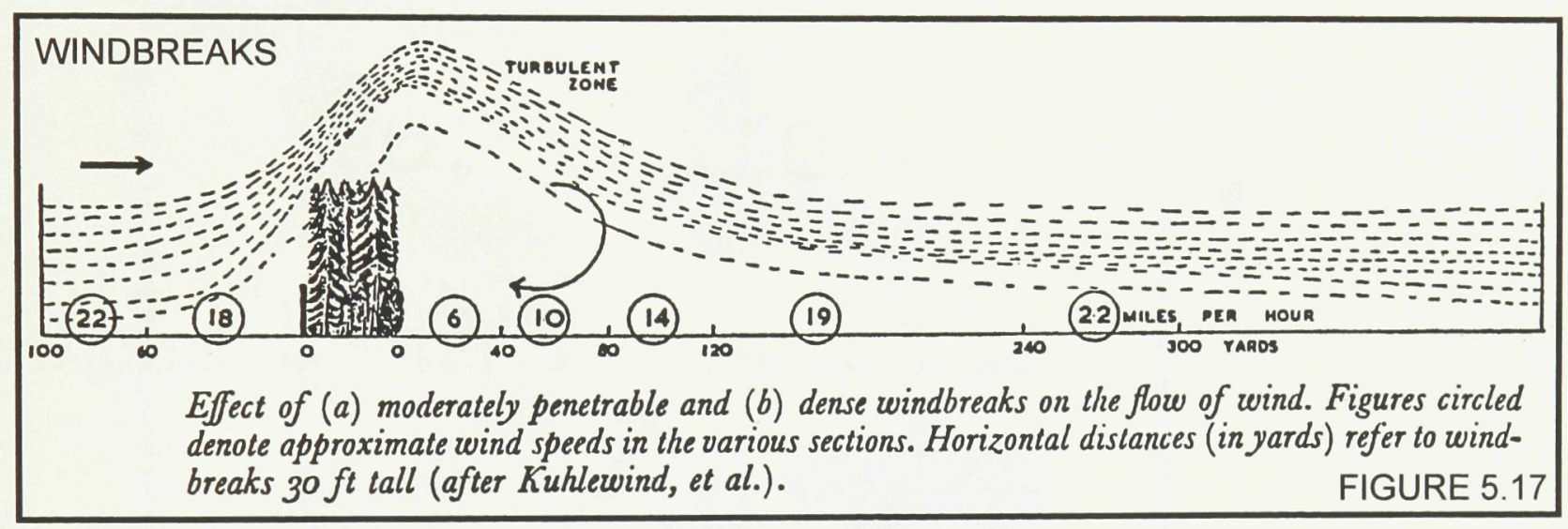




\section{Shade For Cooling}

(Figure 5.18)

Properly selected and located trees provide welcome cooling of streets, structures, yards and public spaces. When planted upwind, shade cools incoming summer breeze before reaching homes and outdoor use areas. As previously stated, as trees mature, there can be measurable reduction in air conditioning demands, as well as recognized improvements to air quality. (Walker, 1979:6-7).

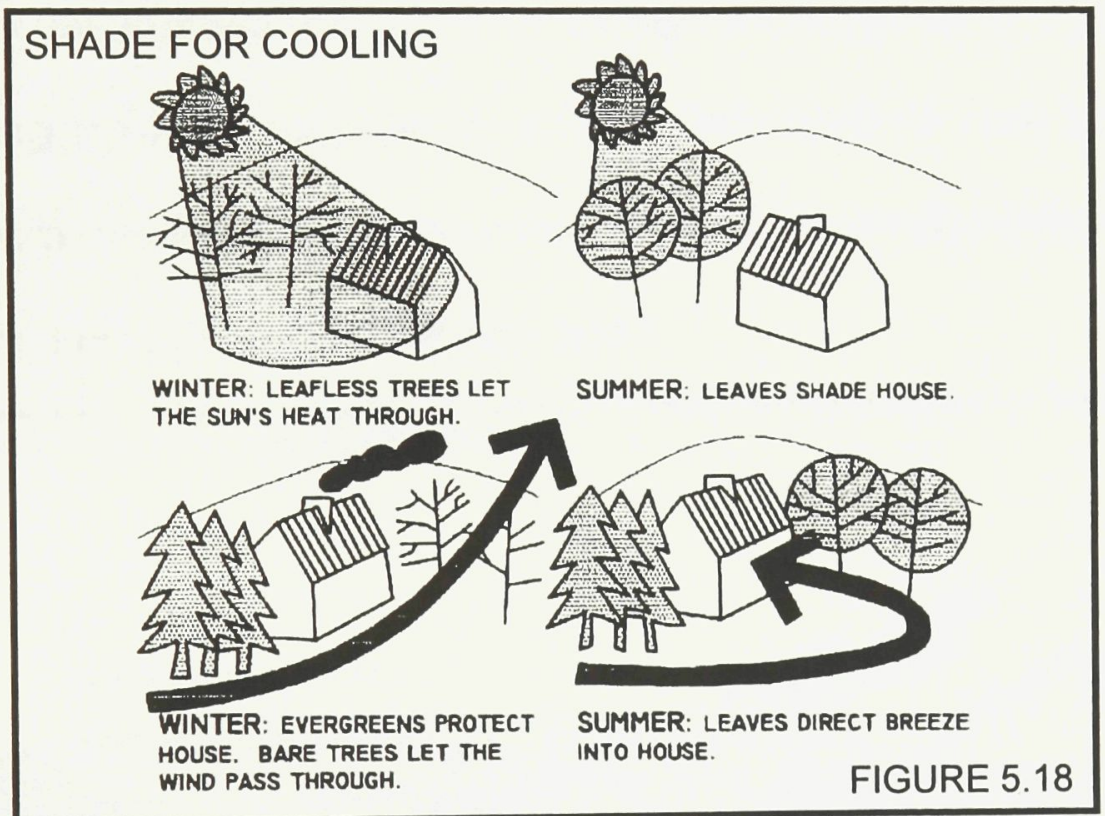




\section{Right To Light Considerations}

(Figure 5.19)

Especially in northern latitudes, light and sun in living and working places has dramatic social and psychological impacts, such as the medical condition known as seasonal affective disorder (S.A.D.). As well, many neighbourhoods have been negatively affected by design and construction, which has reduced or cut off light. Reaction at community meetings, in the author's personal experience, has been vocal and persistent. Currently, zoning and building bylaws do not address this problem. Design guidelines should be developed and ultimately by-laws developed to address this issue for both new and infill developments at the site plan stage, such as those illustrated on the concept plan (Figure 5.2) for built forms 6 and 7.

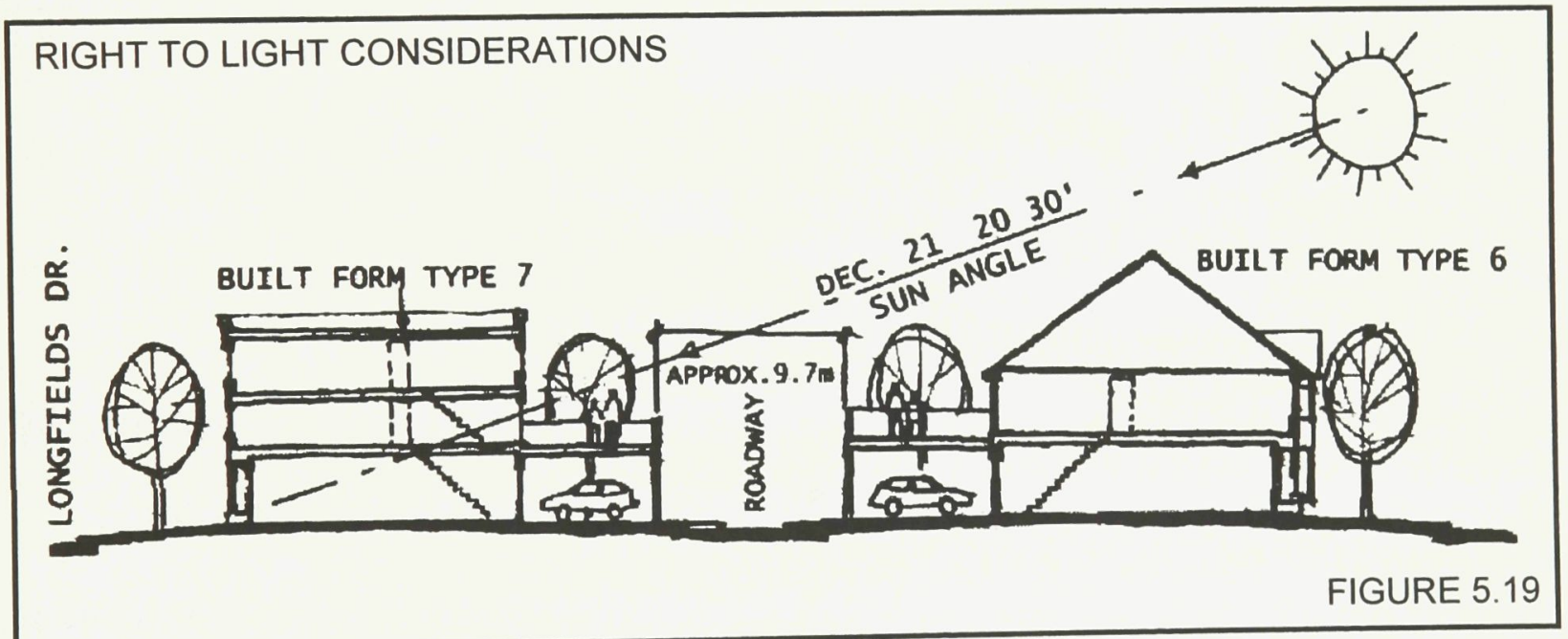


18. Residential Stormwater Storage and Use (Figure 5.20)

Both the opportunity and "low tech" equipment is readily available to promote and encourage the re-use of stormwater "on-site", for homes, parks, or neighbourhood projects such as community gardens and maintenance. Reduced slope grading, (Figure 5.14, number 11) is a related strategy.

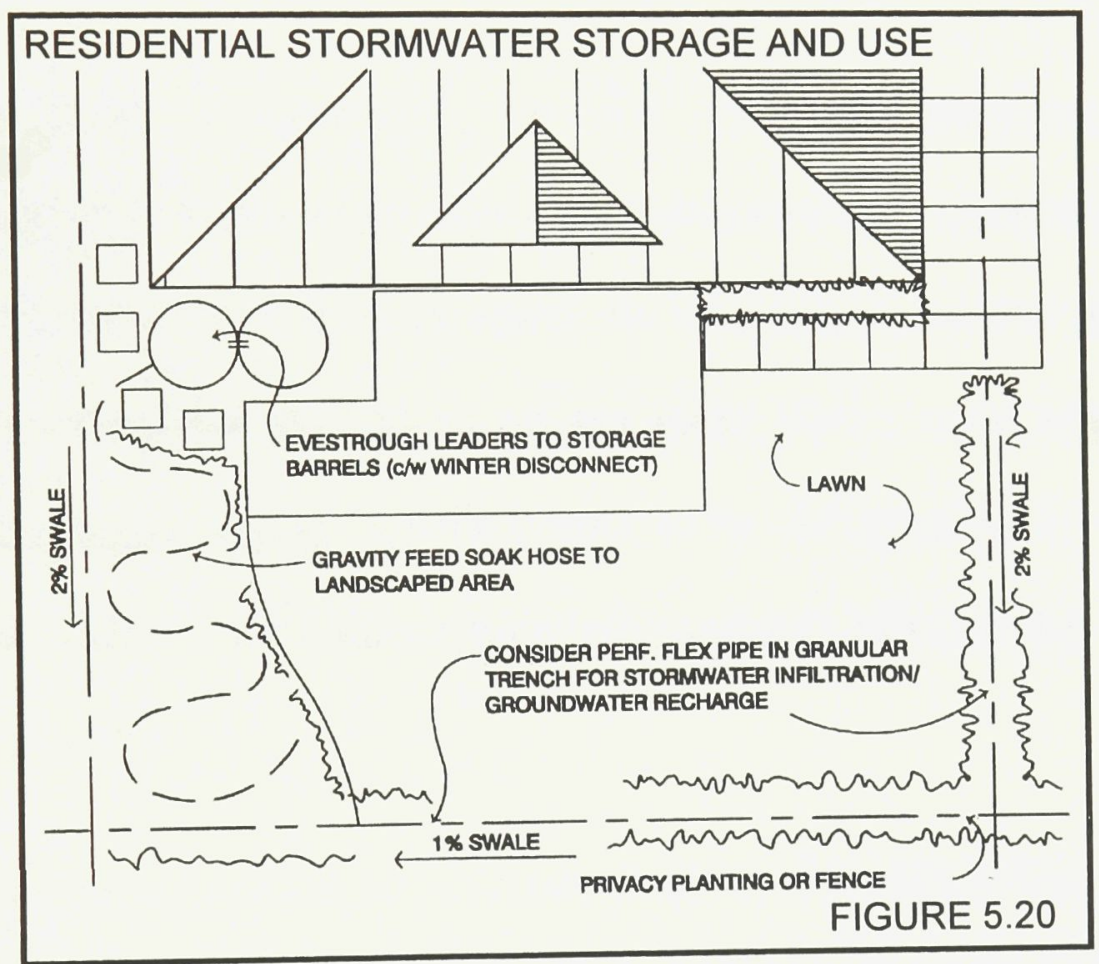

19. Landscape Design for Reduced Water Requirement

Selection of plant material, low maintenance turf seed mixes, and use of porous pavements such as pea gravel or unit pavers to reduce runoff co-efficients and promote infiltration, and other design initiatives (See Numbers $9,10,11)$ can reduce demands on the municipal (treated) water supply system. 
20. Community Gardens/Food Production

Opportunities for "permaculture" - or the integration of limited agricultural and food production activity into urban and suburban neighbourhoods - is demonstrated in the central community park space. Such initiatives rely on the participation and support of community groups. Of course any of the residential lots can support private vegetable gardens and fruit trees.

\section{Irrigation Cistern For Gardens And Park; Community Composting}

Designed in conjunction with a central community / park building, an underground cistern can store rainwater for maintenance of the allotment garden and park. A wind generated pump system might work in conjunction with the cistern and irrigation layout. Similarly, space can be designated for community composting projects, with the product being used in public space or on private yards and gardens.

\section{RMOC Compost Utilization in Construction and Maintenance}

There is potential for the RMOC's existing composting program to become much more visible and integrated into the development of new communities and public spaces. Thousands of cubic meters of valuable compost are produced through the recycling program annually, thereby reducing the need for the extraction of peat moss from wetlands, chemical fertilizer use and other artificial soil amendments. 
23. Central Hazardous Waste Storage and Pickup

A central community building offers an opportunity for the deposit and (short-term) storage of household hazardous wastes. Any reduction in incidents of dumping or inadvertent inclusion in the regular waste stream justifies such a facility, where scheduled pickups by the Regional hazardous waste division could be arranged.

\section{Centralized Emergency Services}

In times of community crisis, provision of basic service from the central community building might be an integrated element of a more sustainable neighbourhood. Power generators, emergency potable water supply, water pumps, fire hoses or extinguishers might be made available. Community responsibility and co-ordination, once again, would be necessary for the success of such an initiative.

25. Community Stewardship - Landscape Construction and Maintenance A general reduction in municipal maintenance budgets, and a desire for a more personal stake in one's neighbourhood, are trends which (on a limited basis) are being directed towards an increase in residents' participation in the construction and on-going maintenance of public spaces, pathways, tot-lots and other landscape features. Education and leadership are the principal ingredients needed to broaden both popularity and support for this initiative within new and established communities. 
26. Solar Powered Lighting

Discussions could be initiated with Nepean Hydro and private sector suppliers to explore availability and reliability of existing technologies so as to reduce demand for power for all public spaces such as parks, pathways and eventually roads. Safety and security, however, should not be compromised due to reduced light quality. Active solar panels might provide water-heating requirements for the central park building.

27. Reduced Vehicular Trips - Pedestrian, Biking Opportunities and Transit This case study location is typical of most Canadian subdivision developments, wherein the use of private vehicles is still dominant. The types of trips taken include travel to and from the workplace (still largely remote from place of residence); to all goods and services such as food shopping, schools and to recreation and entertainment centres - in short, all of the "necessities" of day-to-day family life.

Efforts to make a community more sustainable in this regard involve reducing or removing the need for the use of private vehicles (and the air pollution they create). The use of readily accessible, affordable,efficient mass transit, and the provision of other alternate forms of transportation, are key factors in reducing private vehicle use. This case study project is well located to take advantage of existing and future transit services. Bus stops are now located within a short walk on Longfields Drive, and will be extended to Beatrice and Claridge. In the short term, the Fallowfield Park and Ride (at Woodroffe) is now 
under construction, and a future major transit station is to be situated approximately $650 \mathrm{~m}$ to the north-west (See Figure 4.1). The plan includes ample provision of both biking and pedestrian linkages and choices, as well as both commercial and institutional land uses within the neighbourhood.

\section{Community Policing, Safety and Security}

As illustrated in the concept plan, windows, balconies and porches facing the street, are numerous. Similarly, public spaces are to be open, visually accessible and well lighted. The neighbourhood is designed to be an inviting, safe and secure environment for all age groups.

29. Universal Accessibility

The relatively flat existing grades make a barrier free environment relatively easy to achieve across the entire neighbourhood. However, attention must be paid to curb and roadway design, widths and slopes of pathways, and architectural detailing.

30. Landscape Diversity / Naturalization / Reduced Maintenance Requirements

A healthier, more ecologically diverse landscape treatment is being promoted for this demonstration neighbourhood, where the prevalence of a "manicured" landscape is replaced by more naturalized spaces such as those being promoted by the City of Nepean's "Greening our City" program. In addition to the reduction of maintenance and chemicals, the landscapes are hardy and more suited to the harshness of the Canadian climate. However, substantial 
education at both a municipal (politicians and staff) and public/community level is necessary to achieve greater support for the aesthetic, educational and biodiversity benefits, of such naturalized landscapes. Modifications may be required to certain regulations (e.g., municipal noxious weed control by-law) to allow such landscapes to be developed.

\section{WILDLIFE HABITAT CREATION}

The re-population of our built environment by birds and small mammals is another benefit of a more diverse approach to landscape naturalization. Shade, shelter and food stock will serve to attract wildlife to backyards, streets and parks within the neighborhood, adding interest, educational opportunities and depth to the quality of life for existing and future generations of residents.

The sustainable development legend shown on the concept plan (Figure 5.2) lists the preceding initiatives (No.'s 1-31) and best management practices and illustrates their locations within the case study neighbourhood. As previously mentioned their ultimate location, frequency of application and inclusion will be the prerogative of the City (as the landowner and approval agency) and the builder (as the purchaser and developer of the case study neighbourhood land.)

\section{Cost Estimates For the Concept Plan vs. Conventional Neighbourhood}

Recognizing that economic viability is integral to the global concept of sustainability, the case study was designed to incorporate a cost comparison process. 
From the outset, the cost implication of sustainable development concepts and initiatives was expressed as a concern by the municipal working committee, in terms of the ultimate effect on sale price and long term maintenance. The public, in the open forum (Chapter 6), recognized the economic implications of sustainable development efforts as they related to ultimate affordability.

In early 1999 , the City had prepared a "conventional" street pattern and land use plan for this same parcel of development land as a preliminary exercise in assessing revenues from the sale of city owned land (Figure 5.21). With the completion of the case study concept plan, a process of estimating capital costs of construction, and life cycle cost comparisons, was undertaken.

A construction cost estimate was prepared to demonstrate the additional costs, on a per unit basis, which a builder or developer would incur to construct the various sustainability initiatives as suggested in this case study. These specific items are in addition to those normally included as "best management practices" in a conventional subdivision, and results are summarized in Table 6.1.

Beyond the fundamentals of measurement and calculation of all of the land development costs (e.g., land use areas, roads and infrastructure services, recreation amenities), the long term or "life cycle" cost implications were calculated for comparison, utilizing the municipal "Infracycle" software package which is used by the municipal planning and development department to evaluate land development proposals submitted for approval. 


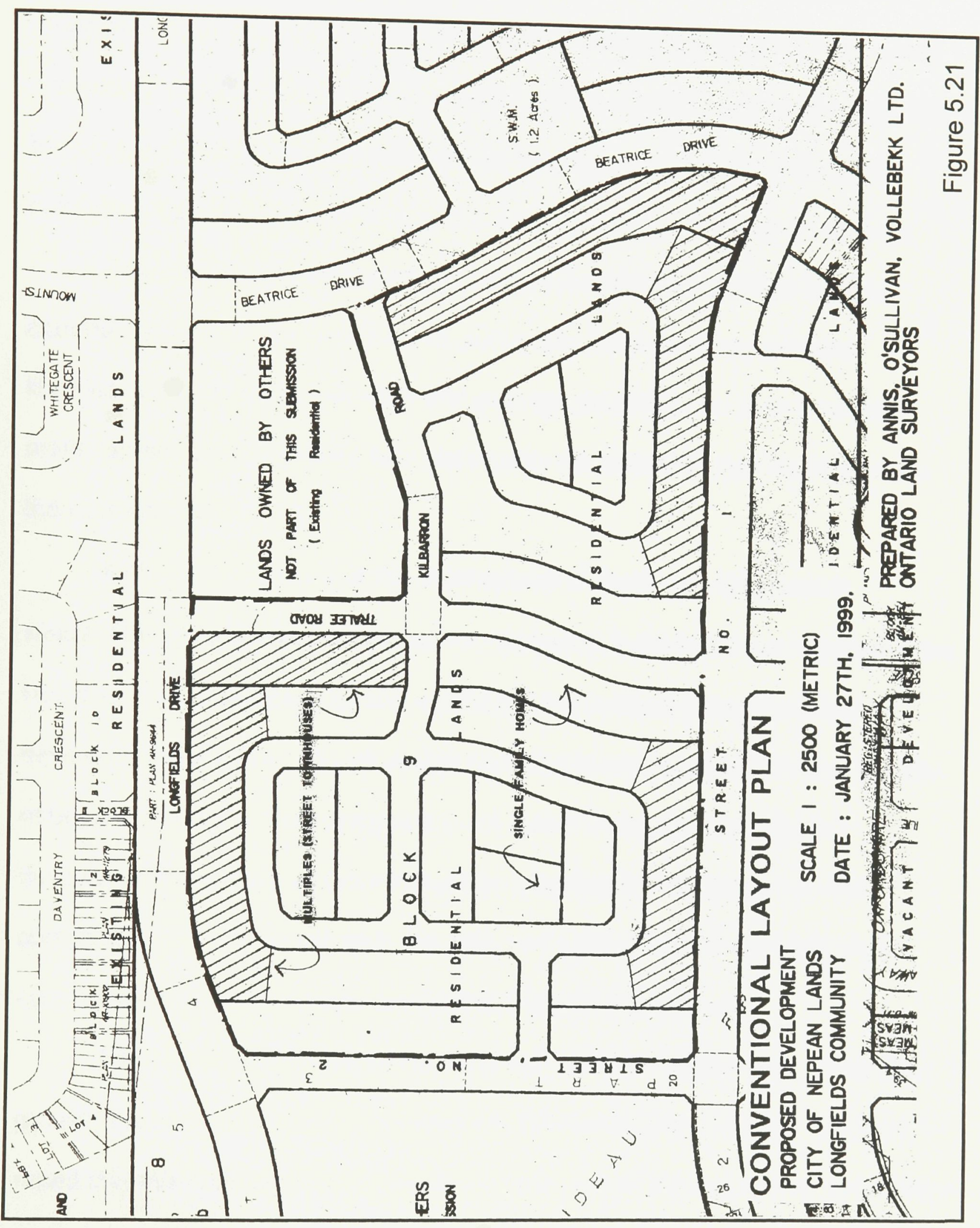


This software requires the input of data such as the various land use areas, densities and persons per dwelling unit. Infrastructure costs (e.g., roads, sidewalks, streetlights, storm and sanitary sewer, water, parkland) are calculated by providing the design standard utilized, quantities, construction costs and provision of the life cycle term (e.g., 25 years for roads, 75 years for sewers).

The standard municipal inputs involve an appropriate share of other community support services such as police and fire protection, parkland, libraries, schools, transit services and garbage collection, so as to provide a more realistic picture of long term community development cost implications to the municipality.

It should be noted that the architectural designs (as expressed in sustainable development initiatives 1-8, Figures 5.3-5.11) are not included in the lifecycle costing exercise, as unit construction is completed by the builder developer at their cost. As unit design and streetscape composition is a function of buyer preference, final designs are not determined until well after land development activities and marketing has proceeded. Therefore, the cost comparison focuses on the land use plan and road pattern of the case study concept plan (Figure 5.2) and conventional layout (Figure 5.21).

After completion of the initial calculations (by the study team), data were provided to municipal staff for entering into the "Infracycle" program. It should be noted that this was the most onerous and time consuming work of the entire case 
study, spanning almost two months and representing approximately $\$ 6500.00$ in study team and municipal staff time.

The "Infracycle" software is owned by a private sector company, who leases it to the City of Nepean and provides training and support in its application, updating and maintenance. This proprietary interest allows for the release of only the final cost comparison summaries as provided in Chapter 6 , Tables 6.2 and 6.3. 


\section{CHAPTER 6 EVALUATION OF THE CONCEPT PLAN}

The strengths and weaknesses of the concept plan are evaluated in this chapter through a review of a short and long term costs, critical review comments from those directly involved in the case study working process, and a review of the sustainability performance of the concept plan.

\section{Cost Comparisons}

As described in Chapter 5, both capital costs of construction and life-cycle cost comparisons were completed for the case study concept plan and a conventional layout plan, the results of which are provided in a series of Tables.

Table 6.1 summarizes the preliminary costs of the sustainable development initiatives as numbered on the concept plan, Figure 5.2. These costs have been specifically itemized as they are in addition to site and landscape development costs included in a conventional neighbourhood layout plan.

It should be noted that there is an approximately $\$ 1500.00$ per unit added cost resulting from sustainability strategies (as estimated in Table 6.1) based on the 10 units per acre ( 25 units per hectare) density derived by the concept plan. If lower or higher densities are ultimately achieved, the unit cost (and impact on sale price and affordability) increases or decreases proportionately. 


\begin{tabular}{|c|c|c|}
\hline \multicolumn{3}{|c|}{$\begin{array}{l}\text { CAPITAL COST ESTIMATE OF } \\
\text { SUSTAINABLE DEVELOPMENT INITIATIVES, } \\
\text { LONGFIELDS CASE STUDY CONCEPT PLAN }\end{array}$} \\
\hline No. 9 & $\begin{array}{l}\text { Linear Greenway/Bioswale (SWM Pond No. } 998 \text { will still be } \\
\text { constructed as well) }\end{array}$ & $\$ 150,000$ \\
\hline No.'s $15 \& 16$ & Additional Rear Lot Planting & $\$ 35,000$ \\
\hline No. 18 & On-Site Rainwater Use & $\$ 60,000$ \\
\hline No. 20 & Community Park Development and Gardens & $\$ 50,000$ \\
\hline No. 21 & Rainwater Cistern and Gravity Irrigation in Park & $\$ 10,000$ \\
\hline No.'s $23 \& 24$ & Community Building and Stewardship Program & $\$ 60,000$ \\
\hline No. 25 & $\begin{array}{l}\text { Community Entrances and Common Landscape Features } \\
\text { (Stewardship / Maintenance Program) }\end{array}$ & $\$ 35,000$ \\
\hline No. 27 & Pedestrian and Bikeway Linkages to Transit Services & $\$ 40,000$ \\
\hline & Approximate Total & $\$ 440,000$ \\
\hline
\end{tabular}

Table 6.2 and 6.3 list the various services provided by the municipality in support of land development over its life-cycle (items 1 through 15). Estimates were prepared and attributed to the components, in terms of their replacement, operations and maintenance, to ultimately derive a per unit cost for residential and non-residential land uses. In cases where services are provided by the Regional Municipality of Ottawa-Carleton (i.e., costs not borne by the City: water distribution, transit, police protection, garbage collection) such items are not included in this municipal cost comparison. 
Depending on the service component, life-cycles are rated from 25 to 75 years, based on replacement history provided by the municipal Engineering and Works Department. Over the life-cycle of these two alternatives, the case study concept plan generated a total estimated cost to the city of $\$ 645,000$ (Table 6.2) compared to $\$ 771,000$ for the conventional plan (Table 6.3), a difference of about $17 \%$ in favour of the case study concept plan.

The major cost difference is found in stormwater (service component No. 4) wherein a greater than $\$ 1,700.00$ per unit long term saving might be realized through the implementation of the linear greenway/bioswale stormwater management alternative (Initiative No. 9, Figure 5.12). Since stormwater is being handled on site under this approach, savings are potentially realized since a proportionate share of a very expensive municipal stormwater management pond and treatment facility need not be attributed to the case study lands.

As noted in Chapter 5, the stormwater pond will be constructed to service the case study land and so, in reality, this cost must be attributed to the parcel of land when it is developed. However, the cost comparison demonstrates the potential economies if this initiative were implemented on a comparable site elsewhere, prior to the design and construction of community wide stormwater management facilities such as those existing in the Longfields community. 


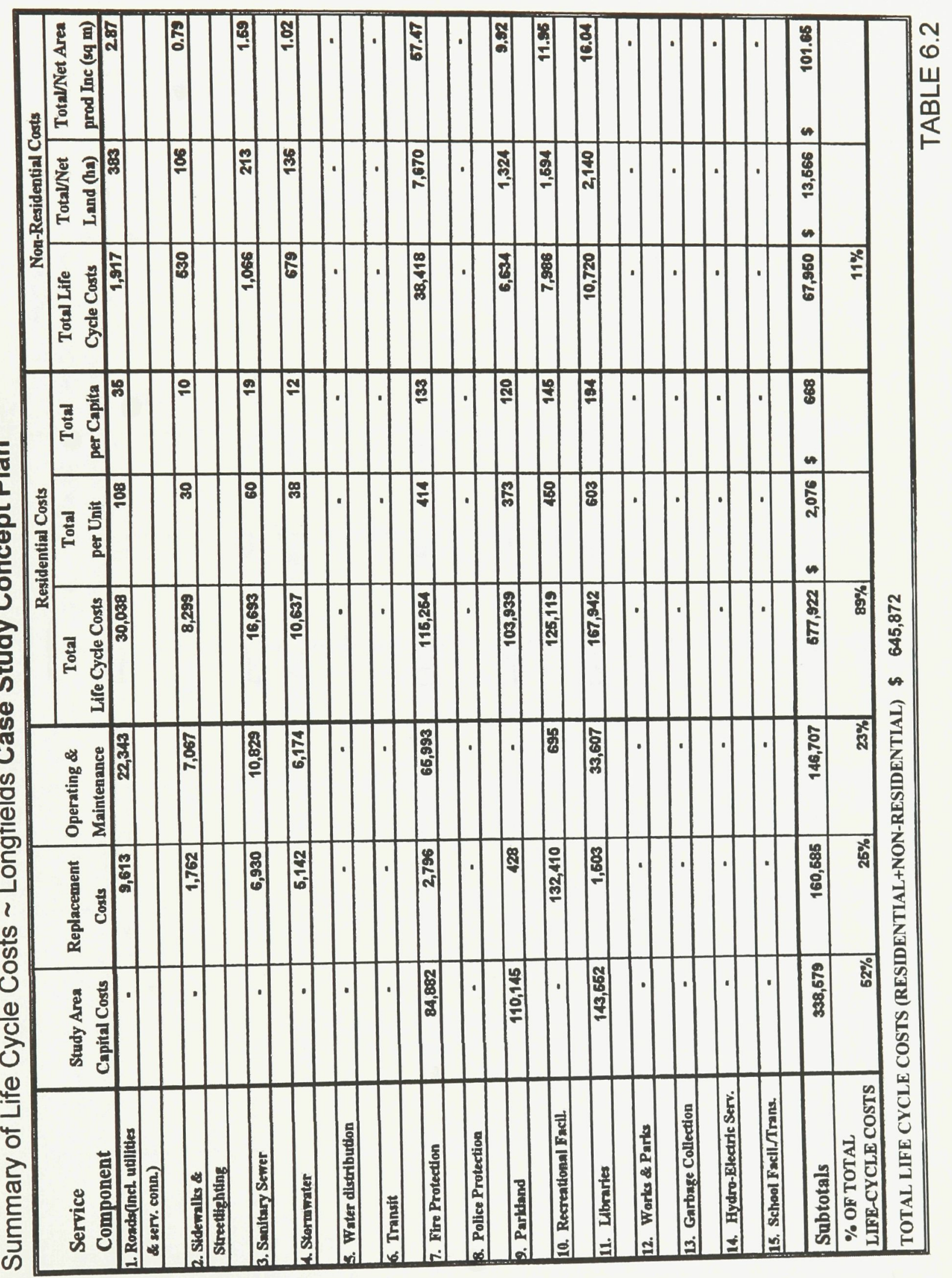




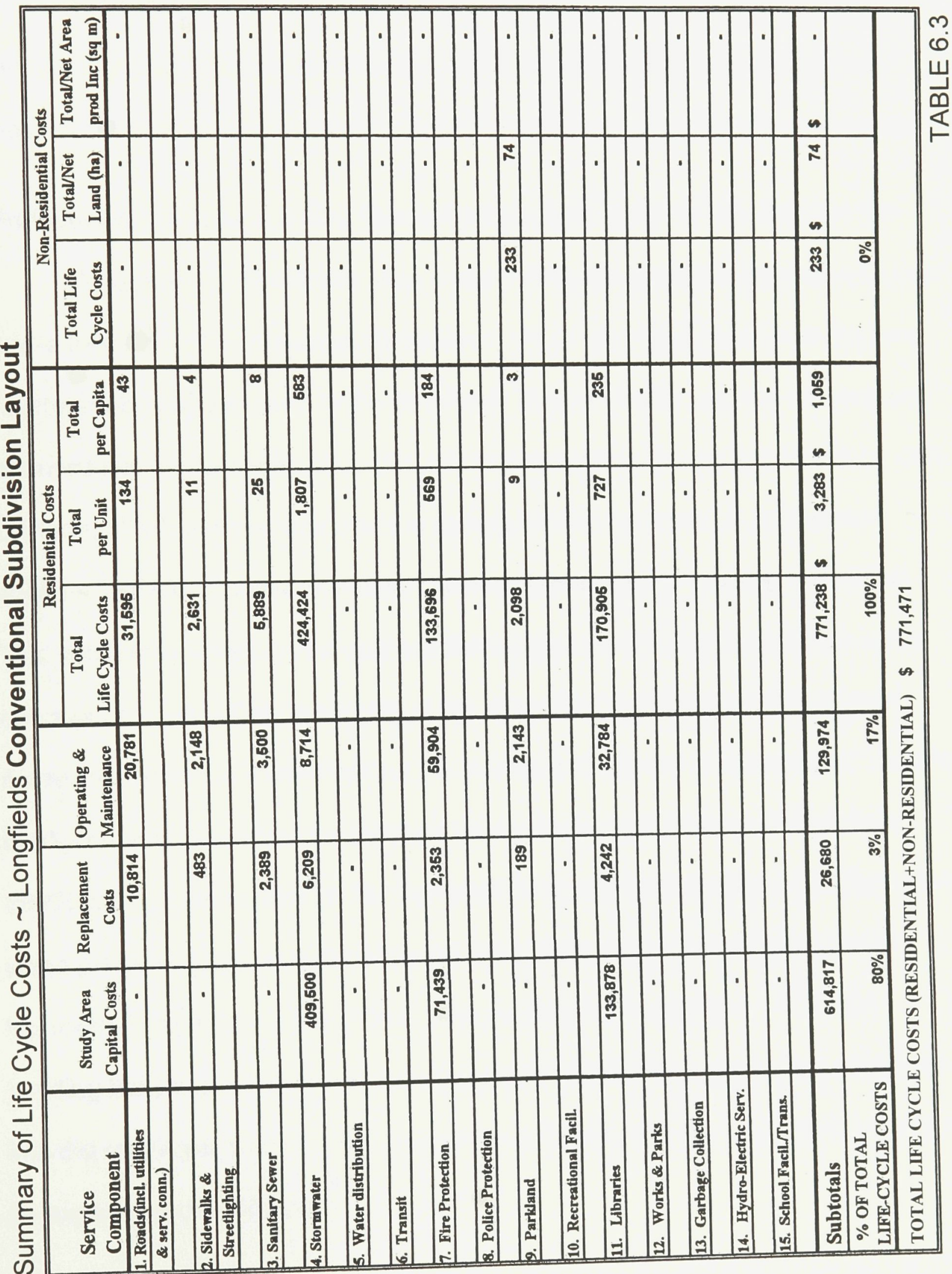




\section{Professional, Public and Development Industry Review Comments}

The concept plan development process involved working sessions with the municipal study team, and forums with both the public and development industry. Critical review comments provided by these groups are now evaluated.

Professional (Municipal Study Team) Review Comments on the Concept Plan

A surprising observation was made during the earliest stages of work and interactions with the municipal study team. Since the popularization of the term "sustainable development" in the Bruntland Report (1987), various national and international conferences have focused on the topic in the decade to follow, (IISD Canada, 1998) yet the term and the concept were unknown, or at best only vaguely familiar, to most municipal representatives on the working committee. This somewhat parallels the author's personal experience and exposure to the concept of sustainable development (as described in Chapter 4). Even more noteworthy was the discovery that the substantial volume of research by Canada Mortgage and Housing Corporation's national research division (dating from 1990) had not penetrated to the municipal level, and was largely new information when presented as background to the case study concept planning process. However, in fairness, many of the "best management practices", which are building blocks of a healthy, more sustainable community, have been integrated into the municipal planning and engineering design process for at least a decade, as experienced by the author. 
After circulation of the preliminary concept plan report to the municipal working committee for review, their comments and criticisms were fed back to the study team. The limited number of comments reflected the fact that most observations and suggestions by municipal departments had been made during the working sessions, and had been incorporated into the concept plan and summary report.

It was noted that the most critical review comments came from a very conservative engineering and works staff. Even more obvious was the split between older, "established" staff members who expressed the greatest concern over any new concepts, whereas younger professional staff seemed more open to discussion and exploration. The study team recognized that older staff members (usually in the ultimate decision-making position) could potentially be barriers to the sustainable development initiatives being proposed. However, the more open-minded attitudes of younger staff was encouraging, when considering the future of innovation in community planning.

Professional review comments were as follows:

1. The poor draining nature of the study area's soils was confirmed by porosity data, resulting in a recommendation that, although the exfiltration trench and groundwater recharge (Initiative No. 10) were interesting and worthwhile initiatives, this was not an appropriate development site, and, if tested on the case study site, the scale of the test should be limited. 
2. The advanced state of the master drainage plan and stormwater management design modelling suggested that the linear bioswale and greenway (Initiative No. 9), although seen as an interesting and positive concept for other communities, would not at this late date serve to reduce the size of the stormwater storage area designed for this sector of the Longfields community. Cost savings for this particular neighbourhood plan could therefore not in reality be projected from this initiative. It was further suggested that the linear bioswale concept would need to be brought into the planning process at a much earlier stage, concurrent with the master drainage design process.

3. Maintenance of the linear bioswale was identified as an issue. Since catch-basin clean-out of debris and sediment is a customary part of the municipality's maintenance program, detail design of the feature would have to include an area around each clean-out large enough for machine access, where minimal damage would occur to wetland and stormwater filtration plantings.

4. Porous pavements referred to in initiative No.19 are not to include asphalt surfaces since, in our climate, the longevity of such pavement relies on free draining base courses to minimize frost heave. Porous pavements should be limited to recreation amenities, pedestrian use areas and possibly limited use parking lots. 
5. Investigations of current solar powered lighting technology (Initiative No. 26) eliminated this as a suggested sustainability concept. The cost was estimated at $\$ 4000.00$ for each solar panel and special light fixture (compared to $\$ 250$ for conventional high-pressure sodium, the municipal standard). Also, the unreliability of the technology (admitted by the providers), the objectionable appearance of the large, pole mounted solar panels, together with long winters and northerly latitude of the study site all served to suggest that compromises to safety and security resulting from reduced light levels were not acceptable. Wind powered pumps for irrigation, however, could be further investigated.

6. Landscape diversity, naturalization and wildlife habitat creation concepts (Initiative No.'s 30 and 31) gave rise to concerns for the attraction of "undesirable" wildlife such as rats, skunks and racoons to the suburban environment. Resident education for composting (Initiative No. 21) both on private properties and at the central park, should describe limitations on certain materials such as kitchen wastes, meat and dairy products.

To summarize, the professional review comments which were subsequently incorporated in the concept plan were primarily directed at the environmental and physical planning aspects of the plan which, of course, is the focus of their day-to-day professional responsibilities. Existing by-laws and codes, practical concerns for emergency services and maintenance, and any 
initiatives which would result in negative public (taxpayer) reactions were of greatest concern.

Public Review Comments on the Concept Plan

Since the success or failure of local stability initiatives relies largely on the general level of public response and support (e.g., Regional Municipality of Ottawa-Carleton blue box recycling program), public interest and commentary on the sustainable development concept plan and initiatives were also gauged as part of the study working process.

The Environment Committee of the City of Nepean organized and placed newspaper advertisements for an "Environmental Symposium on Sustainable Communities", held October 30, 1999 at Nepean City Hall. This demonstration concept plan and case study were presented in a one-day public forum and later analyzed in "round-table" workshops.

The roughly fifty persons who attended represented special committees and environmental interest groups from across the Regional Municipality of Ottawa-Carleton. It was therefore noteworthy that attendees were those with a pre-disposition to environmental issues, and as was revealed during the symposium, had some prior exposure to the topic of sustainable development. Even though well advertised, the low public turnout may have demonstrated a lack of interest in or knowledge of the topic in general among the general population. As well, there were only one or two attendees from municipal departments, either of the City of Nepean or other municipalities in the region. 
Again, we took this as an expression of lack of knowledge of or interest in the topic of sustainable development.

Predictably, "public" reaction was far more wide-ranging than that of the municipal working committee and might be considered as a weakness in the study methodology since it is not a true "public" representation. Public review comments, which were manually recorded by the author and City of Nepean Environmental Committee members, have been organized to respond to the economic, social and environmental framework for sustainable development (Figure 3.1), as follows.

\section{Economic Concerns}

- The economics of the case study were discussed, in that it was recognized that the incremental cost of sustainable development versus "conventional" forms must be clearly explained to a potential purchaser/resident. This "wallet impact" was seen as a true test of the public's willingness to support more sustainable community forms. Costs should include longer term "life-cycle" costs, so as to be fully accountable when comparing more sustainable to conventional communities.

Economic / Environmental Concerns

- The "retrofitting" of existing communities to make them more sustainable was of interest in terms of both costs and techniques. 
Social Concerns

- Public or "neighbourhood level" involvement was lacking in the planning process for this case study project, and it was suggested that more "grass roots" input might have changed the range, quantity, form and support for the sustainable development initiatives being proposed. It was suggested that a "visioning" exercise, or focus group might have gathered important community input at the start of the process.

- A frustration was expressed with the slow pace of incorporating environmental sustainability into the planning process in general. Both municipal and regional government was criticized for a lack of involvement in the support and approval of new sustainable development projects, be they residential, commercial, industrial or recreational.

- Socio-cultural aspects are important when considering the design of more environmentally conscious communities, and more effort must be given to understanding these factors.

- Better public education is required to explain the value of on site community resources (both natural and man-made) and how neighbourhood residents can contribute to their protection, conservation and enhancement. 
- A sense of place, identity and "belonging" is important to the members of a successful community, and social, environmental and economic factors all play a role in creating this feeling.

Social / Environmental Concerns

- Concepts being demonstrated (as expressed by sustainability Initiatives 1-31, Figure 5.2), were seen as basic and "not innovative enough", and would not attract those looking to pay and live in a more environmentally sustainable neighbourhood. Initiatives were seen as "timid".

- The reduction of vehicular (private automobile) dependence must be addressed more aggressively through planning and zoning measures to integrate, for example, employment opportunities into communities thereby allowing for alternate forms of transportation such as walking or bicycling.

\section{Environmental Concerns}

- It was suggested that the "project specific" scale might be better for actual demonstration of more aggressive and innovative concepts, which could be built and purchased (e.g., Conservation Co-op in Sandy Hill, Ottawa). Residents of such projects have a high degree of commitment to the long-term success of such projects. Others questioned if there was an optimum size or "critical mass" for a sustainable community. It was generally felt that larger (e.g., regional) 
scale sustainability is much more difficult to achieve and maintain than the local neighbourhood scale.

- Questions arose regarding the assessment indicators, which might be used to determine if a community is sustainable.

Builder / Developer Review Comments on the Concept Plan

The economic feasibility and "mainstream" public acceptance of a more sustainable neighbourhood is ultimately expressed by marketplace willingness to purchase the constructed product at a price acceptable to the industry. This was a central concern identified as a case study objective (Chapter 4 ) and in the working sessions by the study team and the City (Chapter 5$)$.

Although the combined experience of the study team and the municipal working committee was applied throughout the development of the concept plan, further testing was deemed necessary. A focus group comprising private sector development industry representatives was organized and hosted by the City of Nepean and the author.

The six companies in attendance represented a cross-section of small, innovative builders (10-20 units per year) to larger (500 plus units per year) land developers and "tract" builders. Their invitation was a reflection of their demonstrated leadership in the local development community.

Companies represented were Denmoor Homes, Domicile Developments, Larco Homes, Longwood Corporation, Minto Development Corporation and Tartan Development Corporation. 
After a background review of the concept plan within the context of the sustainable development objectives, critical observations and comments were invited. Again comments have been organized within the economic, social and environmental framework of suitable community planning.

\section{Economic Concerns}

- Can such a sustainable neighbourhood be built and sold profitably?

- The homeowner must see some benefit from the new ideas or concepts, or they will not pay the additional costs related to these.

- The subdivision design must be flexible enough to react to economic fluctuations. Wide, shallow lots and larger homes are popular now in a strong economy, but the plan must be able to react to a market downturn.

- Even in a strong economy, buyers remain cost sensitive. The additional $\$ 1500.00 /$ unit reflected in sustainable development initiatives is another cost which might affect sales.

- The resale market seems to respond well to recovery of the cost of new ideas and initiatives. However, the initial developer has a difficult time recovering such "up front" construction costs when new ideas are introduced to the marketplace.

- Developers have no real desire to be "pioneers" of any of these initiatives. They would prefer to seek locations where ideas have already been tried, so their degree of success can be evaluated, prior 
to any investment or expenditure. Builder-developer image is harmed when new ideas and concepts fail in the marketplace.

\section{Economic / Social Concerns}

- Market research by builder developers has shown that the exterior of the home and streetscapes are not that important to many purchasers. Comparing home prices so as to maximize the interior space and amenities is often more prevalent.

- Buyers who are attracted to new concepts are often very committed purchasers, but this market is weak, usually resulting in a slower sales pace for innovative built forms.

- In the year 2000 , the local Ottawa market is improving and evolving to a preference for more design choices, as compared to the market of a few years ago. This may be largely a reflection of the current economy, and might well revert if the economy slows or stagnates.

- Builder-developers share a desire to know more about the success and failures of various ideas and concepts that have been tried in the local market place. However competition between builders more usually results in a protective attitude. Shared results might enable the advancement of concepts without duplication of error, thereby reducing the cost of experiments with new initiatives.

- Market research is required to demonstrate to the builder-developer that new initiatives are of interest to and would be accepted by the 
purchaser. However, the only true measure of acceptance is the ultimate sale of a home, whereby purchasers prove their willingness to pay the premium involved with such initiatives. Focus groups do not necessarily provide reliable data upon which to base decisions.

\section{Social / Environmental Concerns}

- The local market is very conservative, and will not readily accept design changes or innovations, especially if they are dramatic or different from the "conventional".

- Good project locations can often help overcome difficulties in marketing innovative concepts.

- A "sense of territory" is very important in the local market place. For example, 50-75 units of the same type located together in a subneighbourhood is normal within a larger community context.

Purchasers are not so much concerned about the quality of design of lower cost residential units as they are about the residents of those units and their impact on neighbourhood "quality of life" and resale value.

\section{Environmental / Economic Concerns}

- Streetscape can be negatively affected if various unit types and forms (large singles, small singles, towns and terrace homes) are located in proximity (as opposed to the aforementioned "sense of territory"). However, if unit designs are more expensive, allowing for a higher 
quality of architecture, materials and detailing, these negative effects (or perceptions of such) are often overcome.

- The marketplace is now responding positively to new concepts (such as wide, shallow lot configurations). Development costs may be higher, but potential higher densities offset these costs. Streetscapes and general community livability and aesthetics have been improved and better quality streetscapes and visual appeal are now helping with sales efforts.

- The linear bioswale alternative to stormwater management is a concept which should be further explored and test cases built for monitoring. If current municipal development charges for the use of stormwater management ponds and related maintenance can be reduced as a result of this initiative, the development industry might be able to lower their construction costs which ultimately might improve home affordability. Contributing to such social equity concerns is an objective of sustainable development (Figure 3.1, Table 3.3).

\section{Environmental Concerns}

- The size or "mass" of communities being developed which incorporate many new concepts is often a key to market appeal. If projects or neighbourhoods are too small, such as early efforts in Centrepointe, Nepean they may not be as successful. Cornell (outside Toronto), Mackenzie Town (near Calgary), Bois-Franc in Montreal and the 
Celebration community by the Disney Corporation in Orlando are current examples (provided by the City of Nepean Planning and Development Department and visited by members of the Study Team) of larger, successful neo-traditional communities.

- Climate concerns, especially snow storage and removal, are well known to local purchasers. More dense designs which incorporate rear lanes must address this issue or they will not be successful.

- A dichotomy exists between local municipal governments (wishing to depart from the prevailing, 1970 s to 1980 s community form and aesthetic) and builder developers who are requesting development approvals for more of this same product, exemplified by the garagedominated streetscape. Unfortunately, builder developers and municipal surveys have demonstrated that many residents are quite happy in their "1980's design" neighbourhood, notwithstanding objectionable (to Planners at the City of Nepean and the study team) aesthetics.

- The linear bioswale (Initiative No. 9) and exfiltration trench (Initiative No. 10) stormwater management initiative might be more acceptable if tested on another site not outletting stormwater to the Rideau River, since stormwater quality criteria for the Rideau are quite stringent. Possibly an east or west end site outletting to the Ottawa River would be better suited to advance this initiative. 
- The fact that the stormwater management program for Longfields is already in place is a positive aspect for the testing of the new stormwater initiatives in this demonstration project. If the test scenarios are not as successful as desired, the "existing" stormwater management system is there as a back up, at minimal reversion cost.

- Parking along collector roads such as Longfields (parallel or angle) is a positive suggestion, necessary for the provision of commercial space but also providing a substantial traffic calming effect.

- The modified grid or neo-traditional designs for communities relies on on-street parking to be successful (e.g., for visitor parking). Developers must be able to alleviate purchasers' perceptions that convenient parking (e.g., rear lanes concept) will be difficult.

- Zoning should allow for maximum flexibility so as to react to future changes in marketplace demand, allowing, for example, reversion to residential usage if commercial ventures are not successful, or viceversa.

- Consideration should be given to eliminating the "lot coverage" calculation from the zoning by-law. Consider rather the overall performance of a project in the community. If the design, setbacks, parking, access, and so on all perform successfully as far as the municipality's professionals are concerned, then coverage should not be a concern. 
- There are existing examples of some of the concepts, initiatives and "best management practices" as described for this demonstration project, but no local example where so many initiatives are integrated into a single neighbourhood. Even though the number of initiatives proposed had been reduced during the working sessions with municipal staff (Chapter 5), builders expressed a concern that there were still too many "new ideas" for a conservative marketplace to accept.

- Public Works concerns for snow removal and garbage pickup should not drive community design. A desire for better, healthier, more appealing neighbourhoods should be first priority. Servicing concerns are realistic requirements to be worked out by all Departments involved.

- A residential development zone should be structured in such a way that objectives (e.g., sustainable development) are set as goals, but the marketplace should drive decisions as to the variety of land uses which occur within this zone.

- More work is required for residential lots (with rear lanes) fronting onto collectors and arterials. They are usually perceived as poor quality lots, where sale price is discounted. Streetscape improvements, additional traffic calming and so on might be further discussed. 
At the turn of the $21^{\text {st }}$ century, government policy is not oriented towards the research, development, funding and construction of large scale social housing and new publicly sponsored communities. Consequently, it is up to the private sector development industry to deliver more sustainable neighbourhoods. Many of their concerns and criticisms are effectively barriers to sustainable development, and will be reviewed further in the conclusions, Chapter 7. These must be addressed as the concept plan advances to the final design, land sale, subdivision and site plan submission stages.

\section{Summary of the Barriers to Local Sustainable Development and Recommendations for Advancement}

The preceding critical review of the concept plan revealed barriers to local sustainable development. These barriers can be reviewed from the perspective of the professionals, who prepare, review and approve community plans; the public who purchase homes and live in these neighbourhoods, and the investment and development industry whose response to public demands in the marketplace, is linked directly to success and profitability.

The critical review comments by these groups, and the barriers they reveal, form the basis for the authors, assessment of the performance of the concept plan with respect to sustainable development performance.

Five areas, to varying degrees, were found to form the basis for the barriers: education; cost; community participation and stewardship; environment; and social attitudes and trends. 


\section{Education}

1. Improved awareness in the community in general as well as amongst potential purchasers of the social, environmental and economic objectives of sustainable development is needed. For example, linkages to global environmental problems can be explained. Opportunity for individuals to "make a difference" does exist at several levels.

2. There is a requirement for improvements to municipal, interdepartmental co-operation, as the debate continues over the creation of better, healthier, more sustainable communities. A balance must be found between planning and design objectives and concerns for servicing, maintenance and public works requirements.

3. The public/purchaser must be better exposed to the costs and benefits of sustainable development initiatives whenever possible, together with new and improved development concepts, so as to educate, inform and thereby create new demands and broaden the preferences of a current, predominantly conservative attitude in the marketplace.

4. Testing of the demand for, and feasibility of, sustainable development initiatives with the public/purchaser should be carried out prior to investment. Means and measures for improved sharing of results of the testing of new concepts among the development industry should be found, and possibly the provincial and national homebuilders associations can play a central role in this regard. 
5. As the concept plan advances to the detail design and construction stage, comments collected from the development industry (Chapter 6) are to be considered as they will affect the overall neighbourhood concept, architecture and built forms.

6. Visibility and integration of sustainable development at the local level can be greatly improved from its current low profile and underexposed state. Shifting the focus from a national (CMHC research division) to the local (City / municipal) level will immediately require the engagement of those on the "front line" of community planning and design: private sector consultants and development industry professional staff and municipal review and approval professionals. Official plans, zoning documents, subdivision agreements and site plan approval submissions should contain greater sustainability requirements. For example, stormwater management design requirements and existing forest cover preservation reports are indicators of how such regional and municipal requirements have readily been accommodated by the review and approval agencies and the development industry, and are now generally accepted as "best management practices". This case study recommends an extension of such requirements to incorporate greater neighbourhood sustainability. 
Cost

1. Economic conditions (national, provincial, local) have a direct effect on the future of sustainable development locally, since a strong marketplace invites the trial of new ideas and concepts by the development industry. Results of unsuccessful experiments are "buffered" by strong sales volumes, and are much less critical to project profitability. Timing, therefore, may play a role in the advancement of aspects of local sustainability, since the recovery of the initial construction costs by the original builder/developer is central to the implementation of sustainable development initiatives, and this is most likely to occur when the economy is healthy and growing.

2. The costs involved with both market testing, as well as postconstruction monitoring or sustainability auditing (measuring the real progress or lack of progress towards sustainability) is a barrier for the investment and development industry, who regard such efforts as costly and a complication to an already time consuming development review and approval process. Municipal governments are best suited to take on this role initially, recovering costs through development and permit charges. Once established and demonstrated to the private sector, and if accepted by the public/purchasers, the development industry will, from experience, probably assume this role under mechanisms such as site plan review and approval process or deposit of financial securities. 
3. The relatively low cost of environmental resources such as treated water and soil amendments like peat moss and fertilizers become barriers to the reduction of potable water use, recycling and other such initiatives, since these approaches are perceived to be more time consuming and less convenient. As well, a separate, untreated water system for an entire community is very expensive, and would have a major effect on affordability. Continued research, education, promotion and standarization of the environmental benefits of water re-use and recycling will be necessary, if legislation and local by-laws are to be modified.

\section{Community Stewardship And Participation}

1. The level of interest in neighbourhood environmental programs is improving, but remains far from "mainstream" in current society, where for most families, free time to invest in one's community is perceived as limited. Without real community stewardship being demonstrated to municipalities and demanded of the development industry, significant stewardship initiatives will not be incorporated into new neighbourhood plans.

\section{Environment}

1. Weather and climate in the Ottawa region is a major deterrent to the advancement of many sustainable development concepts, and figures prominently in municipal inter-departmental debates over community 
planning and form, since there are direct expense and maintenance implications. As well, response to transit services and other alternate modes of travel are very weather sensitive in this area.

2. Sustainable development must be considered at the land assembly stage, when master drainage and stormwater management studies are underway. If neighbourhood scale stormwater initiatives are to be successful and realize the cost savings demonstrated in this case study, an overall sustainable stormwater policy for the entire community should be addressed.

3. Certain initiatives (e.g., exfiltration trench) are limited by neighbourhood geography - soils, relief, drainage, microclimate, and proximity of a local watercourse. Inter-municipal co-operation is required to identify and undertake several site studies in different environmental conditions so as to test various sustainability initiatives and share and compare results.

4. Some current technologies (e.g., solar powered lighting and grey water use) must be further researched and developed so as to become feasible for incorporation into neighbourhood plans. As well, current regulations (e.g., grey water re-use and recycling) need to be modified after testing of improved technologies. Improved linkages are required between the design community and sustainable technology equipment suppliers, and this industry must work with municipal approval agencies 
to achieve standards of acceptance for use of their products for use in neighbourhoods. The development industry will not include, nor will municipalities approve, such features in new communities until proof exists of the availability and acceptable, economical technologies.

5. Local climate remains to be a major factor in the reduction of personal vehicle use. Mass transit service will need to become more convenient and significantly less costly than the private automobile to become more accepted and widely used, thereby reducing vehicular trips. High fuel prices, downtown parking costs and reduced investment in new road construction and maintenance must be balanced against transit investment to assist with an attitude shift.

6. Continued development and testing of more flexible approaches to zoning (e.g., residential mixed use, alternate development standards, spot zoning, right-to-light considerations, deletion of lot coverage requirements, development charges and levees) will invite more creativity from the planning and development industry to implement sustainable initiatives and demonstrate new built forms.

Social Attitudes and Trends

1. Reduction in the level of neighbourhood landscape maintenance and the acceptance of more naturalization continues to be difficult in a society with a cultural preference for a more manicured, highly maintained neighbourhood landscape. Demographics may assist in this 
initiative, as it appears (from the author's personal experience) that younger generations are more accepting of natural areas and increased landscape biodiversity.

2. Although current movements such as neo-traditional planning have raised the profile of community social interaction, the development industry and municipal departments continue to focus on physical planning and economics of new neighbourhood developments. Social aspects such as affordability, equity and community participation require a much higher profile in more sustainable neighbourhood planning.

3. Public/purchaser resistance to the integration of various forms and types of housing or smaller land parcels within a neighbourhood, and the continuing demand for "homogeneous" zones of housing type, is a barrier to improving the social aspects of sustainability. Self-interest, perceptions of "investment protection" and resale values prevail, and must be addressed if the development industry is to re-think community composition, streetscape and built form integration. This current public attitude (sometimes described as the N.I.M.B.Y. syndrome, meaning not in my back yard) underscores the fact that it is we - society in general - who are limiting the local level of response to many local sustainable development initiatives. 


\section{Concept Plan Sustainability Performance}

The matrix in Table 6.4 has been developed to assess the concept plan's sustainable development performance.

An understanding of the difficulties in advancing local sustainable development, expressed herein as barriers, leads to an evaluation of the performance of the concept plan when compared to the major aspects of healthy, sustainable communities as defined by CMHC's research division in Table 3.3. The case study's sustainability initiatives (Figure 5.2, No's 1-31) are assessed for their rate of response against CMHC's seven broadly stated objectives. If no rating of response was given, that initiative was not seen as applicable or had no demonstrable affect on that particular aspect of community sustainability.

A high to low "probability for implementation" rating has been drawn from critical review comments and barriers as expressed by the professionals, the public and the development industry.

Initiatives (No's 1-31) contribute varying degrees of community sustainability, and therefore it can be said that some are more important for implementation and achieving sustainability than others. Consequently, the author has carefully assigned an importance weighting number to each, all the while cognisant of the potential for personal inter-generational bias discussed in Chapter 3 (leading up to the framework for global sustainability Figure 3.1) 


\begin{tabular}{|c|c|c|c|c|c|c|c|c|c|}
\hline \multirow{2}{*}{\multicolumn{2}{|c|}{$\begin{array}{c}\text { Case Study Concept Plan } \\
\text { Sustainability Performance } \\
\text { Matrix }\end{array}$}} & \multirow[b]{2}{*}{$\begin{array}{l}\text { Implament } \\
\text { Probability } 1 \\
\text { importance }\end{array}$} & \multicolumn{7}{|c|}{ Major Aspects of Sustalnability in Community Planning (See Table 3.3) } \\
\hline & & & $\begin{array}{c}\text { Resource } \\
\text { Conservation }\end{array}$ & $\begin{array}{c}\text { Environ. } \\
\text { Impact } \\
\text { Reduction }\end{array}$ & $\begin{array}{l}\text { Eoonomic } \\
\text { Viabllty }\end{array}$ & Equily & Liveability & Community & $\begin{array}{c}\text { Heath and } \\
\text { Safety }\end{array}$ \\
\hline \multirow{7}{*}{ 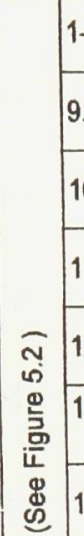 } & 1-8 Built Forms/Unit Types & $1 / 1$ & & & $\mathbf{M}$ & H & H & $\mathbf{H}$ & M \\
\hline & 9. Linear Greenway/ Bioswale/ SWM & $1 / 2$ & & $\mathbf{H}$ & $\mathbf{M}$ & & $\mathbf{M}$ & & \\
\hline & 10. Ex Filtration Trench/ SWM & $3 / 2$ & & $\mathbf{H}$ & $\mathbf{L}$ & & & & \\
\hline & 11. Reduced Slope Grading & $1 / 2$ & & M & $\mathbf{H}$ & & & & \\
\hline & 12. Alternate Standards/ Road ROW's & $1 / 2$ & $\mathbf{M}$ & & $\mathbf{M}$ & & H & H & \\
\hline & $\begin{array}{l}\text { 13. Buried Utilities/Snow Storage/ Street } \\
\text { Trees }\end{array}$ & $1 / 3$ & & $\mathbf{M}$ & & & $\mathbf{M}$ & & \\
\hline & 14. Passive Solar Layout and Design & $2 / 2$ & $\mathbf{L}$ & $\mathbf{L}$ & & & $\mathbf{M}$ & & $\mathbf{M}$ \\
\hline \multirow{6}{*}{ 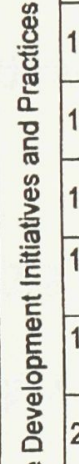 } & 15. Windbreaks/ Cooling Breezes & $2 / 3$ & $\mathbf{L}$ & M & $\mathbf{H}$ & & $\mathbf{H}$ & & \\
\hline & 16. Shade for Cooling & $2 / 2$ & $\mathbf{L}$ & $\mathbf{M}$ & $\mathbf{H}$ & & H & & \\
\hline & 17. Right to Light/ Sun Considerations & $2 / 2$ & & $\mathbf{L}$ & & $\mathbf{M}$ & H & $\mathbf{H}$ & H \\
\hline & $\begin{array}{l}\text { 18. Residential Stormwater Storage and on } \\
\text { Site Use }\end{array}$ & $2 / 2$ & $L$ & $\mathbf{L}$ & $\mathbf{H}$ & & & & \\
\hline & $\begin{array}{l}\text { 19. Landscape Design for Reduced Water } \\
\text { Requirement }\end{array}$ & $1 / 2$ & $\mathbf{M}$ & $\mathbf{L}$ & & & & & \\
\hline & 20. Community Gardens/ Food Production & $3 / 3$ & $\mathbf{M}$ & & H & & $\mathbf{H}$ & $\mathbf{H}$ & \\
\hline \multirow{6}{*}{ 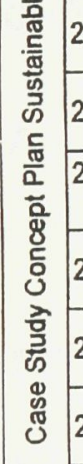 } & 21. Irrigation and Composting & $3 / 3$ & $\mathbf{L}$ & $\mathbf{M}$ & H & & $\mathbf{L}$ & $\mathbf{H}$ & \\
\hline & 22. RMOC Compost Supply Utilization & $2 / 3$ & $H$ & $\mathbf{M}$ & H & & & & \\
\hline & $\begin{array}{l}\text { 23,24. Central Hazardous Waste Storage } \\
\text { and Emergency Services } \\
\end{array}$ & $3 / 3$ & & M & & & $\mathrm{H}$ & $\mathbf{M}$ & $\mathbf{H}$ \\
\hline & 25. Community Stewardship & 2/1 & & & $\mathbf{H}$ & $\mathbf{M}$ & H & $\mathbf{H}$ & $\mathbf{M}$ \\
\hline & 26. Solar Powered Site Lighting & $3 / 3$ & M & $\mathbf{L}$ & & & $\mathbf{L}$ & $\mathbf{L}$ & $\mathbf{L}$ \\
\hline & 27. Reduced Vehicular Trips & $1 / 2$ & $\mathbf{M}$ & M & $\mathbf{H}$ & & M & & $\mathbf{H}$ \\
\hline & 28. Community Policing, Safety and Security & $1 / 2$ & & & & $\mathbf{M}$ & $\mathbf{H}$ & H & H \\
\hline & 29. Universal Accessibility & $1 / 2$ & & & & $\mathbf{H}$ & $\mathrm{H}$ & & H \\
\hline & $\begin{array}{l}\text { 30. Landscape Diversity and Reduced } \\
\text { Maintenance }\end{array}$ & $1 / 2$ & & H & & & $\mathbf{M}$ & & \\
\hline & 31. Wildlife Habitat Creation & $1 / 3$ & & M & H & & M & & \\
\hline
\end{tabular}

LEGEND:

1/1 = High Probability for Implementation / Very Important for Implementation $2 / 2$ = Medium Probability for Implementation / Important for Implementation $2 / 2$ = Medium Probability for Implementation / Less Important for Implementation
$\mathrm{H}=$ High Contribution to Sustainability $M=$ Medium Contribution to Sustainability $L=$ Low Contribution to Sustainability

TABLE 6.4 
Initiatives rated $H, 1 / 1$ and $1 / 2$ have a high degree of contribution to community sustainability, and are regarded as most important for implementation in new community planning and development. The rating assigned may reflect their current status as a tried and proven "best management practice" (which should be more widely applied), or they are relatively economical for the development industry to implement. Such ratings might also have been assigned to reflect a high probability of municipal acceptance without requiring additional time delays in the review and approval process.

Strategies which probably will not be implemented early on are rated $M, L$, $2 / 3$ and $3 / 3$ as a result of currently inappropriate technology or regulations, physical geography limitations, or will require a level of community involvement and stewardship which has not yet been achieved.

Analysis of the Matrix

The following analysis of patterns demonstrated by the $H, 1 / 1$ and $1 / 2$ ratings in the matrix (Table 6.4) is provided to explain the rationale for the assignment of the ratings, and to reveal other factors which contributed to the importance of each initiative.

Built forms and unit types as conceptualized may be seen as the greatest contributors to community sustainability in the short term. They contribute directly to social equity by offering an improved range of choice, adaptability and affordability for families, seniors and the physically challenged. The moderate intensification made possible by these built forms reduces land consumption, 
thereby lowering development costs. All are designed to improve streetscape quality, social interaction on the streets and in public spaces, and lend vitality and choice to the community living environment.

Beyond the potential economies demonstrated by the linear greenway and bioswale initiative, a willingness has been expressed by both the public and the private sector for the implementation and monitoring of this initiative. The concept contributes as well to an improvement to community recreation choices as a passive green space connection.

Reducing the slopes in community grading plans is a simple, regulatory modification which adds no additional cost, yet serves to reduce pressure on the downstream stormwater collection and treatment system. Suggested originally by the municipality, implementation should be straightforward.

New alternate standards for roadways provide for a substantial reduction in land consumption thereby contributing to lower development costs. Community streetscape, social interaction on the streets and community policing all should benefit. This strategy will be implemented when the case study land is developed, thereby offering a monitoring opportunity.

Community stewardship and participation programs exist in the City of Nepean and elsewhere. Interest (especially among the baby-boomer generation whose families have matured) may be seen to increase over the upcoming years. If this occurs, the municipality will benefit from a reduction in maintenance costs, while community landscape will be improved. Residents by these actions and 
their involvement, increase their commitment and sense of belonging to their neighbourhood, a desire clearly expressed during the public forum conducted as part of this case study (Chapter 6).

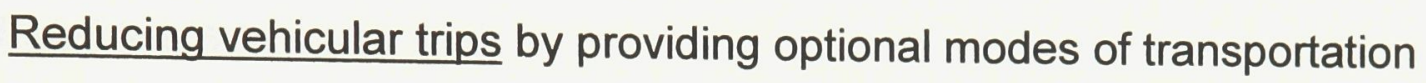
(pedestrian and bike use as well as transit services) is a practise already well established at both a regional and municipal government level. Environmental and resource conservation benefits are obvious, and contributions to a safer and healthier community are related, valid benefits. It remains to be seen whether the presence of these options, and ease of access to them as provided by the concept plan (Figures 4.1 and 5.2), will prompt any significant increase in use.

Forethought, social conscience and good design - not huge expenditures - are required to improve community safety, security and provide for universal access in both residential areas and public open spaces. These initiatives also contribute to social equity by improving the living environment for all age groups and for those with physical disabilities.

Municipal willingness and public interest in reduced levels of landscape maintenance, more diverse landscape types and urban wildlife habitat creation is improving. Such practises not only reduce impact on the environment but result in more interesting and educational communities.

Assessing the major aspects of sustainability in community planning (as expressed by the vertically arranged columns) indicates that most of the initiatives proposed are quite economically viable. These initiatives were 
specifically selected at the outset (as described in Chapter 5) to be so, in order to enhance their chances of implementation by the development industry.

As well, strategies which demonstrated the highest potential effect for the lowest cost were suggested. Many of these "best management practices" have been, and are still being, implemented on a limited basis in new developments across the Regional Municipality of Ottawa-Carleton.

Community livability, health and safety benefit from many of the lowest cost strategies proposed. Changes in by-laws, planning and building regulations and improved community stewardship are the primary requirements for the integration of these worthwhile concepts into new communities.

Social equity may be derived more effectively through other means than the physical planning aspects of sustainability (the focus of this case study). For example, the construction of more, and affordable rental accommodation, social housing projects and improved integration of housing types for a variety of income levels into neighbourhoods are of more direct and immediate effect. However, the built forms, unit types and universal accessibility in new communities can be improved, based on case study recommendations. 


\section{CHAPTER 7 CONCLUSIONS}

\section{Summary and Limitations of the Case Study}

This case study has attempted to meet several key objectives: to develop a neighbourhood concept plan demonstrating sustainable strategies; assess related cost implications; identify barriers to local sustainability and consider requirements to overcome them for improved acceptance, and to re-invest in the sustainable development learning cycle.

The concept plan incorporating practical strategies for improved neighbourhood sustainability was developed, with the input of a professional interdisciplinary team. After review by City Departments, the neighbourhood plan was approved and considered to be realistic for use in advancing discussions with the development industry (with the ultimate goal being the sale of the property). It is the City's desire that the development community implement some or preferably all of the sustainability initiatives proposed consistent with Departmental goals for the demonstration of new community development concepts on this City-owned land.

Cost comparisons were then completed to show the actual construction costs of the sustainability initiatives proposed so as to understand clearly their effect on residential affordability. In this way, the case study demonstrates local level response to the global, social equity concern of sustainable development. The life cycle cost comparison of the concept plan with a conventional neighbourhood plan revealed a roughly $17 \%$ long term potential economic benefit 
from the sustainability strategies in the concept plan, primarily achieved through new stormwater management concepts.

The learning cycle of sustainable development will benefit from the reinvestment of knowledge gained through this case study process. Results have been provided to professionals at the municipal level, who are responsible for the continued assessment and approval of this and other concept plans as they advance to detail design (which is now underway) land sales and construction. In response, the City has already developed a new residential mixed use zoning bylaw which will allow the case study's architectural and built form designs to be further developed and to be incorporated into neighbourhood plans.

The City will consider an application to $\mathrm{CMHC}$ for a research grant to continue with the detail design and post-construction monitoring of this case study concept plan. Results of this case study will at that time be shared with CMHC's research division.

This case study provides a new source of reference for others interested in continued research into local sustainable development, whether at an academic or professional level. Unlike most studies implemented for municipalities, the results of this thesis, when filed with the university, will be available to a potentially much wider audience.

Testing responses to the case study concept plan with the professionals, the public and development industry representatives (the first time for such a process in the Regional Municipality of Ottawa Carleton) revealed various 
barriers to local sustainable development. Barriers identified in this case study, and the recommendations to overcome them, present the immediate challenge for local, neighbourhood sustainable development. Many recommendations are simple and obvious, and yet, unless championed by the local municipal government, the author foresees a painfully slow integration of these aspects of sustainability into new communities. This finding verifies the decade-old prediction of Rees and Roseland (1991:15-26) wherein they called for municipalities to take a much more central role as sustainable development projects were to be built, monitored and comparative cost data audited by the development industry.

As a local level of response to a national and ultimately global agenda, the case study demonstrated strengths and weaknesses as earlier expressed in the sustainability performance matrix, Table 6.4. Although many aspects are demonstrated to be economically viable or beneficial in the short and long term, and community environment and liveability are notably improved, the scale of initiatives and responses possible in one neighbourhood seem insignificant considering the magnitude of the global challenge.

The timing and nature of public input could have been improved. As discussed, attendance at the public forum was not representative of the general public, and they were asked to comment on a case study concept and specific proposed initiatives, rather than participate in their formulation. Results may have been quite different had public input been invited and gathered earlier. 
The "transferability" of lessons learned from this case study might also be questioned. The City of Nepean is not typical of most Ontario municipalities, in that it enjoys a debt free status and above average levels of income and employment. Consequently, municipal policy decisions regarding built forms and densities, provision of open space and leisure amenities, transit services and so on might not be "typical". As well, the case study was conducted during a very prosperous period of growth and expansion, possibly affecting economic considerations and willingness to accept the risks involved with innovative development concepts.

The City of Nepean's impending amalgamation also transfers risk and responsibility for the case study to the greater City of Ottawa. However, sharing of information with the other regional municipalities may actually, as a result, be facilitated.

The municipal working committee's lack of exposure and understanding of the global significance of sustainable development may have overshadowed attitudes and intentions toward the importance of implementing and testing the concept. Further, there was a high level of concern for the ultimate sale of the case study land to the development industry, resulting in economic and "approval process" concerns being foremost in their decision making.

The development industry demonstrated an even more pronounced ignorance of the sustainable development paradigm, and a great degree of scepticism about the case study "exercise", and reluctance to accept their role in 
responsibility. Even though the concept plan and most initiatives proposed were simplified to ensure both their understanding and affordability, the conservative nature of the purchasers and, as a result, development industry representatives, caused resistance to any new responsibilities, costs or regulations. This will be a major limitation to the next logical steps in this process - the construction and monitoring of the plan and its component initiatives.

The case study created a concept plan, and sustainable development guidelines for application at the local level, with no method or intent of enforcement. Rather, their possible inclusion in the development of actual site plan applications (wherein the municipality does have regulatory control) may result in the implementation of some of the initiatives. This will only occur if there remains a commitment to the case study and its role in advancing community sustainability. From the author's personal experience, things such as municipal staff changes and budgets, politically driven land use priorities and larger events such as the imminent municipal amalgamation can easily derail the best intended plans.

The timing of the case study directly limited opportunities for the realization of one of the initiatives with the greatest potential economic benefit, stormwater management (Figure 5.12). It is now understood that such new initiatives must be considered when land is being assembled and the drainage master plan is being computer modelled. 
As well, the physical geography of the site (specifically soils and groundwater conditions) limited the inclusion of other strategies of interest to both the municipality and the development industry such as the exfiltration trench (Figure 5.13). Consequently only limited (if any) construction of this initiative will be carried out, making the monitoring of results less reliable and transferable.

\section{Linkages to the Global Vision for Sustainable Development}

The global paradigm for sustainability embraces a world society which is a wise steward of resources and the environment and is founded on principles of social justice and equitable treatment. The term, however, is largely misunderstood as demonstrated by its often cryptic misuse as a politically-correct slogan in the media and elsewhere, by many who have little comprehension of its global origins or the significance of its unquestionably clear imperative - to sustain life.

How we achieve sustainability is less clear. Optimism and scepticism infuse the continuing debate over the role of sustainable development in the resolution of global inequities. The largely impoverished Third World needs food, employment, income, health care and social development, yet there seems little or no political consensus as to how to address such international and intergenerational and other imbalances, as earlier reviewed in Chapters 2 and 3 . Although small steps at the local level are being made, the chances of a shift in societal attitude towards a more holistic world view appears hopelessly remote, as a free market system expands capitalism around the globe. 
Closer to home, those of us involved in the process of planning, designing and managing environments within communities are advised to take the long view of sustainability, in that at a global and national scale, we seem to be well versed in policy but are short on real measurable results. A knowledge and implementation gap exists, as argued by the Canadian Commissioner of Sustainable Development (Government of Canada, 1998).

In the new millennium, we can expect our children to face new environmental dilemmas, many larger and more difficult to cope with than those we currently face, even though they will have the benefit of ever improving technology. The massive scale of issues such as biodiversity, climate change, ozone and forest depletion, global fresh water supply - still are largely regarded as being beyond the average citizen's ability for response in any meaningful way. At the same time, it is clear that we do not have the luxury of time and procrastination; an in-depth knowledge of the problem of global sustainability will not fix it! We must move ahead even though we as a society will probably never arrive at a universally acceptable strategy. Perhaps, because of equity and sociocultural diversity, a universal strategy is not even feasible.

This case study has subscribed to "thinking globally while acting locally", and has explored methods whereby several of the global guiding principles for sustainability, as prescribed in Our Common Future (WCED, 1987) can indeed be addressed at the local level, with varying degrees of success. 
Although economic and international trade systems, two of the Bruntland Report's principles, are beyond a local scale of response, other aspects can be addressed.

Opportunities for effective citizen participation (political systems, as referred to in the Bruntland Report) may be provided for in early public focus groups. Ideas may be drawn from these to formulate planning concepts for new neighbourhoods. Such focus groups provide an indication of the public's views, which are required by planning departments and politicians in the decision making process which leads to land use decisions at the official plan and zoning stage.

However, the several community resources and stewardship concepts proposed (such as the extended social systems referred to in the Bruntland report) will probably be limited in their success since a minority of citizens appear willing to invest personal time and energy into such community undertakings. The development community, recognizing this situation, is therefore reluctant to invest in the implementation of such ideas, and so public exposure and education to the benefits of such initiatives are very slow to advance.

Community activism in the year 2000 is higher than it has been (in the author's three decades of past professional experience), and is causing municipal councils and bureaucrats (administrative systems, as referred to in the Bruntland report) to revise and adjust the way in which decisions are made. This 
must continue, and probably increase, if administrative systems are to remain responsive and "self-correcting" at the local level and beyond.

Our Common Future stated that production systems should be obligated to protect the environment. Local production systems can preserve valuable natural community resources, and provide open green space for the reinstatement of "natural" areas.

Opportunities for community and private yard gardens to provide limited food production opportunities, but again the probability for implementation and success of such ideas depends upon a seemingly low degree of public interest, notwithstanding the incredible increase in "gardening" as a western world hobby.

Several of the sustainable development initiatives in this study propose new technical systems that can be studied and improved over time. Stormwater management concepts, architectural and built form arrangements, and improved, flexible zoning approaches are technical responses which require testing and continued revision for improvement.

In Chapter 2, the WCED's guiding principles for sustainable development were formulated into common language "mission statements"; requiring new approaches to development and decision making, and the application of improved technologies.

In response, the concept plan does suggest a new development approach, clearly recommending against the introduction of complex, costly initiatives which become potential barriers to implementation. The case study 
further demonstrates life-cycle cost accounting, which must improve and simplify as the process evolves. Economic viability, along with the application of other measurable sustainability indicators, must be further applied and studied by those with appropriate expertise as part of a long term process of sustainability auditing and learning. Only then will we be able to measure improvements over our past community planning and design efforts.

Planning and design decisions which have shaped the concept plan attempt to incorporate the social, economic and environmental aspects of sustainability. However, the physical planning of communities has historically placed economic (and to a limited extent, environmental) considerations above social aspects. This case study attempts to increase social considerations, but there is only slight probability for implementation of the initiatives proposed due to a current low level of public interest. Other limitations (as well as potentials for the future) are discussed below.

\section{Potential Future Work in Local Sustainable Development}

Over the next decade, the author expects to see, initially, more environmentally responsible approaches to the current, neo-traditional planning movement. Co-housing, intensification of existing neighbourhoods, eco-villages, pedestrian pockets and other examples of local neighbourhood innovation will demonstrate features believed to improve community health and sustainability (CMHC, 1999). Adult communities, life lease projects and seniors' developments offering a full range of health care will respond to the demographic profile of aging baby-boomers. All will seek to break out of the conventional suburban 
mould, and borrow certain sustainability concepts (probably those demonstrating greatest public acceptance for least cost) from each other as they advance.

It is further suggested that, in order for sustainable development to take a much higher profile in the current regional land planning and policy debate, it must address a current and basic discord between the public and the region's politicians and planning bureaucracy. Through the official plan and long range policy statements, growth has been re-directed toward urban and suburban infill (lands with existing infrastructure services). Notwithstanding the economic and environmental sustainability of this policy, the public at large, as evidenced by (local) sales statistics from the Corporate Research Group (February 2000), is still drawn overwhelmingly to suburban forms of development. Further, the author's personal experience indicates that well organized and widespread community opposition to any form of neighbourhood infill development will continue to dominate local level municipal hearings for the foreseeable future.

However, when continuing to develop processes for the assessment of sustainability (as discussed in Chapter 3), and applying indicators to monitor the future of these case study lands (and other, yet-to-be-seen sustainability initiatives), we must not lose sight of the social, cultural and income disparities that are evident in many Canadian communities. We must determine the direct effects of our well-intended efforts to increase community sustainability on the cost of renting or purchasing the most basic of accommodation. We must be certain that our efforts are indeed resulting in a better product - healthier, more 
livable communities, rather than a protracted sustainable planning and design process, serving only to contribute to higher development costs. This implied inter-generational equity concern should be the highest priority of agencies such as $\mathrm{CMHC}$, as sustainable development is promoted nationally, and of local municipalities who will ultimately implement new policies and programs.

There are some specific tasks which offer opportunities for further work in sustainable development. First of all, there is a need for much wider education regarding the concept of sustainable development and how local events may contribute to global results. As a result, public and community participation in sustainability initiatives will hopefully increase. The planning and development community, when better informed, might become more supportive of and committed to the objectives of sustainable development.

Geography provided an educational "bridge" to widen the horizons and enrich the professional and academic career of the author, as mentioned in the introduction. Geography and environmental studies programs may potentially play a similar role for many others by taking a leadership role in advancing sustainable development education. There is a body of geographic literature and knowledge which could bridge the information gap now evident to the author in other disciplines which deal with human intervention and the natural environment such as planning, engineering, architecture and urban design. Geography should continue to challenge the sustainable development paradigm as it evolves, expand and update the existing wealth of geographic research literature, and 
ensure graduates have at their disposal the necessary tools to promote the cause of sustainable development as described in Chapter 2 by Boyce (1995:1217), Turner (1993) and Wilbanks (1991:541-556).

There is considerable municipal and development industry interest in both the linear bioswale/stormwater management strategy (Figure 5.12) and the infiltration/exfiltration trench infrastructure design (Figure 5.13). Both initiatives should be further detailed and test cases constructed for monitoring. These concepts represent low cost concepts yielding (potentially) considerable economies which will, if proven workable, achieve development industry and community acceptance.

All built form concepts (Figures 5.3-5.11) were of interest to municipal representatives and the development industry, and they should be designed in detail for test construction. The opportunity will occur as the case study land is sold to the private sector, which will then proceed to prepare final design and construction drawings. Monitoring of their initial marketplace success or failure, and their longer term contribution to aspects of community sustainability should be carried out.

Those of us involved daily in the field of community planning and designeducators, researchers and practitioners - may be challenged and limited by the complexity of where to begin, resulting in the continuation of rather traditional roles which will have little impact on the real world. We must be willing to address increasingly complex environmental design issues in support of sustainable 
development, and assume a more visible, leadership role as advocates of community health and sustainability. When applied at a neighbourhood and community scale, residents must be made aware of their role, relationship and potential response to first local, and ultimately global, sustainability.

Undoubtedly the ebb and flow of popular attitude towards the environment, as discussed in Chapter 3 will continue, but sustainable development must prevail so as to overcome the perception, by many, that it is nothing more than a "feel good" environmental ethic for the middle class, whose concepts are embraced in economically healthy times, only to disappear into the shadows with the next economic recession.

Like pragmatic philosophers J. Dewey, W. James and C.S. Pierce, the author looks ahead optimistically, believing that if sustainable development represents a true environmental philosophy, then it will be proven to improve our common future. 


\section{LIST OF REFERENCES}

Beevers, R. (1988); The Garden City Utopia: a critical biography of Ebenezer Howard; Macmillan, Basingstroke.

Bookout, Lloyd W. (1992); Neotraditional Town planning - A New Vision for the suburbs?; UrbanLand; February

Boyce, James K. (1995); Equity and the Environment: Social Justice Today as a Prerequisite for Sustainability in the Future. Alternatives:

Braudel, Fernand (1987); A History of Civilizations, Lane; N.Y.

Brown, L. and Jacobsen, J. (1997); Assessing The Future of Urbanization; Worldwatch Institute

Campbell, M. (1997); The Environment and Canadian Society; Metro Toronto Teaching Health Units; International Thomsen Publishing.

Canada's Green Plan for a Healthy Environment (1990); Report of the Commissioner of the Environment and Sustainable Development, Canada; ISBN 0-662-26843-1

Candaras, A.M. and Associates Consulting Engineers (1997); Post Construction evaluation of stormwater exfiltration and filtration systems; Concord, Ontario; ISBN 0-7778-7285-4

Caprac, F. (1998); The Turning Point; Science, Society and the Rising Culture; Bantam Books, N.Y.

Cosgrove, D. (1980); Environmental thought in action: pre-modern and postmodern; Transactions of the Institute of British Geographers; 15

CMHC (1993); D'Amour, D.; Towards an investigation of Sustainable Housing; Ottawa 
CMHC (1995 and 1996); Measuring Urban Sustainability: Canadian Indicators Workshop; Centre for Futures Studies in Housing and Living Environments; Ottawa

CMHC (1991); D'Amour, D.; The Origins of Sustainable Development and its relationship to Housing and Community Planning; Research Paper No. 1; Ottawa.

CMHC (1997); Changing Values, Changing Communities; Doc. NH15-156;

Ottawa.

CMHC (1998); Research Highlights, Technical Series 98-101, 98-103; Ottawa.

CMHC (1998-99); External Research Program; Research Priority Areas; Doc H65801/Areas 98; Ottawa.

CMHC (1999); Advisory Document on Sustainable Development (Draft in Progress) January; Ottawa.

Ehrlich, P. (1968); The Population Bomb; Ballantine; New York

Environics International (1998); The Environmental Monitor

Fodor, E. (1999); Gold and Green Report; Institute for Southern Studies;

Durham, N.C.; New Society Publishers (quoted from Sierra magazine July-August 1999)

Government of Canada (1998); Managing for Sustainable Development; Report of the Commissioner of the Environment and Sustainable Development Goudie, A. (1994); The Human Impact On The Natural Environment; MIT Press, Cambridge.

Hart, M. (1997); Additional Resources on Sustainability; Hart Environmental Data, Inc. http://www. subjectmatters.com

Jacobs, Jane (1961); The Death and Life of Great American Cities; Random House; N.Y. 
Johnston, R.J. (1991); Geography and Geographers - Anglo American Human Geography Since 1945; Edward Arnold, London.

Johnston, R.J. (1994); Dictionary of Human Geography (3rd edition); Blackwell Publishers, Oxford.

Kaplan, R.D. (1994); The Coming Anarchy; Atlantic Monthly 373 (2)

Leopold, A. (1941); Wilderness as a Land Laboratory; Living Wilderness 6 (July)

Lyell, C. (1872); Principles of Geology, Appleton; N.Y.

Lyle, J. (1992); Land Lab: The Institute for Regenerative Studies; Sustainable Cities; Eco-home Media; Los Angeles.

Mannion, A.M. (1991); Global Environmental Change: A natural and cultural environmental history; Longman; N.Y.

Maser, Chris (1996); Resolving Environmental conflict - Towards Sustainable Community Development; St. Lucie Press; Delray Beach, Fla.

McCormick, J. (1989); The Global Environmental Movement; Belhaven Press, London.

McHarg, I. (1971); Design with Nature; Falcon Press, Philadelphia U.S.A.

Meadows, D. (1972); The Limits to Growth; Universe; New York.

Metro Toronto Planning Department (1991); Towards A Liveable Metropolis, Toronto, Ontario

Mitchell, G. (1995); Problems and Fundamentals of Sustainable Development Indicators; Sustainable Development 3 (95)

New Home Sales and Market Shares By Geographical Areas in Ottawa-Carleton (1990-1999); The Corporate Research Group Ltd. February 2000

Ottawa Citizen, Jan 2000; C 14 
Organization for Economic Co-generation and Development (1996); Innovative Policies for Sustainable Urban Development; The Ecological City; Paris, France

Pathways to Sustainability: Assessing our Progress (1995); National Roundtable on the Environment and the Economy; Lowe Martin

Perks, William T. and Van Vliet D. (1993); Assessment of built Projects for sustainable communities, $\mathrm{CMHC}$, Ottawa

Province of Ontario Round Table on Economy and Environment (1997)

Rees, W. E. (1992); Ecological Footprints and Appropriate Carrying Capacity What Urban Economics Leaves Out; Environment and Urbanization; 4

Rees, W. and Roseland, M. (1991); Sustainable Communities; Planning for the $\underline{21^{\text {st }} \text { Century; Plan Canada 31.3: } 15-26}$

Rifkin, J. (1991); Biosphere Politics: A Cultural Odessy from the Middle Ages to the New Age; Harper, San Francisco

Royal Commission on the Future of the Toronto Waterfront (1992);

Regeneration: Toronto Waterfront and the Sustainable City; Final Report, Queen's Printer of Ontario

Sarrinen, O. (1979); The influence of Thomas Adams on the British New Town movement in the Planning of Canadian Residential Communities; The Useable Urban Past: Planning and Politics in the Modern Canadian City; MacMillan, Canada

Selman, P. (1996); Local Sustainability; Managing an Planning Ecologically Sound Places; St. Martin's Press; N.Y.

Serageldin, I. (1994); International Conference on Environmentally Sustainable Development; WorldBank Doc UN; 9:2 
Taylor, J. and Smith G. (2000); Healthy People, Sustainable Communities: Emerging roles for Landscape Architects; Landscapes, Vol. 2, No. 1, Southam

Thayer, Robert J. (1994); Gray World, Green Heart: Technology, Nature and the Sustainable Landscape; John Wiley and Sons; N.Y.

Thompson, W.J. (1999); Design for a Small Planet; Landscape Architecture Magazine, December; Washington, D.C.

Turner, R. Kerry (1993); Sustainable Environmental Economics and Management; Principles and Practices; Belhaven Press, London

United Nations (1993); Agenda 21: Program of Action for Sustainable Development; U. N., New York.

Van Vliet, D. (1994); Sustainable Subdivision Planning and Design; Institute of Urban Studies, University of Winnipeg

Vojnovic, I. (1994); The Pathway towards Sustainable Development and Sustainable Urban Forms; Centre for Urban and Community Studies; Department of Geography; University of Toronto.

Walker, H.V. (1979); Energy Conservation Resource Handbook; Royal Architectural Institute of Canada, Ottawa

Wilbanks, Thomas J. (1994); Sustainable Development in Geographic Perspective; Annals of the Association of American Geographers; Bechwell Publishers, Cambridge M.A.

World Commission on Environment and Development (1987); Our Common Future; Oxford University Press

World Health Organization (1992); Commission on Health and Environment/ Report of the Panel on Urbanization, Geneva 